
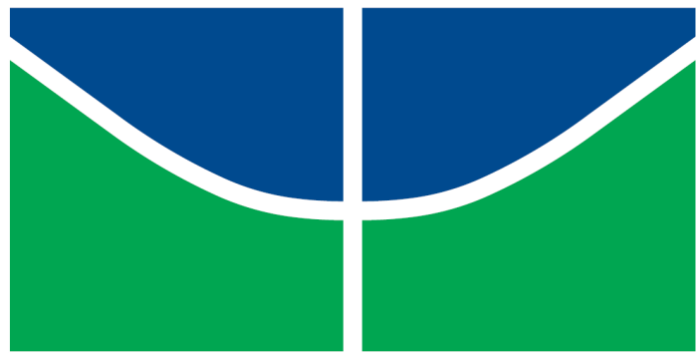

UNIVERSIDADE DE BRASÍLIA

INSTITUTO DE CIÊNCIAS BIOLÓGICAS

PROGRAMA DE PÓS-GRADUAÇÃO EM BIOLOGIA MOLECULAR

\title{
O Genoma de um Baculovírus Isolado de Cadáveres de Larvas de Lonomia obliqua (Lepidoptera: Saturniidae), uma Lagarta de Interesse Médico
}

CLARA WANDENKOLCK SILVA ARAGÃO

BRASÍLIA 
O Genoma de um Baculovírus Isolado de Cadáveres de Larvas de Lonomia obliqua (Lepidoptera: Saturniidae), uma Lagarta de Interesse Médico

Dissertação apresentada ao Programa de Pós-graduação em Biologia Molecular, do Instituto de Ciências Biológicas, da Universidade de Brasília, como parte dos requisitos necessários para a obtenção do título de Mestre em Biologia Molecular.

Orientador: Prof. Dr. Bergmann Morais

Ribeiro

Co-Orientador: Prof. Dr. Fernando Lucas Melo

CLARA WANDENKOLCK SILVA ARAGÃO

BRASÍLIA

2015 
O Genoma de um Baculovirus Isolado de Cadáveres de Larvas de Lonomia obliqua (Lepidoptera: Saturniidae), uma Lagarta de Interesse Médico

Dissertação apresentada ao Programa de Pós-graduação em Biologia Molecular, do Instituto de Ciências Biológicas, da Universidade de Brasília, como parte dos requisitos necessários para a obtenção do título de Mestre em Biologia Molecular.

Aprovada em ___ I__

BANCA EXAMINADORA

Prof. Dr. Bergmann Morais Ribeiro (Presidente)

Prof. Dr. Tatsuya Nagata (Membro efetivo)

Dr ${ }^{\text {a. }}$ Simone Ribeiro (Membro efetivo)

Dra. Érica Soares Martins Queiroz (Membro suplente) 
"Todo aquele que se dedica ao estudo da ciência chega a convencer-se de que nas leis do Universo se manifesta um Espírito sumamente superior ao do homem, e perante o qual nós, com os nossos poderes limitados, devemos humilhar-nos."

Albert Einstein 


\section{AGRADECIMENTOS}

Primeiramente, agradeço à Deus, quem me teceu a vida para estar aqui e poder contemplar todos os fascínios da natureza os quais tento entender por meio do estudo da biologia. Obrigada meu Deus por ser meu porto seguro e força nessa caminhada, obrigada Mãe de Deus e minha Mãe por me carregar nos braços com sua ternura!

Agradeço ao Professor Bergmann, quem tanto admiro como pessoa e profissional, por confiar em mim e me conceder essa grande oportunidade de crescimento intelectual e consequentemente pessoal. Obrigada pela orientação, pelos ensinamentos, pela paciência, pela sabedoria, pela amizade!

Agradeço ao meu co-orientador Fernando, que com toda sua presteza, interesse e disposição em ensinar, me passou conhecimentos essenciais para a conclusão desse trabalho, sendo sempre compreensivo, aberto e amigo! Obrigada de coração boss!

Agradeço aos meus pais, meus progenitores, que nesse ninho de amor me criaram e me ensinaram os valores mais dignos e fundamentais que me estruturam como ser. Obrigada minha amada mãezinha Rosana e meu amado paizinho Hamilton, pelas orações, pelo amor incondicional, pela confiança, pela amizade, pelo colinho, pela cumplicidade, pela prontidão em sempre ajudar, pelo companheirismo, pelo amparo em todos os momentos, e principalmente, por serem os melhores pais do mundo! Meu amor por vocês é imenso! Dedico a conclusão dessa etapa à vocês!

Ao meu amado filhotinho Samuel, fruto que em mim brotou, que me transforma a cada dia, que me ensinou que ser mãe é amar da forma sublime, e que é essa a força que me alavanca ao alcance de coisas que jamais imaginei poderia. Para mim filho, você é a expressão mais pura do amor de Deus em mim vida! Me desculpe os momentos de ausência para a dedicação à pesquisa, mas esse amor materno é magico, e faz com que eu esteja com você todos os momentos! Amo você da forma mais pura que existe em mim!

Ao meu esposo, Filipe, que com toda sua paciência e compreensão, me deu forças para persistir em mais essa etapa da vida, sempre estando ao meu lado, cuidando de mim com carinho, me tolerando, me incentivando, acreditando nos meus potenciais, quando nem eu mesma acreditava mais...Obrigada por ser esse esposo/pai companheiro!

Agradeço aos meus irmãos, Thiago, my big bro, e Lucas, my little bro, que por diversos momentos dessa vida me acompanharam, sempre me dando força, acreditando em mim, e compartilhando desse amor fraterno que existe entre nós! Cada um de vocês me inspira com sua bondade de coração e espírito, e me faz uma irmã muito feliz e apaixonada por vocês meus irmãos amados! Luv you both!

Agradeço a minha amada vozinha Raimundinha, por me ensinar com doçura, paciência e doação, valores que comigo carrego com muito carinho. Não existem limitações quanto a esse amor é eternamente selado entre nós vozinha. Amo você bem gigante!

Agradeço a minha vozinha Claudete, e meu saudoso vovô Pirica (eternamente no coração), que sempre me cercaram de muito amor, e acima de tudo, acreditaram em mim, com muito orgulho e estima! Tê-los em minha vida é um presente de Deus! 
Agradeço a minha linda sobrinha Cinthia, que com sua alegria de criança colore meu mundo, e me faz perceber que a vida está em ser feliz com as coisas mais simples...amo você minha melhor amiga! Conte sempre com sua Tia Cá!

Agradeço a minha titia Maria Fabião queria, que sempre acredita em mim, e mesmo com seu jeitinho danado, está sempre a brincar e sorrir! Amo você minha titia!

Ao meu padrinho amado, Assis Aragão, pelo incentivo, pela fé e por ser um exemplo de vida para mim! Amo você!

Aos meus sogros e a minha cunhada, pela ajuda e incentivo na conclusão dessa etapa! Vocês são muito queridos!

À Lucinha, minha amiga que me acompanha e cuida desde pequenininha, transmitindo esse amor puro em forma de quitutes maravilhosos e abraços apertados nos momentos que mais precisei! Lucinha, você é uma pessoa de luz, que ensina tanto na simplicidade. Amo você!

Agradeço às minhas amigas de infância de sempre, minhas companheiras, amigas incondicionais, confidentes, sempre me colocando para cima, sempre torcendo pelo meu sucesso e felicidade, e sempre dispostas a me dar um ombro amigo e carinhoso a qualquer momento! Naira, Mila, Aninha, Ju, Duda, Su, Lu, Larinha, Lelê, Gabi, Drica, Tatá, Dani e Re, my dolls, my friends for ever, amo cada umazinha de vocês!

Às minhas "bioamigas" irmãs com quem escolhi grudar meu coração, Liginha, Rafa, Nina e Marthinha, que com um carinho especial nessa fase, me apoiaram, me aconselharam, acreditaram em todo meu potencial e me transmitiram toda essa energia positiva que muito colaborou para que eu pudesse concluir mais essa etapa! Estamos juntas na vida, pro que der e vier!

Aos amigos do Ibama que me incentivaram e ajudaram muito nessa missão concomitante: Marília, Fê, Carla, Mônica, Lorena, por sempre acreditarem em mim, e em especial ao Danilo, por todas as conversas e histórias divertidas, pelo apoio de todas as horas, pelo carinho, pelas revisões, opiniões críticas e por toda motivação! Você é muito especial!

Aos meus amigos Daniel (Dzinho and co-co) e Fabrício (Big bro), que se não fosse pelo seu incentivo, amizade e fé em mim e em meus potencias científicos, eu não estaria conquistando esse título! Em especial também à toda co-co-orientação do Dzinho em relação a conclusão desse trabalho, por me nortear, me colocar o pé no chão, critica e aguçar meu senso crítico aconselhar e simplesmente discutir ciência!

Agradeço a todo apoio e incentivo dos amigos do laboratório, Leo, Isabella, Deborah, Roberto, Mayarinha, Mariana, Claudinha, Mateus, Thiago, em especial ao Miguel, por tanto me ajudar nas figuras lindas desse trabalho, e ao Jhon, por me ajudar com o teste de hipóteses.

Aos meus amigos de sempre, Bele, Bu, Lili, Cindão, Carol, Yandra e Pat que sei que muito torcem pelo meu sucesso e estão no meu coração, independente da distância!

À Universidade de Brasília e ao Departamento de Biologia Molecular, por propiciarem as bases do desenvolvimento acadêmico.

Ao Cnpq, CAPEs e FAPDF, pelo apoio financeiro. 


\section{RESUMO}

Lonomia obliqua (Lepidoptera: Saturniidae) é uma lagarta venenosa de importância médica devido a severidade de acidentes causados no Brasil pelo contato dessas lagartas com humanos. Patógenos naturais foram isolados dessa lagarta, como o baculovírus Lonomia oblique multiple nucleopolyhedrovirus - LoobMNPV. Nesse contexto, esse trabalho envolve o sequenciamento, a montagem, a análise da composição genômica e do contexto evolutivo de LoobMNPV. Esse genoma possui 120,023 pb, 134 ORFs, 12 ORFs únicas, 7 regiões homólogas ( $h r s$ ) e conteúdo $\mathrm{G}+\mathrm{C}$ de $35,7 \%$. Baseado em análises que incluem os genes conservados de baculovírus (core genes) de 72 espécies únicas de baculovírus sequenciados, LoobMNPV localiza-se filogeneticamente no grupo I de Alphabaculovirus, pertencente a um clado irmão aos genomas similares a AcMNPV, apresentado também inversões e rearranjos genômicos em relação a esse clado. Uma das ORFs únicas (LoobNPVOrf-35) apresentou similaridade (E-value de $3 \mathrm{e}^{-11}$ ) significativa a um Fator de Terminação de Transcrição (Transcription terminator factor -TTF2) oriundo do lepidóptero Danaus plexippus (GenBank: EHJ68439.1). Por outro lado, ao restringir essa busca aos baculovírus, essa ORF também apresentou similaridade (E-value de $1 \mathrm{e} 10^{-6}$ ) ao Global Transactivator (GTA) de Antheraea pernyi nucleopolyhedrovirus (Genbank:YP_611073.1). Esses resultados indicam duas hipóteses para a possível origem dessa ORF em LoobMNPV: esse gene pode ter sido adquirido independentemente por transferência horizontal de genes, ou é uma variação divergente do gene GTA. Esse genoma também apresentou a ausência dos genes da catepsina e quitinase, que por sua vez estão envolvidos na liquefação do hospedeiro ao final da infecção, propiciando a dispersão dos corpos de oclusão do baculovírus no ambiente. Essa ausência pode estar relacionada ao hábito gregário observado em Lonomia obliqua.

Palavras-chave: Lonomia obliqua, LoobMNPV, baculovírus, Transcription terminator factor-TTF2, Global Transactivator-GTA, catepsina, quitinase. 


\begin{abstract}
Lonomia obliqua (Lepidoptera: Saturniidae) is a poisonous larvae of medical importance due to the severity of accidents caused by the contact of these larvae with humans occurred in Brazil. Natural pathogens were isolated from these larvae, such as the baculovirus Lonomia oblique multiple nucleopolyhedrovirus - LoobMNPV. In this work, we have sequenced the genome of the baculovirus LoobMNPV and analyzed its genomic composition and evolutionary history. The genome is 120.023 bp long, comprising 135 putative ORFs, 12 unique ORFs, 7 homologous regions (hrs), and 35, 7\% $\mathrm{G}+\mathrm{C}$ content. Furthermore, in an evolutionary context, based on analysis that include the core genes from 72 unique species of sequenced baculovirus, LoobMNPV is located among Alphabaculovirus group I, as a sister-clade of the AcMNPV-like genomes, also presenting genomic inversions and rearrangements when compared to this clade. Interestingly, one unique ORF (LoobNPVOrf35 ) showed significant similarity (E-value equals to $3 \mathrm{e}^{-11}$ ) to a eukaryotic Transcription Terminator Factor (TTF2) from the lepidoptera Danaus plexippus (GenBank: EHJ68439.1). On the other hand, when restricting this search only to baculoviruses, this ORF also demonstrated similarity (E-value of $1 \mathrm{e}^{-6}$ ) to the Global Transactivator (GTA) gene from Antheraea pernyi nucleopolyhedrovirus (Genbank: YP_611073.1). These results indicated two hypothesis: this gene may have been independently acquired from the host through horizontal transfer, or it is a divergent variation of the GTA. This genome also lacks the cathepsin and chitinase genes that are involved in the host liquefaction at the end of the infection, benefiting the spread of the baculovirus occlusion bodies in the environment. This absence may be due to the gregarious habits observed in Lonomia obliqua,
\end{abstract}

Key words: Lonomia obliqua, LoobMNPV, baculovirus, Transcription terminator factor-TTF2, Global Transactivator-GTA, cathepsin, chitinase. 


\section{ÍNDICE DE FIGURAS}

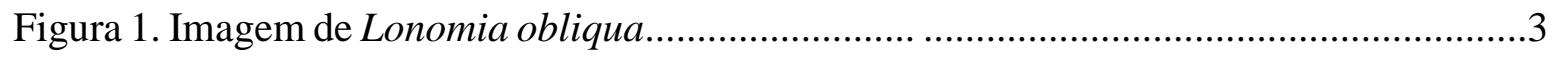

Figura 2. Ciclo de desenvolvimento de Lonomia obliqua.................................................4

Figura 3. Hábito gregário de Lonomia obliqua ..............................................................

Figura 4. Ultra micrografias das cerdas de Lonomia obliqua .............................................

Figura 5. Aspecto das lesões hemorrágicas causadas por Lonomia obliqua ...........................8

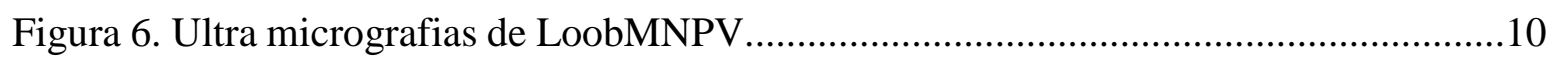

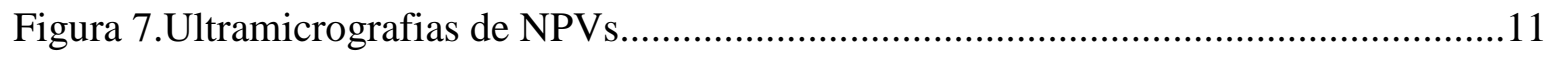

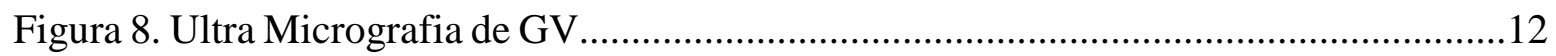

Figura 9. Diagrama esquemático da estrutura dos corpos de oclusão................................13

Figura 10. Ciclo de infecção de baculovírus....................................................................... 18

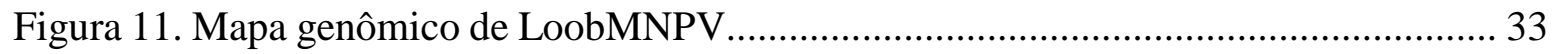

Figura 12. Região de baixa cobertura de LoobMNPV .................................................... 34

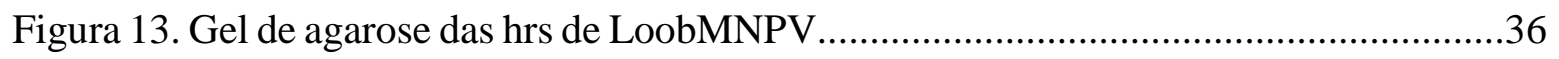

Figura 14. Alinhamento múltiplo de região repetitiva das $h r s$ de LoobMNPV ....................37

Figura 15. Árvore filogenética da família Baculoviridae ................................................39

Figura 16. Mapa comparativo do genoma de LoobMNPV a outros Alphabaculovirus........42

Figura 17. Sintenia genômica de LoobMNPV em relação a outros Alphabaculovirus..........44

Figura 18. Árvore filogenética de LoobNPVOrf-35 e os genes TTF2 e GTA......................50

Figura 19. Alinhamento LoobNPVOrf-35 e os genes TTF2 e GTA..................................53

Figura 20. Contexto gênico do gene GTA em Alphabaculovirus grupo I..............................55 


\section{ÍNDICE DE TABELAS}

Tabela 1. Descrição dos genes conservados (core genes) em baculovírus...........................15

Tabela 2. Iniciadores para amplificação da região de baixa cobertura do genoma de

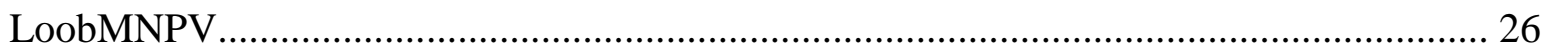

Tabela 3. Procedimento da reação de PCR da região de baixa cobertura do genoma de

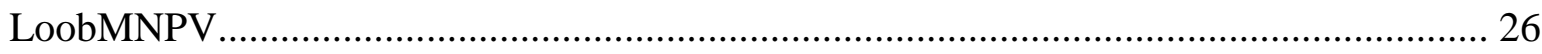

Tabela 4. Programa de amplificação da região de baixa cobertura do genoma de

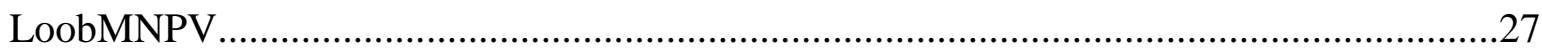

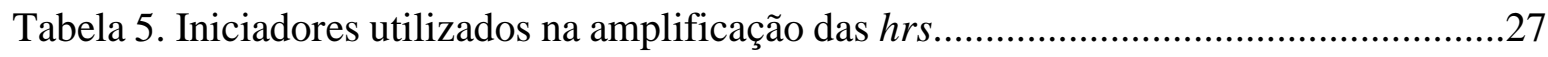

Tabela 6. Procedimento da reação de PCR da região das hrs de

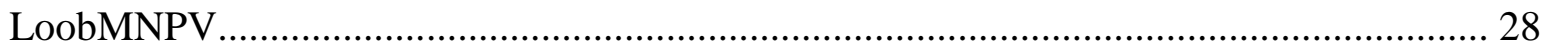

Tabela 7. Programa utilizado na amplificação das hrs do genoma de

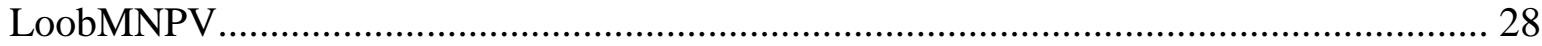

Tabela 8. Tamanho das $h r s$ e seus respectivos fragmentos de amplificação LoobMNPV......35 


\section{LISTA DE ABREVIATURAS E SIGLAS}

$\mu 1$ microlitros

$\mu \mathrm{m}$ micrometros

aa amino ácido

CPV do inglês Cytoplasmatic Polyhedroses (Poliedroses citoplasmáticas)

GTA do inglês Global Transactivator (Transativador Global)

GV Granulovírus

HGT do inglês Horizontal Gene Transfer (Transferência Horizontal de Genes)

kb kilo bases

$\mathrm{M}$ molar (mol/L)

ML do inglês Maximum likelihood (Máxima Verossimilhança)

MNPV do inglês multiplenucleopolyhedrovirus (Nucleopoliedrovirus múltiplo)

nm nanômetros

NPV do inglês nucleopolyhedrovirus (Nucleopoliedrovírus)

OB do inglês Occlusion bodies (Corpos de Oclusão)

ODV do inglês Occlusion Derived Virions (Vírions Derivados de Oclusão)

ORF do inglês Open Reading Frame (Fase de Leitura Aberta)

$\mathrm{pb}$ pares de base

PCR do inglês Polimerase Chain Reaction (Reação em Cadeia da Polimerase)

SNPV do inglês singlenucleopolyhedrovirus (Nucleopoliedrovirus único)

TTF2 do inglês Transcription Terminator Factor 2 (Fator de Terminação de Transcrição)

w/v do inglês weight/volume (peso/volume) 


\section{SUMÁRIO}

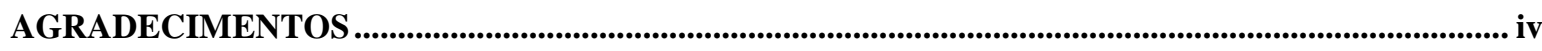

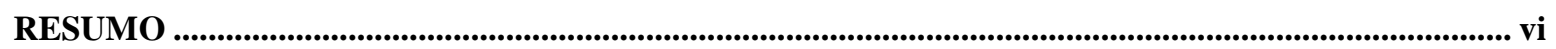

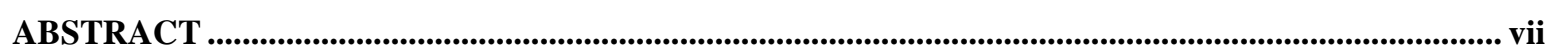

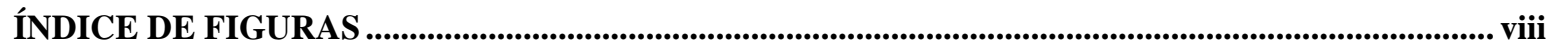

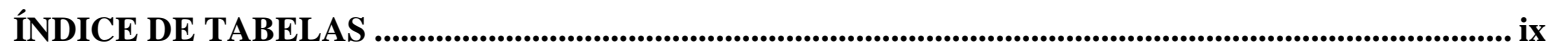

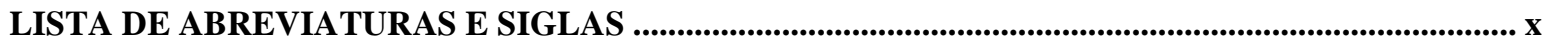

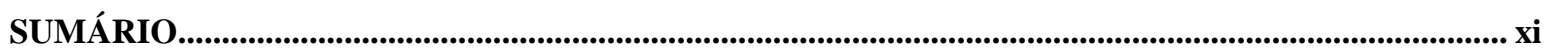

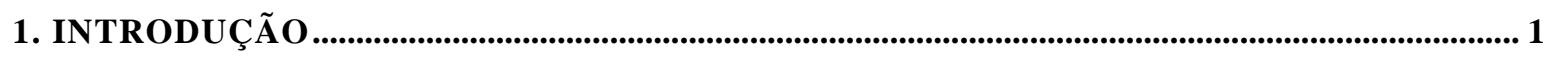

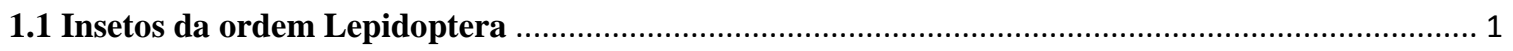

1.2 Lepidópteros de importância médica ……………...................................................................... 2

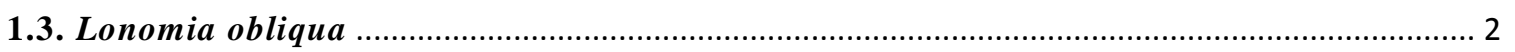

1.3.1 Epidemiologia e acidentes causados por $L$. obliqua ….......................................................... 5

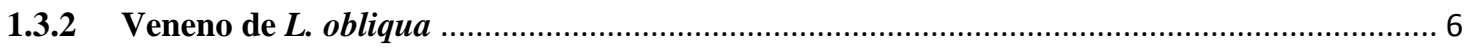

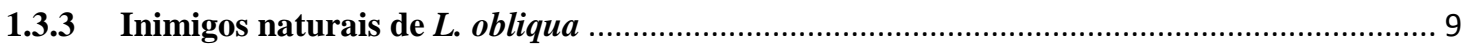

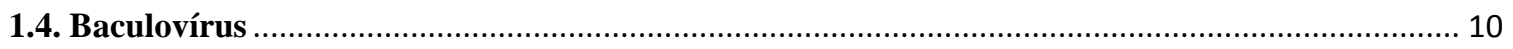

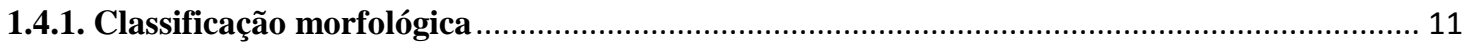

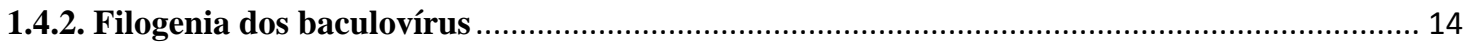

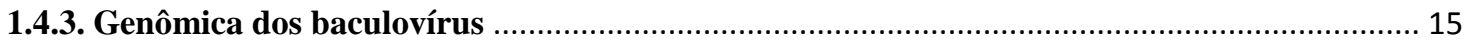

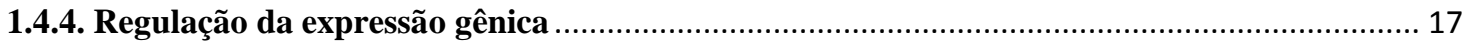

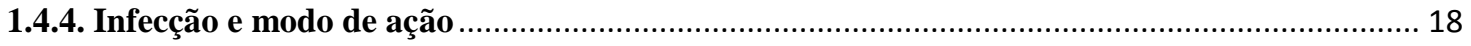

1.4.6 Importância dos baculovírus ……………….................................................................... 20

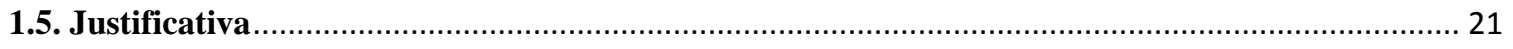

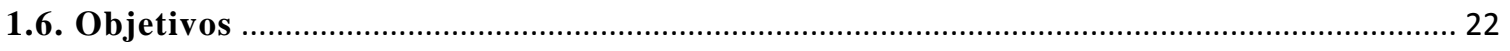

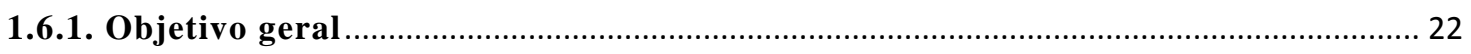

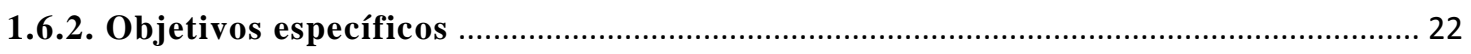

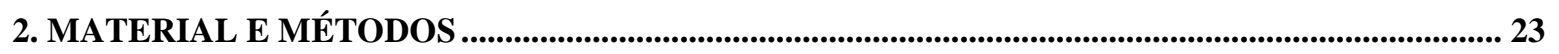

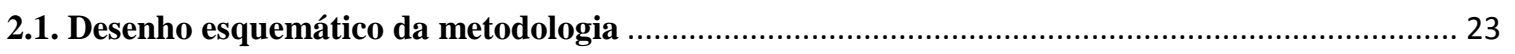

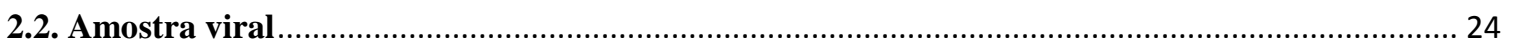

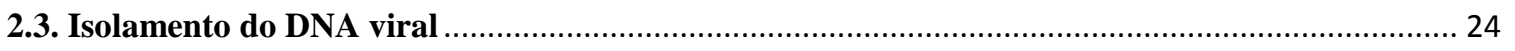

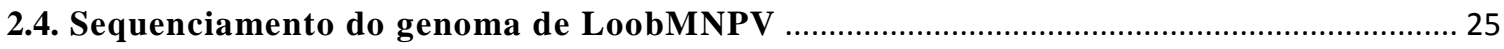

2.5. Anotação e montagem do genoma de LoobMNPV ……..................................................... 25

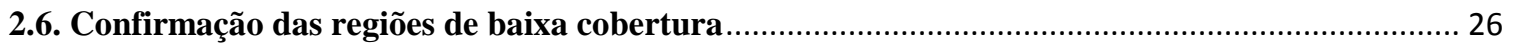

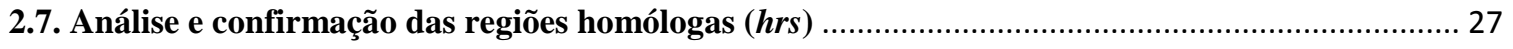


2.8. Análise filogenética

2.8.1. Análise filogenética de LoobMNPV em relação à família Baculoviridae ............................ 29

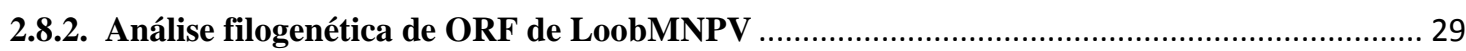

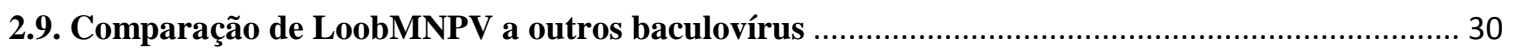

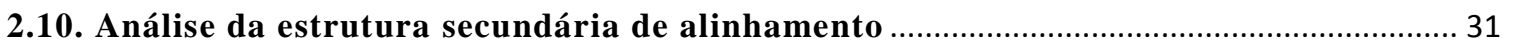

3. RESULTADOS E DISCUSSÃO

3.1. Análise da sequência genômica de LoobMNPV ............................................................. 31

3.1.1. Análise de região de baixa cobertura do genoma de LoobMNPV .................................. 34

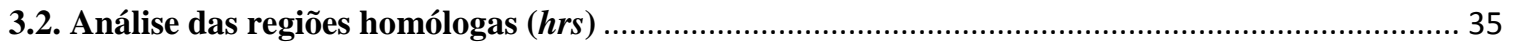

3.3 Análises do contexto filogenético de LoobMNPV na família Baculoviridae ................................ 38

3.4. Comparações de LoobMNPV a outros Alphabaculovírus ..................................................... 40

3.5 . Análise das ORFs únicas encontradas em LoobMNPV ....................................................46

3.5.1. ORF única que contêm peptídeos sinal e região transmembrana ................................. 47

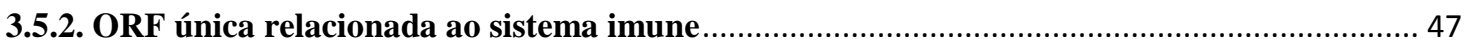

3.5.3. ORF única relacionada a fator de terminação de transcrição ....................................... 48

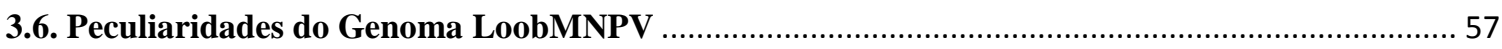

3.6.1. Ausência dos genes da catepsina e quitinase no genoma de LoobMNPV ...........................57

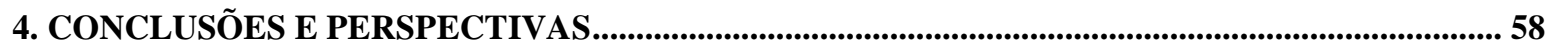

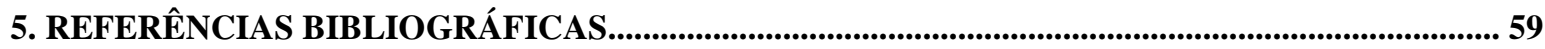

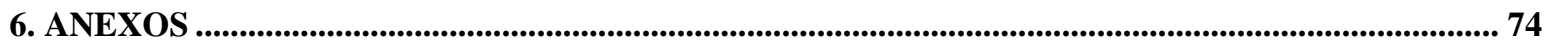




\section{INTRODUÇÃO}

\subsection{Insetos da ordem Lepidoptera}

Os insetos compreendem cerca de $59 \%$ de todos os animais do planeta e desempenham papel chave nos ecossistemas terrestres (Wilson, 2003), como a participação em processos de decomposição, ciclagem de nutrientes, fluxo de energia, polinização, dispersão de sementes (Freitas et al. 2003), bem como regulação de populações de plantas e de outros animais por interações ecológicas (Didham et al. 1996).

Em relação aos insetos pertencentes à ordem Lepidoptera, estima-se que esta possua cerca de 146 mil espécies descritas com previsão de 255.000 espécies a serem descobertas (Heppner 1991). Esses insetos possuem asas recobertas com escamas na fase adulta (do grego lepido $=$ escamas; ptera $=$ asa) e corpo vermiforme na fase larval, podendo algumas espécies apresentarem cerdas ou pelos (Pesce \& Delgado 1971). As lagartas de lepidópteros são caracterizadas por um corpo cilíndrico dividido em cabeça, composta pelo aparelho bucal mastigador, os stemmata (estruturas para visão) e as antenas; o tórax, composto por três pares de pernas verdadeiras; e o abdômen, com 10 segmentos e quatro pares de pernas falsas que auxiliam na fixação e locomoção (Moraes 2003). Possuem ainda sistema digestivo completo, sistema nervoso ventral e coração dorsal, com circulação realizada por bombeamento da hemolinfa e respiração traqueal, com aberturas laterais denominadas espiráculos (Moraes 2003).

Essa ordem compreende indivíduos com desenvolvimento holometabólico, que consiste em um ciclo biológico caracterizado pelas fases de ovo, larva (lagarta), pupa (crisálida) e adulto (imago) (Moraes 2003). São divididos em dois grupos: Rhopalocera, representada por borboletas com hábitos diurnos, e Heterócera, representada por mariposas com hábitos noturnos (Cardoso 2005).

Os lepidópteros são principalmente conhecidos devido aos elevados prejuízos causados em culturas agrícolas de importância econômica, como o algodão e a soja (Cruz 2002). Entretanto, algumas espécies também são consideradas relevantes, como o caso do bicho da seda (Bombyx mori) na sericultura, bem como aquelas responsáveis pela ocorrência de acidentes dermatológicos, como as pertencentes às famílias Megalopygidae, Limacodidae e Saturniidae (Haddad et al 2003). 


\subsection{Lepidópteros de importância médica}

Os lepidópteros considerados relevantes na área médica são aqueles que podem causar danos à saúde humana. Quando decorrentes do contato com as formas adultas aladas de mariposas, esses acidentes são denominados lepidopterismo, caracterizado por dermatoses intensas, com aspecto papuloso e pruriginoso. Os principais causadores desses acidentes são mariposas de espécies pertencentes à família Hemileucidae, que possuem cerdas urticantes no abdômen das fêmeas e provocam surtos em áreas rurais (Jorg 1933).

Por outro lado, o erucismo (de origem latina eruca = larva) é o termo utilizado para designar intoxicações decorrentes do contato com a fase larval dos lepidópteros. O perfil clínico resultante desses acidentes pode variar desde uma simples queimação no local do contato até um quadro de hemorragia intensa, dependendo da espécie envolvida e do estado físico da vítima (Pesce \& Delgado 1971).

Sob o ponto de vista histórico, no Brasil, os primeiros relatos sobre acidentes envolvendo lagartas datam desde a época da colonização, na "Carta de São Vicente" de 1560, a qual o padre Anchieta relatou o medo dos índios frente a algumas lagartas que causavam reações de dor após o contato físico, sendo denominadas "tatá-raná" em Tupi-Guarani, que significa "como fogo", mais tarde originando na língua portuguesa a palavra "taturana" (Costa, 1994). Já no final da década de 60, surgiram as primeiras publicações relatando casos de envenenamento por contato com lagartas do gênero Lonomia na América do Sul, mais especificamente com a espécie Lonomia achelous na Venezuela (Arocha-Piñango 1967), e no Brasil os primeiros relatos datam do final da década de 80, envolvendo a espécie Lonomia obliqua no sul do país, em que as vítimas apresentavam, após contato com o animal, irritações cutâneas, dermatites, queimaduras, alergias, distúrbios na coagulação sanguínea causando hemorragias generalizadas, insuficiência renal aguda, e, nos casos mais graves a morte (Duarte et al. 1990).

\subsection{Lonomia obliqua}

Lonomia obliqua, Walker, 1855, a lagarta hospedeira do vírus objeto de estudo desse trabalho, é classificada como pertencente à ordem Lepidoptera, subordem Ditrysia, superfamília Bombycoidea e família Saturniidae (Stehr 1987). Essas lagartas são 
caracterizadas pela coloração verde claro em sua base e preto no ápice, contendo seis segmentos com uma mancha branca em cada, cabeça saliente de coloração marrom-clara com um septo marrom-escuro na parte superior, peças bucais bastante salientes (Duarteet al. 1990), e ornamentação dorsolateral de estruturas pontiagudas ramificadas de aspecto arbóreo (Figura 1). Essas estruturas, denominadas cerdas, são capazes de secretar toxinas que possuem como função biológica a defesa contra predadores naturais (Cardoso 2005). Suas propriedades urticantes são oriundas de um líquido produzido por células tricógenas, presente no interior de suas cerdas, que ao penetrar a pele são quebradas e liberam o líquido que exerce sua ação irritante (Alexander, 1984).

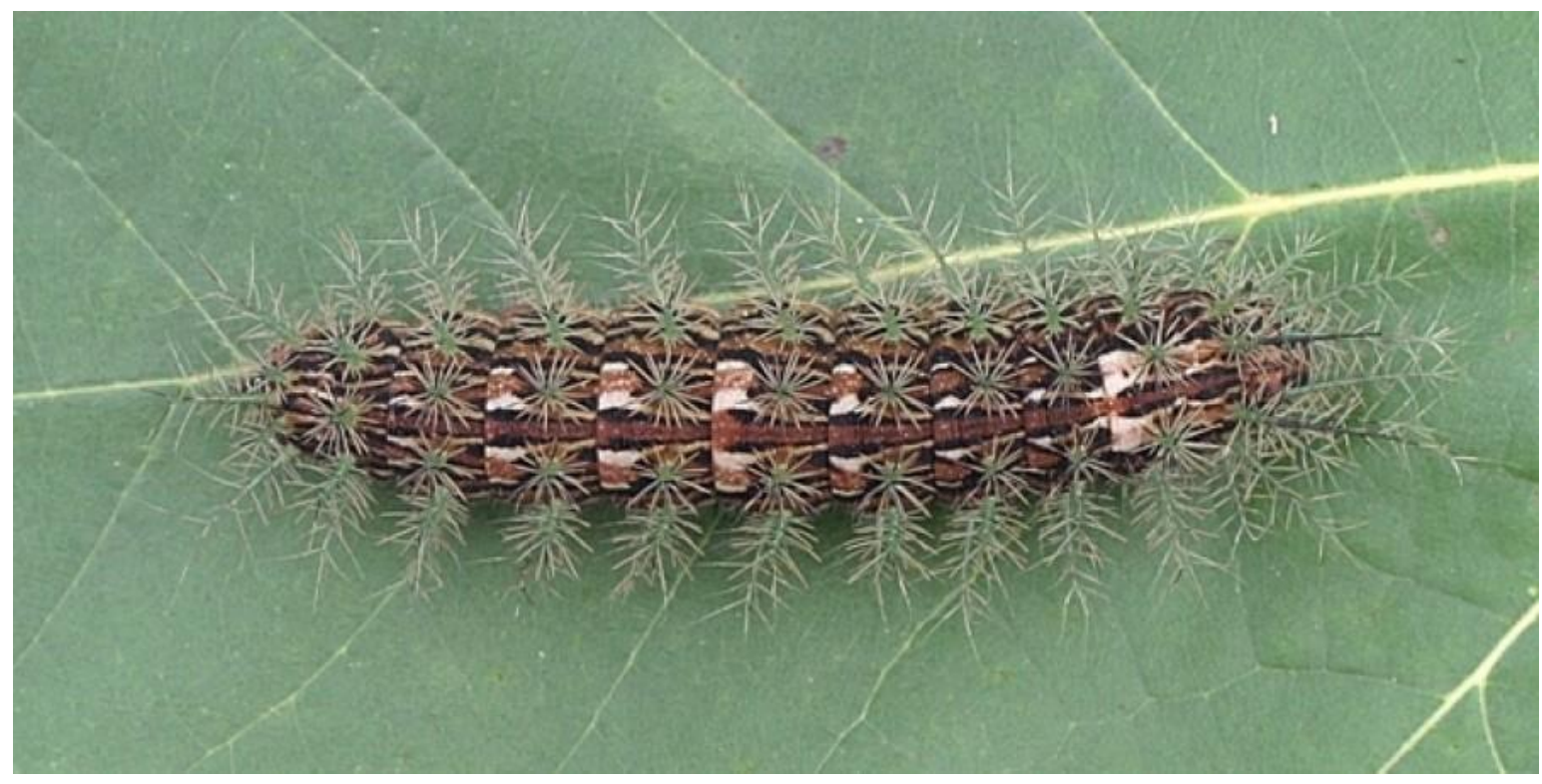

Figura 1. Lagarta Lonomia obliqua Walker, 1855 (Lepidoptera: Saturniidae) (Fonte: Lonomia obliqua. . In: WIKIMEDIA COMMONS, WIKIPÉDIA, a enciclopédia livre. Flórida: Wikimedia Foundation, 2015. Disponível em: <http://commons.wikimedia.org/wiki/File:Lonomia-obliqua-citsc-1.jpg>. Acesso em: 28 fev. 2015.)

Conforme Lorini (1999), L. obliqua possui um ciclo biológico de cerca de 185 dias, sendo que os insetos adultos (mariposas) vivem apenas uma média de 6,8 dias, uma vez que possuem peças bucais atrofiadas e não se alimentam. Ainda, apresentam acentuado dimorfismo sexual, e devido ao hábito noturno, sua cópula ocorre à noite, com acasalamentos que chegam a durar mais de 10 horas. Posteriormente, ovopositam sobre troncos de árvores, e mantêm-se no estágio de ovo por um período que pode variar de 17 a 30 dias (Lorini 2005). Ao eclodir, as larvas passam por seis estágios de desenvolvimento (instares), com alteração 
de tegumento (muda) a cada instar, podendo atingir cerca de sete centímetros de comprimento ao final desse estágio. Posteriormente, durante o estágio de pupa, permanece em dormência sob restos vegetais por 30 a 100 dias, até emergirem as mariposas, reiniciando o ciclo (Lorini 1999) (Figura 2).

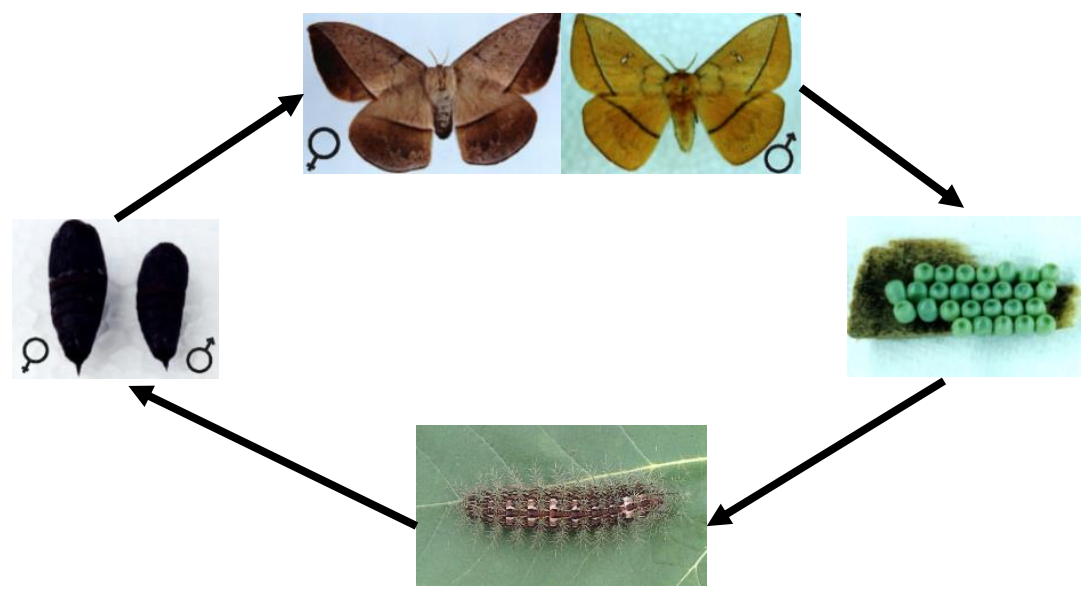

Figura 2. Ciclo de desenvolvimento holometábolo de Lonomia obliqua. Adaptado de (CIT 1999).

Lonomia obliqua possui hábito gregário durante cinco instares do desenvolvimento larval (Figura 3), vivendo em colônias com mais de 50 indivíduos sobre o tronco de diversas árvores de cujas folhas se alimentam, com suas cabeças apontando para fora em relação ao grupo, e, caso venham a ser perturbadas, tornam-se ativas e movimentam-se em linha (Lorini et al. 2007). Durante o período noturno, sobem os galhos mais altos em busca de alimento, e durante o dia permanecem agrupadas e camufladas nas partes mais inferiores e sombreadas dos troncos das árvores, fato esse que facilita a ocorrência dos acidentes com humanos (Lorini 1999).

O hábito gregário, bem como o mimetismo observado nesses insetos, é considerado uma forma adicional às defesas morfológicas (espículas) e químicas (toxinas) apresentadas por estes organismos, uma vez que animais de hábito gregário estão menos sujeitos a serem predados, e o mimetismo permite que a espécie explore ambientes de risco ou de grande exposição, como por exemplo, a superfície de troncos e folhas (Vulinec, 1990).

As árvores de maior preferência do gênero Lonomia são o Araticum (Rollinia emarginata), o Cedro (Cedrella fissilis) e o Ipê (Tebula pulcherrima). Entretanto, essa espécie parece adaptada também às árvores frutíferas, como os pessegueiros, abacateiros, ameixeiras e outros (Moraes 2003). 


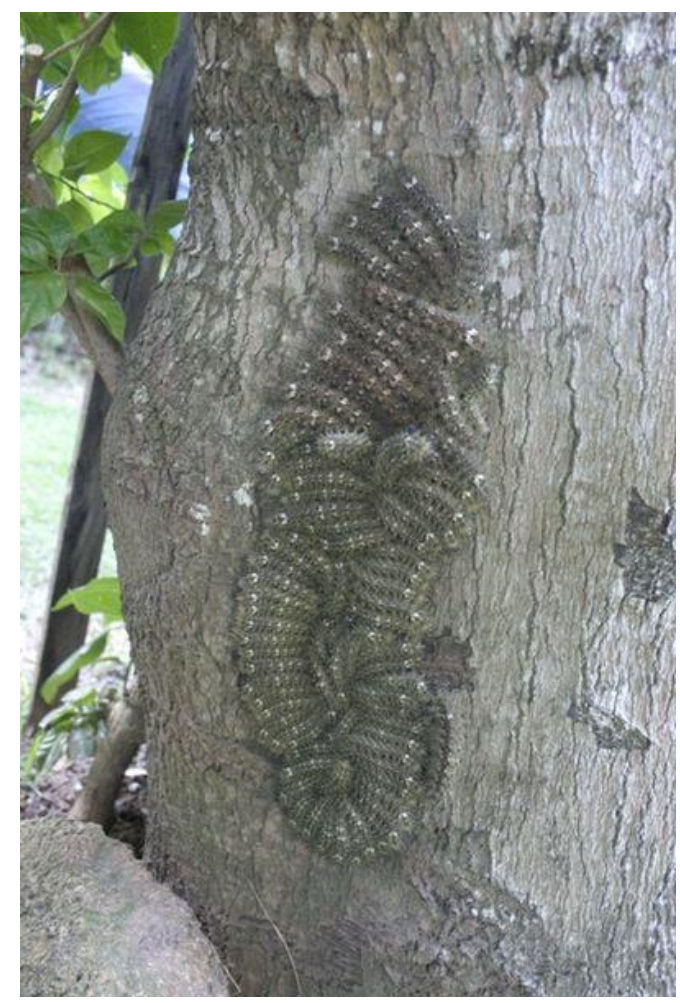

Figura 3. Hábito gregário da lagarta Lonomia obliqua. (Fonte: Lonomia Obliqua. In: WIKIMEDIA COMMONS, WIKIPÉDIA, a Enciclopédia Livre. Flórida: Wikimedia Foundation, 2015. Disponível Em: $<$ http://commons. wikimedia.org/wiki/File:Lonomia-Obliqua-Citsc-2.jpg?uselang=pt-Br $>$. Acesso Em: 28 Fev. 2015).

\subsubsection{Epidemiologia e acidentes causados por L. obliqua}

As populações de L. obliqua são exclusivamente encontradas no continente americano (Lemaire, 1972), e no Brasil, são principalmente encontradas nas regiões Sul e Sudeste (Duarte et al. 1990). Estudos iniciais indicavam que a distribuição geográfica do inseto parecia estar restrita à áreas rurais e regiões de maior quantidade de fragmentos florestais, no entanto, a espécie aumentou sua área de ocorrência, sendo também encontrada em núcleos urbanos, com ocorrência mais expressiva nos estados do Rio Grande do Sul, Santa Catarina, Paraná e São Paulo (Lorini 1999).

A maior incidência dessas lagartas, segundo Abella et al. (1999) pode estar relacionado à fatores como a alteração e redução de seu habitat natural causado pelo desmatamento, uso extensivo e intensivo de agrotóxicos, alteração das condições climáticas, levando a decorrente diminuição do número de seus inimigos naturais, bem como adaptações das larvas à plantas exóticas ou introduzidas (Lorini 1999). Todos esses fatores favorecem a 
aproximação das lagartas com os seres humanos, aumentando consequentemente o número de casos de acidentes.

Dados do Centro de Informação Toxicológica do Rio Grande do Sul (CIT) (Moraes 2002), indicaram o aumento do número de casos de acidentes causados por lagartas venenosas, como é o caso da série coletada entre 1998 e 2002, com mais de 688 casos de envenenamentos. Desde então, diversos estudos vem sendo realizados com o intuito de avaliar o número acumulado de acidentes hemorrágicos causados por essa espécie no Sul e Sudeste do Brasil (Abella et al. 2006).

Nesse sentido, tem-se que no estado de Santa Catarina, por exemplo, durante o período 1990 a 2007, foram registrados aproximadamente 2.200 acidentes, sendo que 40 pacientes $(1,8 \%)$ desenvolveram insuficiência renal aguda e a gravidade do envenenamento determinou risco de vida. Proporcionalmente, no Rio Grande do Sul, 1.839 casos de acidente foram registrados no Centro de Informações Toxicológicas no período de 1989 a 2005, com ocorrência de 13 óbitos, e no Estado do Paraná, entre os 199 casos de acidentes que ocorreram no período de 1977 e 1999, e houve cinco óbitos (2,5\%) (CIT 2008)(Rubio, 2001).

\subsubsection{Veneno de L. obliqua}

Dermatite de contato e urticária são reações cutâneas comuns em acidentes com larvas venenosas, e as consequências dessas reações estão geralmente limitadas ao local de ocorrência (Hossler 2010). No entanto, o contato com L. obliqua está associado a uma série de outros sintomas severos que podem acarretar na morte (Pinto et al. 2010).

O veneno de L. obliqua é produzido por células epiteliais secretoras, encontradas nos canais de cada espicula, conforme apresenta a ultra micrografia da figura 4. Ao tocar a pele, a cerda se fragmenta e libera o conteúdo de veneno (Veiga et al. 2001). 


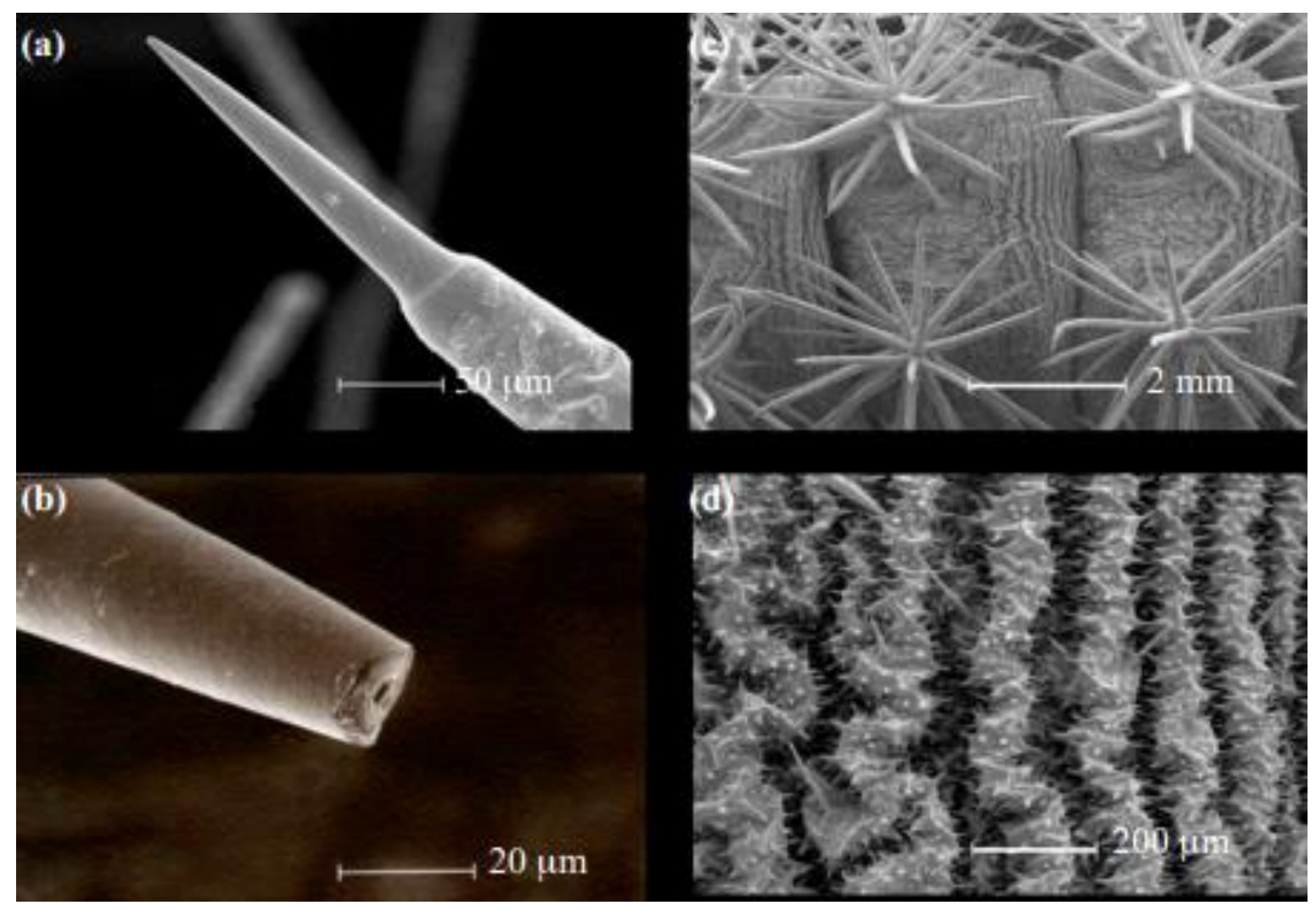

Figura 4. Ultra micrografia de varredura apresentando ultra estrutura das cerdas de L. obliqua. (a) espícula íntegra; (b) espícula quebrada na articulação, com canal interno exposto; (c) estrutura completa das espículas; (d) visão aproximada do tegumento que fixa as espículas. Adaptado de (Veiga et al. 2001) (Reprodução autorizada pela editora).

O efeito do veneno provoca distúrbios nos fatores de coagulação nas primeiras seis horas de contato, provocando desde hematomas na pele e nas mucosas, até síndromes hemorrágicas intensas, como hemorragia nas mucosas gengival e nasal, abdominais, pulmonares e em casos mais severos hemorragia cerebral, choque, insuficiência renal aguda, e risco de morte (Zannin et al. 2003; Gamborgi et al. 2006).

Os sintomas iniciais são reações de inflamação como dermatite urticante logo após o contato, seguida de reações sistêmicas como cefaleia, febre, náuseas, dores musculares e hipertensão. Sinais de sangramento como os hematomas, equimoses, hematúria e melenas são frequentemente observados entre 6 e 72 horas após o contato (Kowacs et al. 2006), conforme figura 5 . 

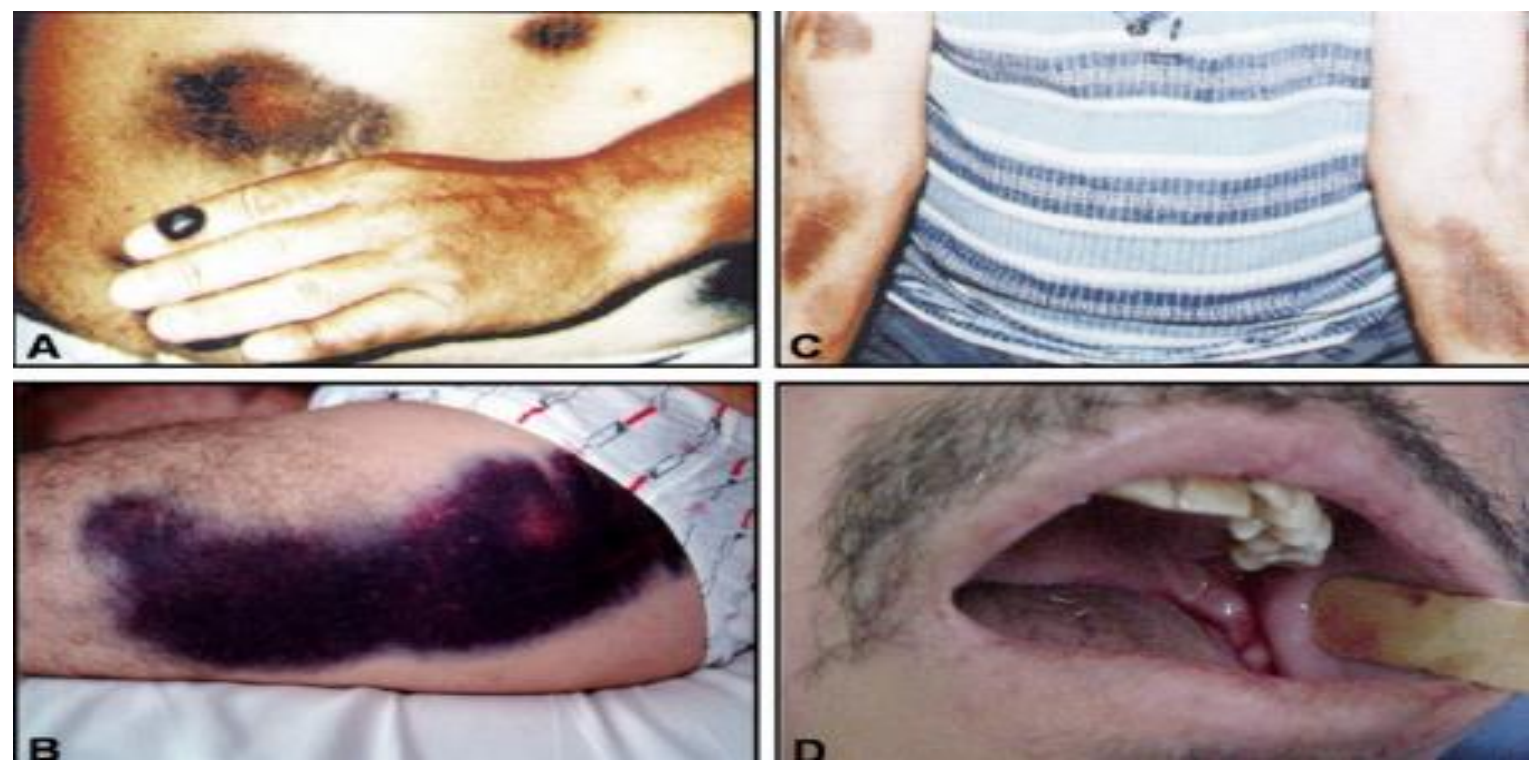

Figura 5. Aspecto das lesões hemorrágicas após o contato com L. obliqua. (a) Hematoma; (b)e (c) Equimoses e (d) hemorragia da mucosa gengival. Adaptado de (CIT 1999).

O veneno de L. obliqua provoca distúrbios na coagulação sanguínea, conforme foi verificado em dados laboratoriais de pacientes afetados, que mostram diminuição dos níveis plasmáticos dos fatores de coagulação fibrinogênio, FV, fator VIII (FVIII), FXII (Zannin et al. 2003). Foi mostrado também que o veneno dessa lagarta causa hemólise intravascular em ratos, com a redução do número de eritrócitos e o aumento de hemoglobina no plasma, levando a um quadro de hemoglobinúria (Seiber et al. 2006).

Portanto, o veneno possui uma alta atividade proteolítica, pro-coagulante e fibrinogenolítica (Veiga et al. 2003), uma vez que é composto por enzimas (ativadores de fator $\mathrm{X}$, prototrombinas e fibrinogenases) que participam dessas atividades, conforme relatado em estudos de isolamento e caracterização dessas enzimas obtidas a partir do veneno de lagartas L. obliqua (Alvarez-Flores et al. 2006; Donato et al. 1998; Pinto et al. 2004). A prototrombina e o fator $\mathrm{X}$ geram trombina intravascular, que leva a ativação do sistema de coagulação consequentemente o consumo do fibrinogênio e de outros fatores de coagulação. Desse modo, as diversas toxinas presentes no veneno dessas lagartas atuam sinergicamente no indivíduo afetado, de modo a produzir síndromes hemorrágicas pós-contato com quadro sistêmico secundário, e desse modo, deve ser tratada do mesmo modo que acidentes ofídicos (Kelen et al. 1995).

Diante desse fato e de tantos casos relatados, e devido à falta de um medicamento específico para o tratamento da síndrome hemorrágica, o soro antilonômico (SALon) foi 
produzido pelo Instituto Butantã - SP, a partir das cerdas de L. obliqua de último instar, imunizadas em cavalos, de onde é obtido uma alta concentração de imunoglobulinas purificadas (Dias da Silva et al. 1996). Sua eficácia é atualmente comprovada, capaz de reestabelecer os parâmetros fisiológicos de coagulação em pacientes envenenados e em experimentos modelo (Caovilla \& Barros 2004), e faz parte do cronograma do Programa Nacional de Animais Peçonhentos do Ministério da Saúde, podendo ser aplicado conforme a gravidade do envenenamento por via intravenosa (Brasil 2005).

\subsubsection{Inimigos naturais de L. obliqua}

Diante do aumento da dispersão e da abundância das populações de L. obliqua, e visando ações de controle dessa espécie para prevenir acidentes com a população, faz-se necessário estudar e analisar seus agentes naturais de controle biológico. Nesse sentido, Mores (2002) identificou que dentre os principais inimigos naturais da lagarta L. obliqua estão as larvas de moscas (Diptera: Tachinidae) e vespas (Hymenoptera: Ichneumonidae) que perfuram o tegumento das lagartas e se alimentam de estruturas internas, impedindo o prosseguimento do ciclo biológico da lagarta na passagem para pupa. Foram identificados também como seus predadores o hemíptero Alcaeorrhychus grandis (Hemiptera: Pentatomidae), bem como o nematoide isolado de seu tubo digestivo, o Hexamermis sp. (Nematoda: Mermithidae).

Dentre esses patógenos naturais de L. obliqua, um deles é o objeto de estudo desse trabalho, o vírus Lonomia obliqua multiple nucleopolyhedrovirus (LoobMNPV) pertencente à família Baculoviridae (Figura 6) (Wolff et al. 2002). 

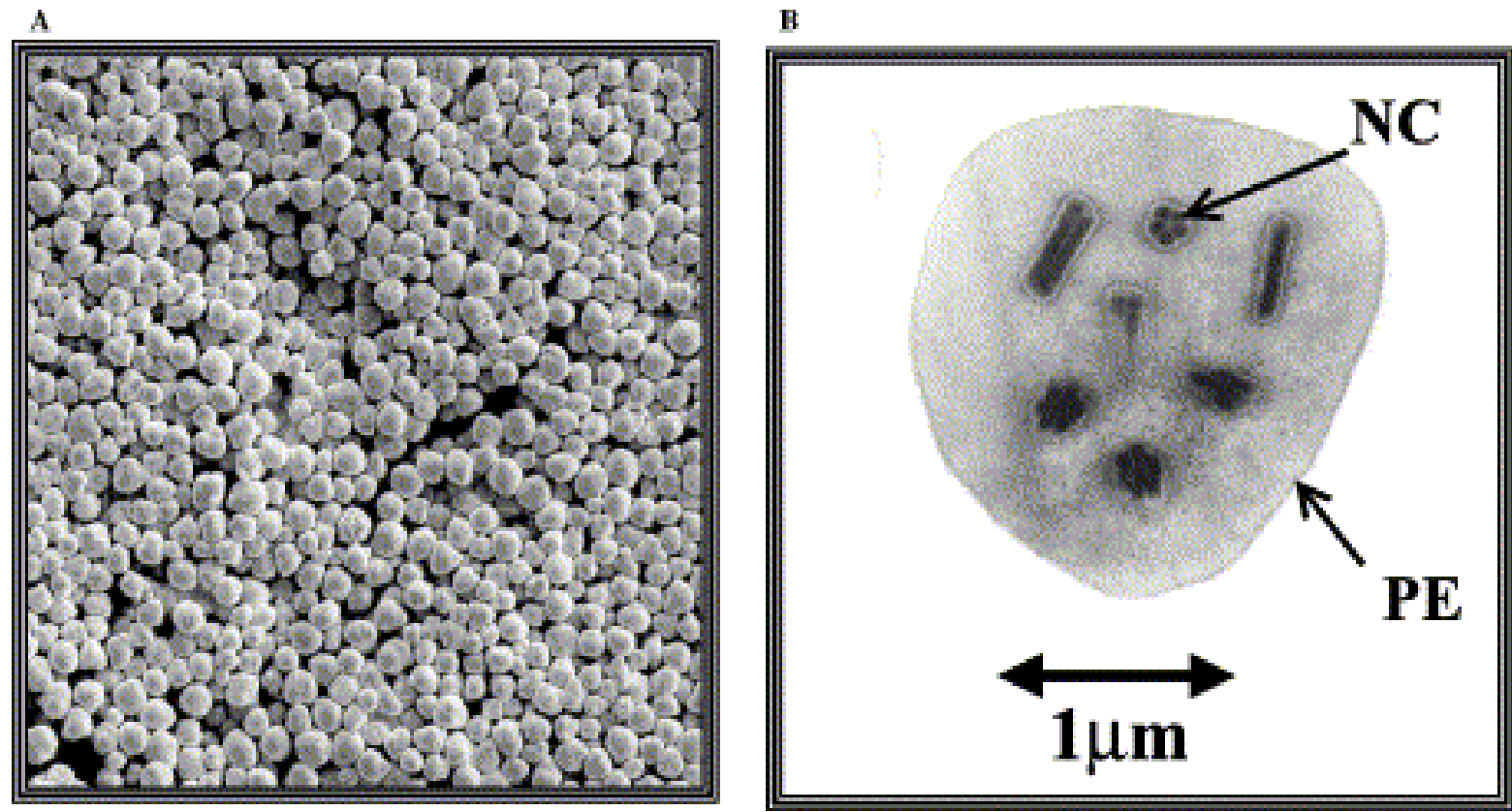

Figura 6. Lonomia obliqua multiple nucleopolyhedoovírus (LoobMNPV). (a) Ultra micrografia de varredura dos poliedros de LoobMNPV ; (b) Ultramicrografia de transmissão mostrando detalhe de um poliedro de LoobMNPV, contendo mútiplos nucleocapsídeos (NE) envolto pelo envelope do poliedro (PE) (Wolff et al., 2002) (Reprodução autorizada pela editora).

\subsection{Baculovírus}

Segundo Rohrmann 2013, sob o ponto de vista histórico, a descoberta dos baculovírus está primeiramente relacionada à sericultura, que ocorre há mais de 5.000 anos, onde as culturas de larvas da seda apresentavam patologias, que desde então, os chineses já dispunham de métodos para combatê-las. Com o aperfeiçoamento da microscopia de luz no século XIX, foi possível observar que corpos de oclusão de formato poliédrico, denominados de poliedroses, eram um dos causadores de sintomas nos insetos afetados. No entanto, apenas a partir da década de 40, com o avanço da microscopia eletrônica, foi possível observar que haviam vírions em formato de bastão contidos nesses corpos poliédricos (Bergold 1947 apud Rohrmann 2013).

Posteriormente, dois tipos distintos de poliedroses foram descritas, as poliedroses nucleares (do inglês- nuclear polyhedroses - NPVs - hoje denominados nucleopoliedrovirus) e as citoplasmáticas (do inglês cytoplasmic polyhedroses - CPVs) (Xeros 1952 apud Rohrmann 2013). Diferentemente dos nucleocapsídeos em forma de bastão dos NPVs, que 
são vírus de DNA fita dupla, os CPVs possuem capsídeos icosaedros e genomas de RNA fita dupla, sendo classificados como da família Reoviridae (gênero Cypovirus) (Rohrmann 2013).

$\mathrm{Na}$ classificação atual, os NPVs são baculovírus que pertencem à família Baculoviridae (do latim baculum = bastão, devido ao formato dos nucleocapsídeos), uma grande família de patógenos inseto-específicos, quem infectam as ordens Diptera, Hymenoptera, e Lepidoptera (Rohrmann 2013). Possuem DNA fita dupla, circular e superenovelado, com genomas que variam de 80 a $180 \mathrm{~kb}$, e codificam aproximadamente 90 a 180 genes. Os genomas são empacotados em nucleocapsídeos que possuem aproximadamente 230-385 nm de comprimento, e 40-60 nm de diâmetro (Akermann, 1983; Federici, 1986).

\subsubsection{Classificação morfológica}

Na década de 20, uma outra categoria de baculovírus além dos NPVs foi caracterizada pela presença de corpos de oclusão de aspecto granular e com formato elipsoidal, denominados granulovirus (GVs) (Paillot 1926 apud Rohrmann 2013). Portanto, a primeira divisão da família Baculoviridae foi dada em dois grandes grupos, de acordo com a morfologia de seus corpos de oclusão: os nucleopoliedrovirus (NPVs) (Figura 7) e os granulovirus (GVs) (Figura 8) (Vago 1974 apud Rohrmann 2013).

(a)

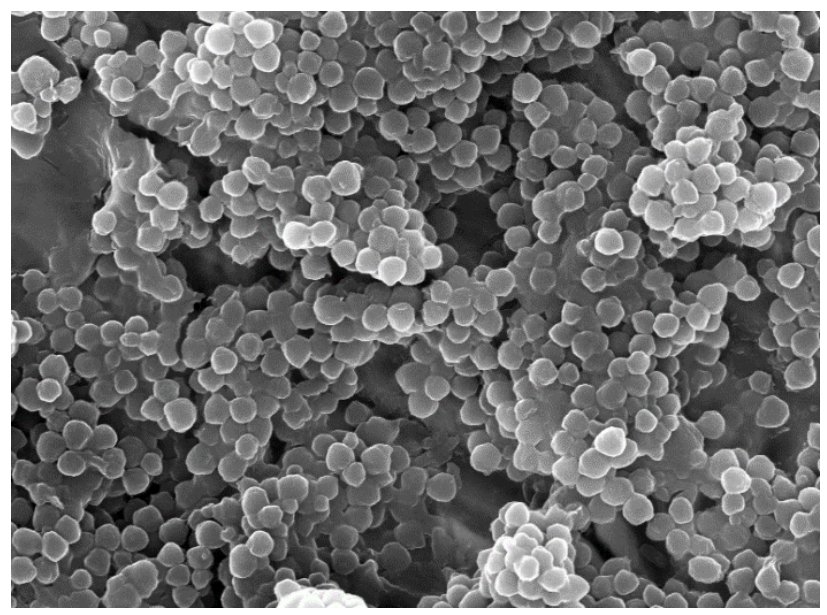

(b)

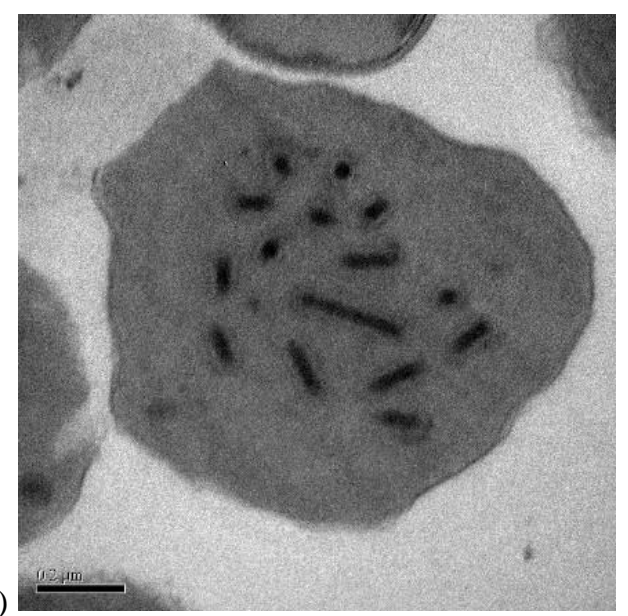

Figura 7. Ultra micrografias de corpos de oclusão de nucleopoliedrovírus (NPVs). (a) Microscopia eletrônica de varredura de corpos de oclusão (OBs); (b) Poliedro contendo nucleocapsídeos únicos (single). Fotos do Laboratório de Virologia da Universidade de Brasília. 


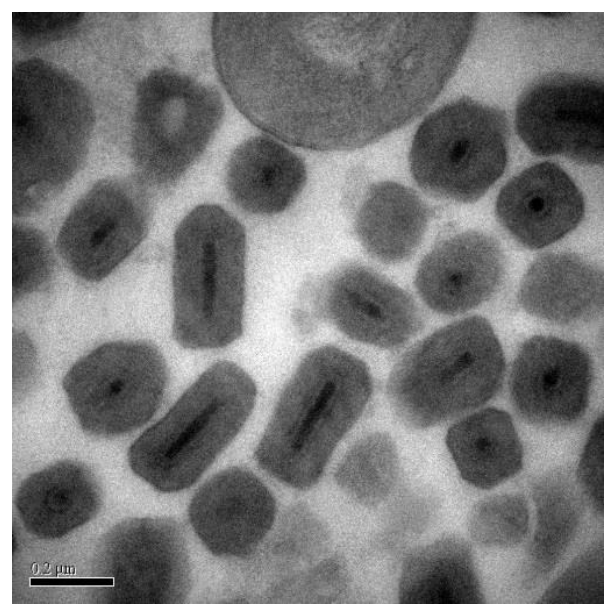

Figura 8. Ultra micrografia eletrônica de transmissão de Granulovírus (GV), mostrando grânulos contendo um vírion (single). Fotos do Laboratório de Virologia da Universidade de Brasília.

Além disso, os baculovírus são caracterizados por dois fenótipos de infecção, que possuem nucleocapsídeos com estruturas similares, porém divergentes quanto a origem e composição de seus envelopes, bem como no papel que desempenham no ciclo do vírus (Rohrmann 2013) (Figura 9).

A primeira forma são os vírions derivados da oclusão, responsáveis pela infecção vertical via oral inseto-inseto (do inglês occlusion-derived virions - ODVs). Os ODVs são contidos em corpos de oclusão (do inglês occlusion bodies - OBs) (Figura. 9), constituídos por uma matriz proteica composta por granulina (se for GV) ou poliedrina (se for NPV) (Akermann, 1983). Os $O B s$ são estruturas adaptadas para serem estáveis à diversas condições ambientais, inclusive às condições adversas do intestino médio de seus hospedeiros, permitindo que os vírions se mantenham estáveis e resilientes, como é o caso, por exemplo, de estudos que mostram sua tolerância ao passar pelo trato intestinal de pássaros, facilitando também sua dispersão (Entwistle et al. 1978). A segunda forma fenotípica são os vírions extracelulares ou virions brotados (do inglês budded virions -BVs) (Figura 9) que são responsáveis pelo espalhamento da infeção sistêmica horizontalmente, célula a célula do hospedeiro e não estão oclusos em uma matriz proteica (Keddie et al. 1989). 


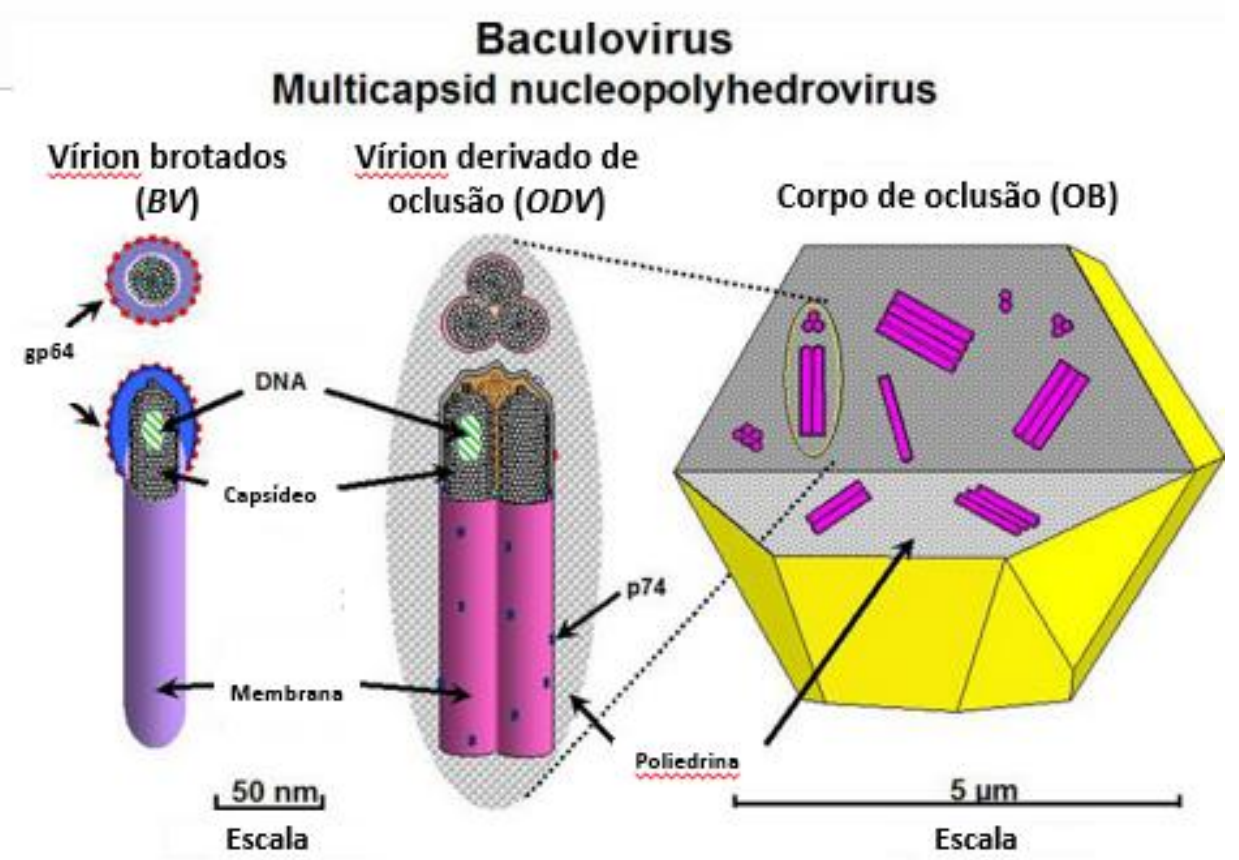

Figura 9. Diagrama esquemático da estrutura dos corpos de oclusão de baculovírus (OBs), dos vírions derivados de oclusão (ODV) e dos vírions intracelulares (BV). Os ODVs estão contidos um uma matriz cristalina composta de proteína (poliedrina, se for NPV, ou de granulina, se GV), formando o OB. No caso, a figura apresenta um OB de NPV. O envelope e nucleocapsídeos de ODV e BV contêm proteínas, dentre elas as destacadas na figura (GP64, e p74). Adaptado de (Fonte: Baculovirus In: WIKIMEDIA COMMONS, WIKIPÉDIA, a Enciclopédia Livre. Flórida: Wikimedia Foundation, 2015. Disponível Em: <http://commons.wikimedia.org/wiki/Baculovirus\#mediaviewer/File:Nucleopolyhedrovirus_german.png>. Acesso Em: 28 Fev. 2015).

Uma característica peculiar dos baculovírus é a organização dos nucleocapsídeos dentro de seus envelopes, sendo únicos (do inglês single) ou múltiplos (do inglês multiple), ocluídos pela matriz cristalina (Akermann, 1983). Sugere-se que o fenótipo de múltiplos nucleopoliedrovírus (MNPV, do inglês multiple nucleopolyhedrovirus) acelera a habilidade do vírus em estabelecer uma infecção, uma vez que vários nucleocapsídeos podem simultaneamente infectar a mesma célula, e iniciar a replicação, enquanto outros nucleocapsídeos podem iniciar o espalhamento da infecção e estabelecer infecções secundárias. No entanto, a formação de MNPV pode ser influenciada pelo tipo de célula infectada, podendo esse fenótipo ser decorrente de uma influência fisiológica ou ambiental (Rohrmann 2014). Ressalta-se que ambos fenótipos MNPV e SNPV foram encontrados em baculovírus que infectam lepidópteros, enquanto que os baculovírus infectam outras ordens 
foram encontrados apenas SNPVs. Os GVs, também são categorizados como single e multiple, no entanto, GVs múltiplos são mais raros (Falcon, 1985).

\subsubsection{Filogenia dos baculovírus}

Uma das hipóteses para a origem dos baculovírus está relacionada à origem dos vírus de inseto de DNA fita dupla há, aproximadamente 310 milhões de anos atrás, no período Carbonífero da era Paleozóica (Thézé et al. 2011), juntamente com o surgimento dos primeiros insetos (Luque et al. 2001). À medida que os insetos proliferavam, diferentes linhagens de vírus associados progressivamente se especializaram e co-evoluíam de acordo com a ordem de seus hospedeiros, uma vez que estudos filogenéticos mostram convergência dos baculovirus com a ordem de seus insetos hospedeiros (Herniou et al. 2004).

Baseado nesses padrões de associação do vírus ao hospedeiro, num processo de evolução hospedeiro-dependente, a filogenia da família Baculoviridae baseada nos genes conservados de baculovírus (core genes) é dividida em quatro gêneros: Alphabaculovirus, que são NPVs e infectam lepidópteras, Betabaculovirus, que são GVs e também infectam lepidópteras, e Gamma e Deltabaculovirus, que infectam as ordens Hymenoptera e Diptera, respectivamente (Jehle et al., 2006).

A maior divisão filogenética dentre os baculovírus foi observada em Alphabaculovirus, que resultou na separação de dois grandes grupos monofiléticos (grupo I e II) (Herniou et al. 2001). Esses dois grupos diferem significativamente no seu conteúdo gênico, como por exemplo, os NPVs do grupo I possuem a proteína de fusão de envelope GP64 nos BVs, enquanto os NPVs pertencentes ao grupo II não possuem a GP64, mas utilizam a proteína F como proteína de fusão de envelope (Pearson \& Rhormann 2002). Sugere-se que a linhagem de grupo I foi originada quando uma variante de NPV incorporou a GP64, o que resultou na derivação desse grupo como uma linhagem distinta (Jiang et al. 2009). No entanto, apenas com o sequenciamento e deposição de mais sequencias nos bancos de dados, aumentando-se a amostragem, será possível se entender por completo a evolução dos baculovirus como um todo. 


\subsubsection{Genômica dos baculovírus}

O primeiro genoma do baculovírus a ser sequenciado foi o de Autographa californica multiple nucleopolyhedrovirus (AcMNPV) (Ayres et al. 1994), o baculovírus mais estudado e caracterizado, sendo também o mais utilizado como vetor de expressão de proteínas, devido a sua plasticidade de infeção, por infectar diversas espécies e diversas linhagens de células de lepidópteros (McIntosh et al. 2005). Esse genoma apresenta 133,9 kb, 156 regiões de fase de leitura ( do inglês open reading frames - ORFs) e conteúdo G+C de $41 \%$ (Ayres et al. 1994). Desde então, o número de novos sequenciamentos de genomas de diferentes espécies de baculovírus é cada vez maior, variando tamanhos de genomas de 817 kb (Neodiprion lecontei nucleopolyhedrovirus (NeleNPV) (Lauzon et al. 2004) a 17,87 kb (Xestia c-nigrum granulovirus - XcGV) (Hayakawa et al. 1999). Com esse aumento de genomas sequenciados e publicados, é possível, cada vez mais, se inferir as relações filogenéticas dentre os baculovírus. Atualmente, 115 genomas foram sequenciados e depositados no GenBank, dentre os quais 72 são de espécies únicas de baculovírus (anexo 1).

Por meio de comparações entre os genomas de baculovirus já sequenciados, foi possível observar a existência de um conjunto de genes conservados em comum, denominados do inglês core genes. Os core genes estão envolvidos em funções biológicas como transcrição de genes, produção de proteínas estruturais dos vírions, bem como estabelecimento da infecção no intestino médio do hospedeiro (van Oers \& Vlak 2007; Rohrmann 2011). A tabela 1 apresenta a função relacionada de todos os core genes de baculovírus. Desses genes, 37 são genes compartilhados que já foram identificados em todos os baculovírus sequenciados até o momento (Garavaglia et al. 2012; Yuan 2011).

Tabela 1. Descrição da função dos genes conservados (core genes) em todos os baculovírus.

\begin{tabular}{cc}
\hline Core gene & Função \\
\hline lef-2 & Replicação de DNA/fator associado a primase \\
lef-1 & DNA primase \\
pif-2 & Requerido pelo fator de infectividade per os (PIF-2) \\
p47 & Subunidade da RNA polymerase \\
lef-8 & Subunidade da RNA polymerase \\
ac53 & Envolvida na montagem de nucleocapsídeos/Ubox/domínio similar RING \\
vp1054 & Proteína de nucleocapsídeo \\
\hline
\end{tabular}




\begin{tabular}{cc}
\hline Core gene & Função \\
\hline lef-9 & Subunidade da RNA polimerase \\
Dnapol & Replicação de DNA \\
Desmop & Presente no nucleocapsídeo \\
PIF-6 & Requerido pelo fator de infectividade per os (PIF-6) \\
Vlf1 & Envolvida na expressão dos genes p10 e polh \\
ac78 & Função desconhecida/região transmembrana \\
gp41 & Proteína de tegumento \\
ac81 & Função desconhecida \\
p95 & Proteína associada ao capsídeo viral \\
vp39 & Proteína mais abundante do capsídeo \\
lef-4 & Subunidade da RNA polimerase /enzima de capping \\
p33 & Sulfidril oxidase \\
p18 & Regressão dos nucleocapsídeos \\
odv-e25 & Proteína de envelope de ODV \\
Helicase & Desenovelamento de DNA \\
PIF-4 & Requerido pelo fator de infectividade per os (PIF-4) \\
$38 k$ & Requerida para a montagem de nucleocapsídeos \\
lef-5 & Fator de iniciação de transcrição \\
p6.9 & Proteína do nucleocapsídeo \\
p40 & Subunidade de complexo proteico \\
&
\end{tabular}

Esses core genes foram provavelmente incorporados aos genomas desses vírus antes de processos de diversificação, uma vez que são encontrados em todos os quatro gêneros da família Baculoviridae, enquanto outros genes são encontrados em apenas alguns desses gêneros, sugerindo que essa incorporação ao genoma tenha ocorrido mais recentemente. Outros são ainda encontrados na maioria dos grupos, mas ausente em outros, podendo sugerir também deleção ou perda gênica (Miele et al. 2011). No entanto, apenas uma pequena porção do genoma viral de baculovírus codifica genes que são comuns a todos eles, uma vez que mais de 800 grupos ortológos diferentes já foram encontrados em baculovirus (Jehle et al., 2006).

Além disso, outros elementos são comumente encontrados nos genomas de baculovírus, como as regiões homólogas (do inglês homologous regions - hrs). Essas regiões são elementos de DNA palindrômico e repetitivo (Kool et al. 1995), envolvidos em funções como origens de replicação (oris) (Pearson \& Rohrmann 1995), ativadores (enhancers) de transcrição gênica (Kuzio et al. 1999; Pang et al. 2001), bem como sítios de recombinação 
homóloga (Hayakawa et al. 1999). Essas regiões são altamente variáveis e sua homologia com diferentes vírus é muito limitada, mas no entanto, dentro do mesmo genoma há regiões de repetição similares (Rohrmann, 2011).

O gene da poliedrina de AcMNPV, também foi a primeira sequência gênica de baculovírus a ser sequenciado (Hooft Van Iddekinge et al. 1983), e com isso, esse foi o primeiro gene a ser utilizado para se realizar análises filogenéticas (Zanotto et al. 1992). No entanto, como se trata de um gene altamente conservado, o sinal filogenético desses genes geralmente é difuso (Jehle et al. 2006), podendo refletir em diferenças reais na filogenia devido a fatores como recombinação (Herniou \& Jehle, 2007). Por outro lado, análises filogenéticas realizadas com grande banco de dados, como os core genes, se mostra mais acurada, robusta e informativa, e por isso, análises mais recentes tem utilizado esses genes (Herniou et al. 2003).

\subsubsection{Regulação da expressão gênica}

A infecção dos baculovirus é um processo sequencial, dado numa cascata transcricional, onde cada fase de expressão de genes depende do sucesso da fase anterior, sendo esse processo crucial para o sucesso da replicação viral. Desse modo, a expressão de proteínas virais podem ser categorizadas pelo seu momento de expressão no contexto replicativo, e são divididas nos seguintes estágios: precoce (do inglês early), tardio e muito tardio (do inglês late e very late), (Miller 1997). No início de infecção, os baculovírus exploram o sistema transicional da célula hospedeira para expressar seus genes precoces, que são transcritos antes da replicação do DNA viral, utilizando a RNA polimerase II do hospedeiro (Friesen, 1997).

Na fase tardia da infecção, depois que já foi iniciada a replicação do DNA viral, os baculovírus agem independentemente utilizando sua própria maquinaria de RNA polimerase para transcrição de genes tardios (Blissard \& Rohrmann 1990; Yang et al. 1991). Esse complexo de RNA polimerase viral inicia a transcrição a partir de elementos promotores localizados de 30-90 pb a montante do códon de iniciação ATG (Blissard \& Rohrmann 1990; Gross et al. 1993). Como a expressão tardia de genes é necessariamente dependente da 
replicação do DNA viral, estudos mostraram que quando essa replicação é inibida, a expressão tardia de genes não é observada (Friesen \& Millert 1987; Rice \& Miller 1986).

\subsubsection{Infecção e modo de ação}

O modo de infecção dos baculovírus é complexo, uma vez que, como previamente descrito, envolve dois tipos de vírions, os BVs e os ODVs. O ciclo de infecção (Figura 10) se inicia quando as larvas de insetos consomem, por via oral, alimentos contaminados com $O B s$. Vale ressaltar que a transmissão e replicação de baculovírus ocorre exclusivamente nos estágios larvais dos insetos. Uma vez ingeridos, os $O B s$ percorrem o intestino anterior e adentram o intestino médio, um ambiente com suco gástrico de $\mathrm{pH}$ altamente alcalino $(\mathrm{pH}$ 10-11) e rico em enzimas digestivas (Terra \& Ferreira 1994). Os baculovírus evoluíram de forma adaptativa para tolerar e explorar esse microambiente extremo, uma vez que a própria alcalinidade do intestino médio provoca a dissolução dos $O B s$ e liberação dos $O D V s$.

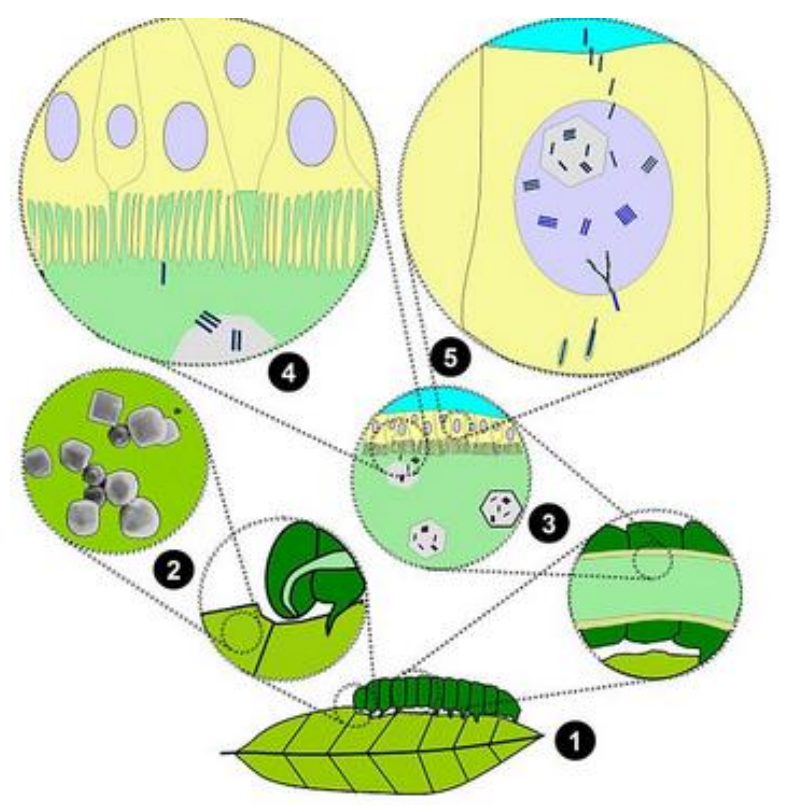

Figura 10. Ciclo de infeção de baculovírus. (1-2) o inseto se alimenta dos $O B s$ presente nas folhas. (3) Lúmen do intestino médio da lagarta, com condições alcalinas. (4) $O B$ s sendo dissolvidos no intestino médio, liberando os $O D V s$. (4) $O D V s$ que infectam as células epiteliais com microvilosidades. (5) Replicação viral no núcleo da célula. Adaptado de (Baculovirus. In: WIKIMEDIA COMMONS, WIKIPÉDIA, a Enciclopédia Livre. Flórida: Wikimedia Foundation, 2015. Disponível Em: <http://commons.wikimedia.org/wiki/Baculovirus\#mediaviewer/File:Npv-Lebenszyklus.jpg>. Acesso Em: 28 Fev. 2015). 
Posteriormente, para infectar as células epiteliais do intestino médio, os ODVs necessitam atravessar a membrana peritrófica, uma estrutura que consiste numa matriz rica em quitina, mucopolissacarídeos e proteínas, com função de proteção mecânica inata do epitélio do intestino médio, bem como barreira contra micro-organismos (Adams e McClintock 1991; Hegedus 2009). Os ODVs rompem essa membrana por intermédio de diversos fatores virais de degradação (Derksen \& Granados 1988), como metaloproteases virais (enhancinas) que clivam proteínas constituintes dessa membrana, como a mucina, uma proteína de alto peso molecular fortemente glicosilada, produzida pelas células epiteliais (Wang \& Granados 1997).

Para a efetiva entrada do ODV na célula, há uma combinação de fatores que estão envolvidos, como a ligação do envelope dos vírions aos receptores celulares, ativando enzimas que permitem o acesso viral por meio de fusão com a membrana da célula hospedeira, e a liberação dos nucleocapsídeos. Dentre esses incluem-se os genes relacionados à fatores de infecção oral (P74, PIF-1, PIF-2,PIF-4, e PIF-5) (Fang 2009; Kikhno 2002; Rohrmann 2013).

Uma vez na célula, os nucleocapsídeos são transportados para a membrana nuclear, num processo que envolve a polimerização de actina (Goley, E.D., 2006), onde a replicação viral inicia-se, formando um estroma virogênico com alta produção de mRNAs e progênie viral, que posteriormente são espalhados sistemicamente em forma de BVs, estabelecendo infecções secundárias que são mediadas por proteínas de fusão de membrana como a GP64 ou a proteína F (Guarino et al. 1992; Keddie 1989)(Figura 11b e c).

O último passo da infecção viral (Figura 11c) é destinado a manter nucleocapsídeos montados no núcleo, para que se tornem oclusos. Nesse momento há uma super-expressão de genes ativados por promotores muito tardios, resultando na produção de níveis elevados de proteínas estruturais do $O B$, como a poliedrina e a P10. A poliedrina é a proteína de maior abundância do $O B$, que cristaliza e envolve os vírions numa rede (Braunagel 2007). Até $10^{10}$ poliedros podem ser produzidos por larva nesse momento final da infeção, representando cerca de 30\% do peso seco da larva (Miller et al. 1983). A P10 é uma proteína fibrilar que está envolvida na desintegração da célula do hospedeiro e montagem dos OBs (Van Oers et al. 1994). 
Após esse último estágio, duas enzimas virais são cruciais para a quebra da cutícula do hospedeiro, a catepsina e a quitinase, uma vez que elas são responsáveis por liquefazer a larva, permitindo a liberação dos poliedros produzidos, que irão infectar horizontalmente outros indivíduos (Hawtin et al., 1997).

\subsubsection{Importância dos baculovírus}

A importância dos baculovirus nas relações ecológicas da natureza está em seu papel de controlar as populações de insetos, uma vez que são patógenos naturais. Como exemplo, sabe-se que eles são reguladores das populações de mariposas na América do Norte, sendo responsáveis por mais de 50\% da mortalidade (Podgwaite 1981).

No âmbito da agricultura, por serem patógenos específicos de insetos e não possuírem efeitos em plantas, mamíferos, peixes, aves ou outros organismos não-alvo, os baculovírus são excelentes candidatos para o uso alternativo de pesticidas, sendo utilizados como bioinseticidas no controle biológico de pragas em monoculturas. Como exemplo, o baculovirus Anticarsia gemmatalis nucleopoliedrovírus (AgMNPV) já foi é amplamente utilizado no controle da lagarta da soja, em mais de 1 milhão de hectares anualmente no Brasil (Moscardi, 1999). No entanto, existem limitações em seu uso, como a demora para matar os insetos, espectro restrito de hospedeiros, bem como dificuldades técnicas e econômicas para a produção in vitro e comercialização, alteração da eficácia em campo devido a condições climáticas, dentre outros. (Moscardi, 1999).

Além disso, os baculovírus são amplamente utilizados como vetores de expressão de genes heterólogos no qual são produzidos baculovírus recombinantes com genes codificando proteínas de interesse, que são clonados sob o comando do promotor do gene da poliedrina, uma vez que essa proteína é produzida em grandes quantidades durante a infecção (King \& Possee 1992). Ainda, os baculovirus são utilizados como ferramentas de terapia gênica, uma vez que infectam somente insetos e não replicam em vertebrados, plantas ou microorganismos, mas no entanto, com promotores adequados, são capazes de transduzir em células animais (Mäkelä et al. 2006), realizando uma entrega gênica de proteínas heterólogas de interesse (Kost et al. 2005). 


\subsubsection{Lonomia obliqua multiple nucleopoliedrovírus (LoobMNPV).}

LoobMNPV foi primeiramente isolado e caracterizado por Wolff et al.(2002), e foi denominado Lonomia obliqua multicapsid nucleopolyhedrovirus. Esse vírus foi analisado por microscopia eletrônica sua ultraestrutura, apresentando corpos de oclusão típicos de baculovírus, de tamanho variando de 1,0 a 1,4 $\mu \mathrm{m}$, contendo múltiplos nucleocapsídeos no mesmo envelope viral. Conforme o perfil de restrição gerado a partir da digestão do genoma por enzimas de restrição, esse vírus apresentou um tamanho de aproximadamente $95.500 \mathrm{pb}$. $\mathrm{O}$ gene da poliedrina desse vírus foi sequenciado, e a partir dessa sequência, uma árvore filogenética foi realizada, pela qual LoobMNPV ficou agrupado junto ao grupo I NPV, sendo mais relacionado a Amsacta albistriga NPV.

\subsection{Justificativa}

Ante ao crescimento das populações de L. obliqua em diversas regiões do Brasil, observa-se também um consequente aumento relacionado aos acidentes e até óbitos causados a humanos por essas lagartas, dada sua toxicidade quando em contato com a pele humana (Moreira \& Moresco 2007). Com a descoberta e identificação do baculovírus que infecta essas lagartas (Wolff et al., 2002), LoobMNPV, objeto de estudo desse trabalho, é possível analisar a viabilidade de utilizá-lo como ferramenta de controle biológico no combate ao desequilíbrio das populações desse inseto, auxiliando diretamente a medicina preventiva.

Ainda, o maior conhecimento de novos membros da família Baculoviridade, como é o caso de LoobMNPV, permite uma melhor análise do contexto filogenético que abrange esses vírus, possibilitando uma melhor compreensão dos processos evolutivos e biológicos aos quais estão envolvidos, e que por sua vez, podem até ser transpostos e utilizados em outras áreas do conhecimento.

Sendo assim, o objetivo desse trabalho foi analisar e organizar o genoma do baculovírus Lonomia obliqua multiple nucleopoliedrovírus (LoobMNPV), e fazer correlações quanto a sua filogenia frente aos outros baculovírus, bem como analisar suas peculiaridades, com o intuito de se conhecer mais acerca desse vírus com potencial para utilização em programas de controle biológico. 


\subsection{Objetivos}

\subsubsection{Objetivo geral}

Montar o genoma do baculovírus LoobMNPV e analisar sua composição genômica e seu contexto evolutivo em relação a outros baculovírus.

\subsubsection{Objetivos específicos}

- Isolar o DNA viral de LoobMNPV a partir de larvas de L. obliqua infectadas;

- Sequenciar o DNA de LoobMNPV;

- Realizar a montagem e anotação do genoma

- Analisar composição gênica de LoobMNPV;

- Analisar a relação filogenética e contexto evolutivo de LoobMNPV comparado aos outros baculovírus;

- Analisar as peculiaridades do genoma de LoobMNPV como a presença de ORFs únicas, regiões homólogas $(h r s)$ e ausência de genes encontrados em outros baculovírus; 


\section{MATERIAL E MÉTODOS}

\subsection{Desenho esquemático da metodologia}

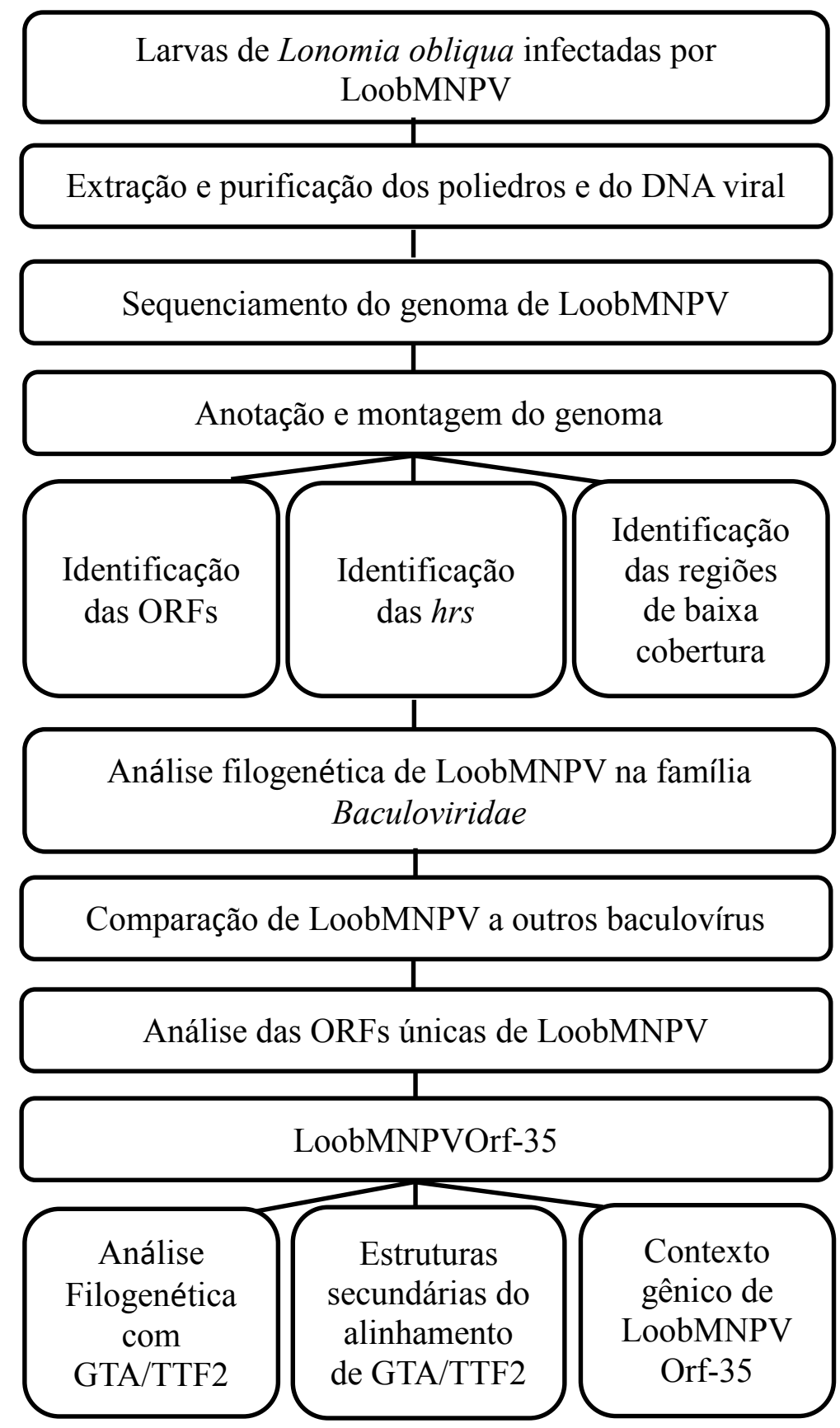




\subsection{Amostra viral}

O baculovírus objeto desse estudo foi gentilmente fornecido pelo Prof. Dr. José Luiz Caldas Wolff, da Universidade Presbiteriana Mackenzie, isolado a partir de extrato larvas de Lonomia obliqua infectadas. Essas larvas infectadas foram mantidas a uma temperatura de $10{ }^{\circ} \mathrm{C}$, no Laboratório de Biologia Molecular e Virologia, da Universidade Presbiteriana Mackenzie e posteriormente cedidas ao laboratório de Baculovírus da Universidade de Brasília, que por sua vez as manteve sob as mesmas condições, até o momento de procedimentos para isolamento e purificação do DNA viral.

\subsection{Isolamento do DNA viral}

Os corpos de oclusão $(O B S)$ foram obtidos a partir do extrato de larvas de L. obliqua infectadas e mortas, que foram purificadas conforme O'Reilly et al. (O'Reilly et al 1992), Primeiramente, os cadáveres foram homogeneizados com água destilada $\left(\mathrm{ddH}_{2} \mathrm{O}-\mathrm{w} / \mathrm{v}\right)$. O extrato obtido foi posteriormente filtrado por três camadas de gaze para remoção dos resíduos teciduais, e submetido à centrifugação a 7,000 $x \mathrm{~g}$ por 10 minutos. Posteriormente, o precipitado foi novamente suspendido e lavado em SDS $0.5 \%(\mathrm{w} / \mathrm{v})$ e centrifugado sob as mesmas condições descritas acima, com intuito de se obter os poliedros que ficam na porção precipitada, separando-o do DNA e debris celulares que ficam no sobrenadante, que por sua vez é descartado. Esses passos de lavagem e centrifugação foram repetidos quatro vezes até se obter o precipitado final, que por fim foi lavado em $\mathrm{NaCl} 0.5 \mathrm{M}$ e suspendido em água destilada $\left(\mathrm{ddH}_{2} \mathrm{O}\right)$.

Para obtenção e purificação dos $O B s$, um gradiente de sacarose foi realizado, colocando o material em um gradiente de sacarose a 40-65\%, que por sua vez foi centrifugado a $104.000 \times \mathrm{g}$ por 40 minutos a $4^{\circ} \mathrm{C}$. A banda referente aos $O B s$ foi coletada, e diluída em um

fator de quatro em água destilada $\left(\mathrm{ddH}_{2} \mathrm{O}\right)$ e posteriormente submetida novamente à centrifugação a 7,000 $x \mathrm{~g}$ por 15 minutos a $4^{\circ} \mathrm{C}$. Os $O B s$ foram então dissolvidos em solução alcalina e o DNA purificado conforme o protocolo descrito em O'Reilly et al. (1992). A 
quantidade e a qualidade do DNA isolado obtido pelo gradiente de sacarose foram determinadas por gel de eletroforese a $0.8 \%$ em gel de agarose, bem como em equipamento NanoDrop ® (Nano Drop 2000c, Thermo Cientific, Wilmington, DE, USA).

\subsection{Sequenciamento do genoma de LoobMNPV}

O DNA viral referente ao baculovírus LoobMNPV extraído de larvas de Lonomia obliqua infectadas foi sequenciado através da técnica de piro sequenciamento, realizada em sequenciador 454 Genome Sequencer (GS) FLX ${ }^{\mathrm{TM}}$ Standard, da marca comercial Roche, na Macrogen Inc, localizada no Seoul, República da Korea.

\subsection{Anotação e montagem do genoma de LoobMNPV}

A montagem de novo e anotação do genoma de LoobMNPV foi realizada com o auxílio do programa Geneious 7.1.6 (Biomatters). De acordo com os seguintes parâmetros: sensibilidade média do mapeamento da montagem/alinhamento, e interação de 25 vezes. No processo de montagem, as possíveis regiões de fase de leitura, ou ORFs (do inglês Open Reading Frames), foram selecionadas a partir dos seguintes parâmetros: resíduo de aminoácido metionina (ATG) como códon de iniciação de transcrição, sobreposição mínima de ORFs adjacentes e ORFs com no mínimo 150 pares de base (50 aminoácidos). As ORFs nessas condições foram selecionadas para análises posteriores.

A análise de similaridade das possíveis ORFs foi realizada utilizando a plataforma BlastP (Altschul et al. 1990), com o intuito de identificar homologia e identidade proteica das ORFs encontradas no genoma de LoobMNPV em comparação à outras sequencias encontradas em outros organismos, especialmente em outros baculovírus.

Realizou-se ainda, a busca por motivos conservados no genoma de LoobMNPV, dentro da região de 200 pb a montante de cada ORF única de LoobMNPV.

Com o intuito de confirmar a montagem, uma digestão in silico foi realizada utilizando as enzimas de restrição BamHI, EcoRI e PstI. O perfil de digestão desse resultado foi comparado ao perfil previamente apresentado no trabalho de identificação do vírus LoobMNPV (Wolff et al. 2002). 


\subsection{Confirmação das regiões de baixa cobertura}

Durante a montagem do genoma, foi observada uma região de baixa cobertura (na posição 54,268 a 54,957 do genoma), uma vez que se apresentou fora dos parâmetros estabelecidos no programa Geneious 7.1.6. (Biomatters), onde apenas regiões com mais de 50 reads gerados pelo sequenciamento foram consideradas. Desse modo, afim de confirmar a montagem do genoma e em especial dessa região, realizou-se uma reação em cadeia da polimerase (PCR) com os iniciadores citados na tabela 2, e conforme o procedimento estequiométrico apresentado na tabela 3 e programa de PCR apresentado na tabela 4. O resultado da PCR foi analisado por eletroforese em gel de agarose a 0,8\%, conforme descrito em Sambrook et al. (1989).

Tabela 2. Iniciadores para amplificação da região de baixa cobertura do genoma de LoobMNPV.

\begin{tabular}{cc}
\hline Nome do iniciador & Sequencia \\
\hline LoobMNPV baixa cobertura Primer F & GTGCCCTACAAGAAATATTCGCA \\
LoobMNPV baixa cobertura Primer R & GCGCCAACAATTTAATGGTAGC \\
\hline
\end{tabular}

Tabela 3. Procedimento da reação de PCR, de volume final de $50 \mu 1$, utilizada para a amplificação da região de baixa cobertura do genoma de LoobMNPV. A enzima Taq DNA polimerase e o tampão utilizado são da marca pht (Photoneutria Biotecnologia e Serviços Ltda.), e o dNTP é da marca Promega.

\begin{tabular}{ccc}
\hline Reagentes & Volume $(\boldsymbol{\mu l})$ & Concentração final \\
\hline Primer F $(10 \mu \mathrm{mol})$ & 1 & $0,2 \mu \mathrm{mol}$ \\
Primer R $(10 \mu \mathrm{mol})$ & 1 & $0,2 \mu \mathrm{mol}$ \\
dNTP mix $(10 \mathrm{mM})$ & 1 & $0,2 \mathrm{mM}$ \\
Tampão $10 \mathrm{X}$ & 5 & $1 \mathrm{X}$ \\
$\mathrm{MgCl}_{2}(50 \mathrm{mM})$ & 1,5 & $1,5 \mathrm{mM}$ \\
Taq DNA polimerase $(5 \mathrm{U} / \mu \mathrm{l})$ & 0,5 & $2,5 \mathrm{U}$ \\
DNA viral $(\mathrm{LoobMNPV})$ & 1 & $1 \mathrm{ng}$ \\
$(50 \mathrm{ng} / \mu \mathrm{l})$ & & - \\
Água ultrapura $(\mathrm{Milli}-\mathrm{Q})$ & 39 & \\
\hline
\end{tabular}


Tabela 4. Programa utilizado na amplificação da região de baixa cobertura de LoobMNPV.

\begin{tabular}{llll}
\hline \multicolumn{1}{c}{ Etapa } & Temperatura $\left({ }^{\circ} \mathbf{C}\right)$ & Tempo & Ciclos \\
\hline Desnaturação inicial & 94 & $1: 00$ minuto & - \\
Desnaturação & 94 & 1:00 minuto & 35 \\
Anelamento & 55 & $0: 20$ segundos & 35 \\
Extensão & 72 & $1: 30$ minuto & 35 \\
Extensão final & 72 & $7: 00$ & - \\
Resfriamento & 12 & $\infty$ & -
\end{tabular}

\subsection{Análise e confirmação das regiões homólogas (hrs)}

Para detectar as regiões homólogas (hrs- do inglês homologous regions) presentes no genoma de LoobMNPV, buscas computacionais por DOTPLOT pelo programa Geneious 7.1.6. (Biomatters) e pela plataforma Tandem Repeat Finder (http://tandem.bu.edu/trf/trf.html) (Benson 1999) foram realizadas, afim de se analisar a composição e localização dessas regiões repetitivas e in tandem. A partir dessas sequencias encontradas, um alinhamento da unidade de repetição de cada $h r$ foi realizada utilizando MAFFT (Katoh et al. 2002).

Posteriormente, após detectar as hrs, com o intuito de se confirmar o tamanho e a posição no genoma de LoobMNPV, PCRs foram realizados com as 7 regiões homólogas encontradas no genoma com os iniciadores citados na tabela 5, conforme a reação de PCR da tabela 6 , bem como com o programa utilizado na reação de PCR conforme tabela 7. O resultado da PCR foi analisado por eletroforese em gel de agarose $0,8 \%$.

Tabela 5. Iniciadores utilizados na amplificação das hrs de LoobMNPV.

\begin{tabular}{ccc}
\hline Nome do iniciador & Sequência $\left(\mathbf{5}^{\prime} \mathbf{> 3}^{\prime}\right)$ & $\begin{array}{c}\text { Posição inicial do iniciador } \\
\text { no genoma }(\mathbf{p b})\end{array}$ \\
\hline hr1-F & AGAGTTGGAAATTTCGCGCTC & 6,267 \\
hr1-R & GTTTTTACTCTGTCCGCGCG & 6,150 \\
hr2-F & CCCGCTAATGAACCGTGTGA & 21,586 \\
hr2-R & AACCGTTTAAATCCTTCGTGT & 22,316 \\
hr3-F & GCTGGAGTAAATTGTTCAATCGC & 32,413 \\
hr3-R & TTTCCATAACGGGGTGCCAA & 33,627 \\
hr4-F & TAGGGCACAATAGCAGCAGC & 54,972 \\
hr4-R & ACGTGCCAAGTCGAATCTGA & 55,927 \\
hr5-F & CTGCGTTTGTTCGACCCAAT & 72,093 \\
hr5-R & CTGAAACGCGACAACAGTCC & 72,952
\end{tabular}




$\begin{array}{ccc}\text { hr6-F } & \text { CGCATAACCTTTAGCGTGACT } & 91,455 \\ \text { hr6-R } & \text { TCATGTCGGCCAATGAGGAC } & 91,995 \\ \text { hr7-F } & \text { AATGCGCAAAAGAACGGGTC } & 100,516 \\ \text { hr7-R } & \text { AACAACTAAACTGCGCCCCA } & 101,532\end{array}$

Tabela 6. Procedimento da reação de PCR, de volume final de $50 \mu 1$, utilizada para a amplificação das sete hrs do genoma de LoobMNPV. A enzima Taq DNA polimerase e o tampão utilizado são da marca Ludwig biotech e o dNTP é da marca Promega.

\begin{tabular}{ccc}
\hline Reagentes & Volume $(\boldsymbol{\mu l})$ & Concentração final \\
\hline Primer F $(10 \mu \mathrm{mol})$ & 1 & $0,2 \mu \mathrm{mol}$ \\
Primer R $(10 \mu \mathrm{mol})$ & 1 & $0,2 \mu \mathrm{mol}$ \\
dNTP mix $(10 \mathrm{mM})$ & 1 & $0,2 \mathrm{mM}$ \\
Tampão $10 \mathrm{X}$ & 5 & $1 \mathrm{X}$ \\
$\mathrm{MgCl}_{2}(50 \mathrm{mM})$ & 1,5 & $1,5 \mathrm{mM}$ \\
Taq DNA polimerase $(5 \mathrm{U} / \mu \mathrm{l})$ & 0,5 & $2,5 \mathrm{U}$ \\
DNA viral (LoobMNPV) & 1 & $1 \mathrm{ng}$ \\
$(50 \mathrm{ng} / \mu \mathrm{l})$ & 39 & - \\
Água ultrapura (Milli-Q) & & \\
\hline
\end{tabular}

Tabela 7. Programa utilizado na amplificação das hrs de LoobMNPV.

\begin{tabular}{|c|c|c|c|c|c|c|c|c|c|}
\hline Etapa & \multicolumn{7}{|c|}{ Temperatura $\left({ }^{\circ} \mathbf{C}\right)$} & Tempo & Ciclos \\
\hline Desnaturação inicial & \multicolumn{7}{|c|}{94} & 2:00 minuto & - \\
\hline Desnaturação & & & & 94 & & & & $0: 45$ segundos & 35 \\
\hline \multirow[t]{2}{*}{ Anelamento } & hr1 & $\mathrm{hr} 2$ & hr3 & $\mathrm{hr} 4$ & hr5 & hr6 & hr7 & \multirow{2}{*}{ 0:30 segundos } & \multirow[t]{2}{*}{35} \\
\hline & 68 & 65 & 60 & 65 & 63 & 63 & 68 & & \\
\hline Extensão & & & & 72 & & & & 1:00 minuto & 35 \\
\hline Extensão final & & & & 72 & & & & $10: 00$ & - \\
\hline Resfriamento & & & & 12 & & & & $\infty$ & - \\
\hline
\end{tabular}




\subsection{Análise filogenética}

\subsubsection{Análise filogenética de LoobMNPV em relação à família Baculoviridae}

Para analisar a posição filogenética de LoobMNPV em relação à família Baculoviridae um alinhamento realizado por MAFFT (Katoh et al. 2002) foi realizado, utilizando sequencias de aminoácido concatenadas contendo os 37 genes conservados (core genes) (tabela 1) encontrados em todos os 72 genomas de baculovirus (um isolado de cada espécie de baculovírus) atualmente disponíveis no banco de dados do GenBank (anexo 1).

Através do programa jMmodelTest (Posada 2003), foi realizada a predição do modelo de evolução da árvore. Desse modo, com base nos resultado apresentados por esse programa, a árvore referente à família Baculoviridae foi construída pelo método estatístico de Máxima Verossimilhança (ML- do inglês Maximum Likelihood) (Chor \& Tuller 2005) realizado por intermédio do programa de probabilidade filogenética PhyML 2.2.0 (Guindon 2003) na plataforma do pacote Geneious 7.1.6 (Biomatters). O suporte dos ramos foi calculado método de bootstrap (100 repetições de bootstrap não-paramétrico)(Felsenstein 1985). A mesma árvore também foi realizada pelos programas e RAxML (Stamatakis 2006) e FastTree (Price et al. 2009), que usa o método SH-like (Shimodaira \& Hasegawa 1999) para calcular o suporte do ramo. O modelo de evolução de DNA utilizada foi o GTR (do inglês Generalised time-reversible) (Tavaré 1986), utilizando o parâmetro de distribuição gama (Stacy, 1962) para calcular as taxas de variação entre os nucleotídeos. A edição de cada árvore filogenética construída foi realizada utilizando o software FigTree v1.4.0 (Rambaut).

\subsubsection{Análise filogenética de ORF de LoobMNPV}

Uma ORF de LoobMNPV (LoobNPVOrf-35) e os genes Global Transactivator GTA e Transcription terminator factor 2- TTF2 foram alinhados por MAFFT (Katoh et al. 2002), utilizando sequências de aminoácidos concatenadas a partir de um conjunto de dados constituído pelos genes GTA encontrados em Alphabaculovirus, bem como pelos genes TTF2 de maior similaridade à LoobNPVOrf-35, conforme anexo 2. O método utilizado também foi ML através do algoritmo PhyML 2.2.0 (Guindon 2003), com modelo de substituição de aminoácidos JTT (Jones et al. 1992) e 100 repetições de bootstrap não 
paramétrico (Felsenstein 1985) através da plataforma Geneious 7.1.6 (Biomatters). A edição da árvore filogenética construída também foi realizada utilizando o software FigTree v1.4.0 (Rambaut).

Com o intuito de demonstrar evidência estatística em relação a melhor hipótese da posição de LoobNPVOrf-35 na árvore GTA/TTF2, se agrupado à GTA ou à TTF2, o programa Bayes factor estimator (Baele et al. 2013), do programa MrBayes (Ronquist et al. 2012) foi utilizado, comparando a probabilidade marginal das duas hipóteses distintas, utilizando estatística Bayesiana, que requer conhecimento do espaço paramétrico representado pela sua distribuição a posteriori dos dados.

\subsection{Comparação de LoobMNPV a outros baculovírus}

O genoma de LoobMNPV foi analisado utilizando o programa CGView Comparison Tool (Grant \& Stothard 2008), com o objetivo de comparar o conteúdo gênico de LoobMNPV com os seguintes baculovírus mais relacionados a ele: Autographa californica multiple nucleopolyhedrovirus (AcMNPV) (Ayres et al. 1994) (NCBI n: L22858), Atheraea pernyi nucleopolyhedrovirus (AnpeNPV) (Nie et al. 2007) (NCBI $\mathrm{n}^{\circ}$ : DQ486030), Dendrolimus kikuchii nucleopolyhedrovirus (DekiNPV) (NCBI n: JX193905), Maruca vitrata multiple nucleopolyhedrovirus (MaviMNPV) (Yun-Ru Chen et al. 2008) (NCBI n: EF125867), e Thysanoplusia orichalcea multiple nucleopolyhedrovirus (ThorMNPV)(Cheng \& Carner 2000) (NCBI nº: JX467702).

Os dados gerados foram analisados no programa Circos (Krzywinski et al. 2009), permitindo a plotagem de um gráfico comparativo de acordo com o grau de identidade de LoobMNPV em relação aos outros baculovírus supracitados, bem como suas posições e conteúdo dos nucleotídeos $\mathrm{C}+\mathrm{G}$. Ainda, com esses dados, foi efetuado também um gráfico comparativo em forma de fitas, permitindo comparação da sintenia dos genomas acima relacionados em relação à LoobMNPV, possibilitando a visualização de inversões, rearranjos genômicos e inserções gênicas. 


\subsection{Análise da estrutura secundária de alinhamento}

Um alinhamento com a sequência de aminoácidos de uma ORF de LoobMNPV (Orf35) foi realizado por meio da plataforma T-coffee (Notredame et al. 2000). Esse alinhamento foi posteriormente submetido à uma outra plataforma denominada ESPript 3 (Robert \& Gouet 2014), que prevê estruturas secundárias de sequências de aminoácidos. Portanto, com esse intuito de se analisar as conformações estruturais secundárias presentes nos domínios dessas sequências alinhadas, utilizou-se como base os dois cristais previamente descritos na literatura mais similares a sequência dessa ORF (PDB ID: 3mwy (Hauk et al. 2010) e PDB ID: 1 z63 (Durr et al. 2005)), que foram extraídos do Protein Data Bank. Esses cristais foram alinhados com os genes de GTA de AnpeMNPV e EppoMPV, bem como com os genes de TTF2 de Danaus plexippus, Bombyx mori, Chelonia mydas e Pterotopus alecto e a sequência de LoobNPVOrf-35

\section{RESULTADOS E DISCUSSÃO}

\subsection{Análise da sequência genômica de LoobMNPV}

O genoma de LoobMNPV (GenBank n KP763670) possui 120.023 pb (figura 11), conforme a anotação realizada com 10,003 reads, que resultou em uma cobertura média do genoma de 20.5 vezes, com desvio padrão de 7.8. O tamanho do genoma foi superior ao previamente analisado por Wolff et al. (2002), de 95,000 pb, que obteve essa estimativa de tamanho a partir de análises por enzimas de restrição. Esse mesmo perfil de restrição foi realizado in silico com os dados obtidos a partir da montagem do genoma de LoobMNPV, que apresentou um perfil similar ao previamente descrito. De acordo com uma convenção pré-estabelecida (Ayres et al. 1994), o primeiro nucleotídeo do genoma é a Adenina do códon de iniciação ATG do gene da poliedrina (polh). Desse modo, todas as 134 regiões de fase de leitura (ORFs) encontradas no genoma de LoobMNPV foram numeradas sucessivamente de acordo com a direção desse gene. Foi observado, portanto, que 72 dessas ORFs possuem a mesma orientação que o gene polh, enquanto as outras 62 ORFs encontram-se na orientação reversa. 
Todas as ORFs encontradas no genoma de LoobMNPV foram analisadas utilizando o programa Blast do banco de dados do NCBI (Altschul et al. 1997), e apenas sequencias com um valor de E-value abaixo de $\left(\mathrm{E}<10^{-3}\right)$ foram consideradas. Esse valor foi dado como corte visto que sequencias que compartilham um alto grau de similaridade apresentam em geral uma ancestralidade compartilhada recente, com alinhamentos contendo diversos resíduos idênticos, poucas substituições e gaps e baixo valor de E-values (Kerfeld \& Scott 2011).

O genoma de LoobMNPV possui $35.7 \%$ de conteúdo $\mathrm{G}+\mathrm{C}$, que é representado pelo gráfico interno da figura 11. As ORFs LoobNPVOrf-2 (ORF 1629), LoobNPVOrf-10 (p74), LoobNPVOrf-20 (odv-e56), LoobNPVOrf-41 (pif-1), LoobNPVOrf-46 (p40), LoobNPVOrf52 (odv-e25), LoobNPVOrf-65 (gp41), LoobNPVOrf-72 (iap-2), LoobNPVOrf-101 (odve66), e LoobNPVOrf-114 (sod) e LoobNPVOrf-123 (pif-2) apresentaram altos picos de conteúdo $\mathrm{G}+\mathrm{C}$. 


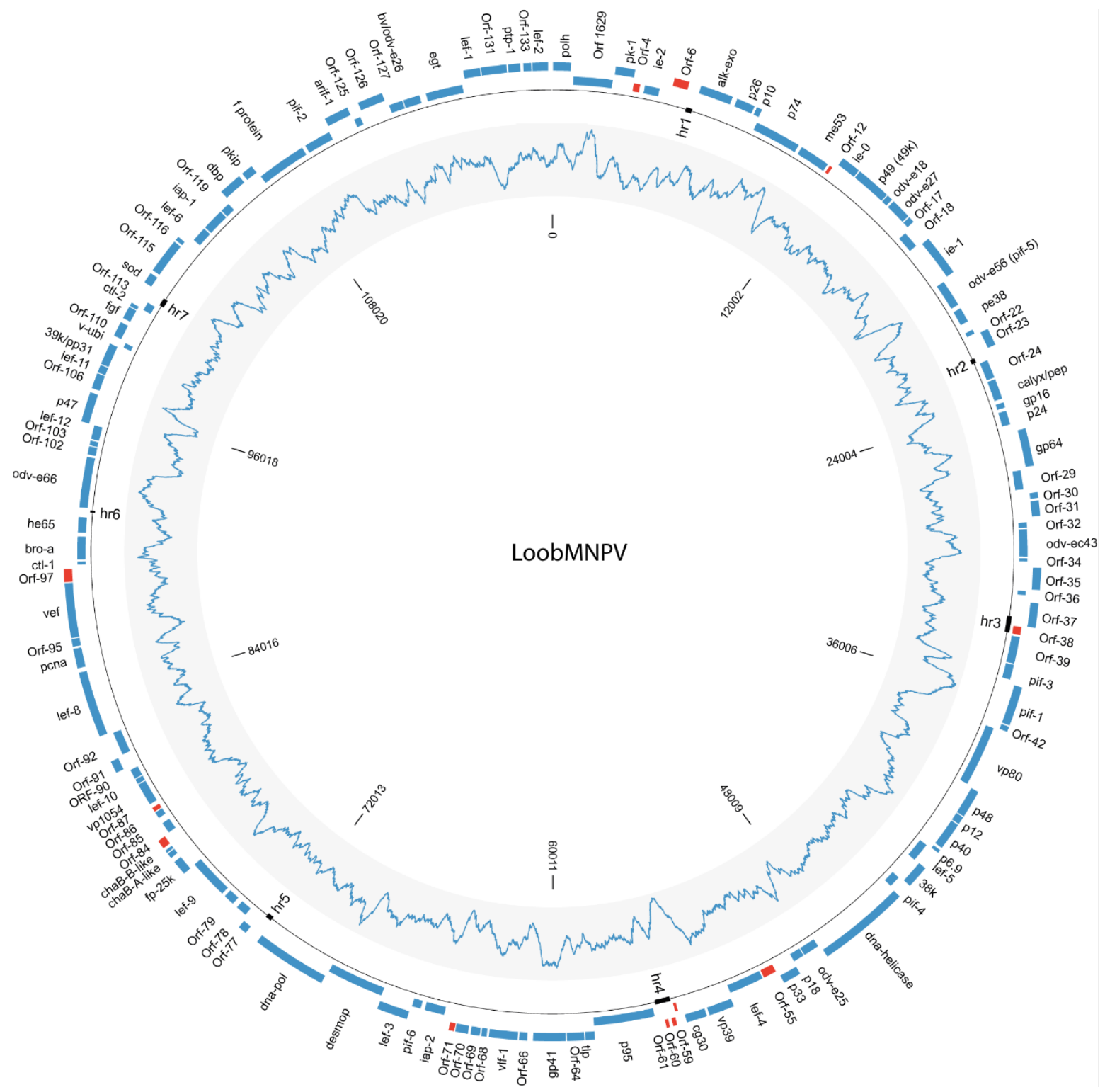

Figura 11. Mapa genômico de LoobMNPV. As 134 ORFs, e seus respectivos nomes, encontram-se representadas na porção externa do mapa, conforme sua localização e ordem no genoma. As ORFs únicas estão destacadas em vermelho, e as hrs estão destacadas em preto, no aro interno ao do mapa. O percentual de conteúdo $\mathrm{G}+\mathrm{C}$ de cada $\mathrm{ORF}$ de LoobMNPV é demonstrado no gráfico interno azul. $\mathrm{O}$ aro mais interno indica a posição no genoma em pares de bases.

Esse percentual de conteúdo $\mathrm{G}+\mathrm{C}$ está relacionado a propriedades como tamanho dos genomas e das ORFs, uma vez que um maior conteúdo $\mathrm{G}+\mathrm{C}$ implica em uma menor quantidade de códons de parada (Mitchell 2007; Oliver \& Marín 1996), bem como está relacionado a regiões que sofreram transferência horizontal de DNA, visto que, quando comparadas ao genoma do hospedeiro, possuem diferentes composições de conteúdo $\mathrm{G}+\mathrm{C}$ devido às diferentes pressões evolutivas a qual foi submetido (Aran \& Hanseok 2008). 


\subsubsection{Análise de região de baixa cobertura do genoma de LoobMNPV}

Com o intuito de confirmar uma região de baixa cobertura de reads (sequências de fragmentos oriundos do sequenciamento) na montagem do genoma de LoobMNPV (cobertura $<50$ reads), localizada em uma região do genoma que abrange o gene $\operatorname{cg} 30$ (LoobMNPVOrf-58) e LoobMNPVOrf-59 (figura 12a), os iniciadores "LoobMNPV baixa cobertura Primer F" e "LoobMNPV baixa cobertura Primer R" foram confeccionados (tabela 2), para amplificação por PCR e confirmação dessa região. Como resultado da reação realizada, obteve-se uma sequência de aproximadamente 750 pares de base, conforme demostrado no gel de agarose $0,8 \%$ representado pela figura $12 \mathrm{~b}$. O resultado foi de acordo com o esperado, segundo predição feita no programa Geneious 7.1.6. (Biomatters), confirmando que apesar de possuir baixa cobertura nessa região, a montagem ainda assim foi dada de forma correta.

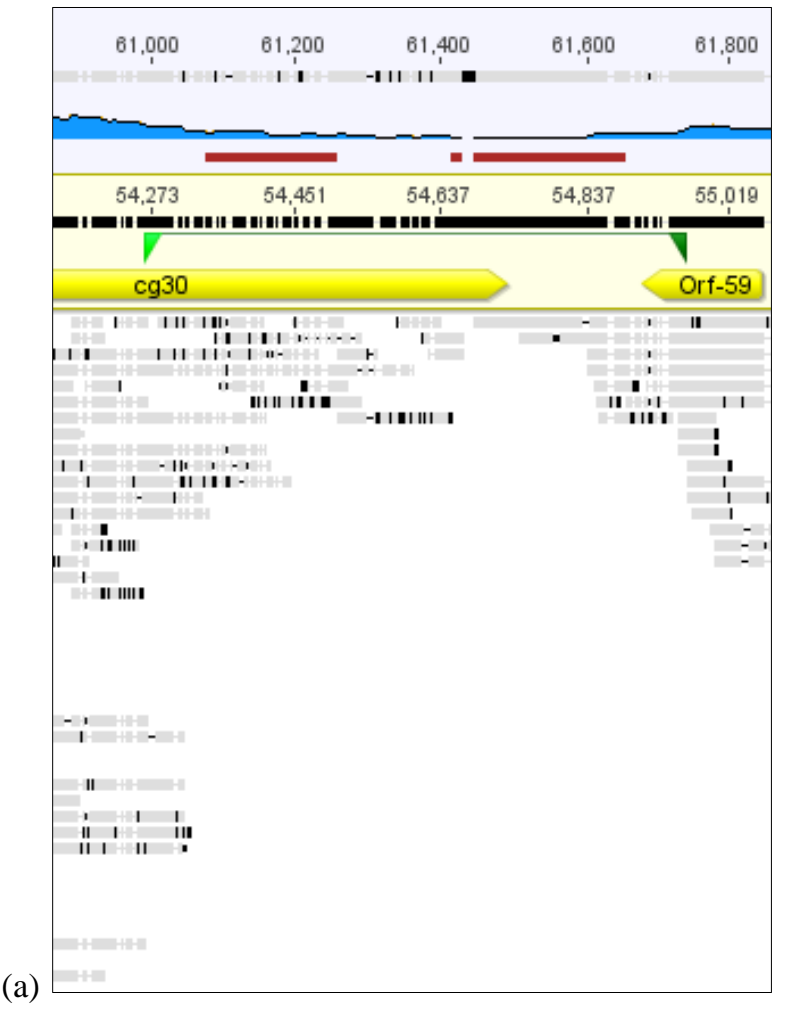

(b)

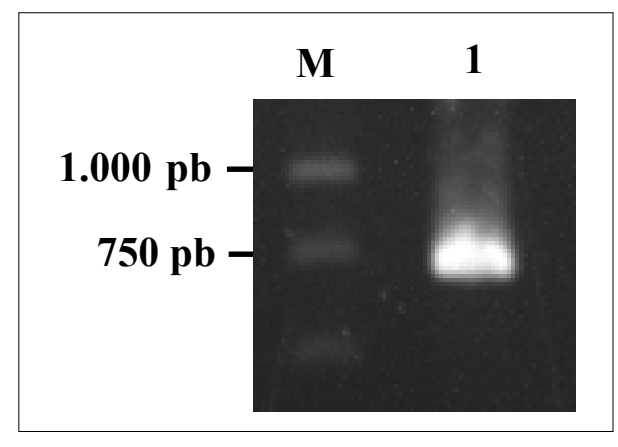

Figura 12. Região de baixa cobertura na montagem do genoma de LoobMNPV. (a) Localização da região de baixa cobertura no contexto genômico, entre o gene cg30 (LoobMNPVOrf-58) e LoobMNPVOrf-59 (em amarelo). A baixa cobertura é indicada pelo baixo número de reads (retângulos pretos e cinzas), conforme ilustra o gráfico em azul, destacando as regiões de menor cobertura em vermelho. Os iniciadores confeccionados para amplificar essa região estão em verde, indicando toda região de amplificação. (b) Gel de agarose $0,8 \%$ apresentando amplificação de região de baixa cobertura do genoma de LoobMNPV (1) de 743 pb. M representa o marcador da marca Promega $1 \mathrm{~kb}$ Ladder. 


\subsection{Análise das regiões homólogas (hrs)}

Sete regiões homólogas ( $h r s$ ) foram encontradas no genoma de LoobMNPV. Essas regiões repetitivas de DNA palindrômico estão em geral espalhadas pelos genomas de diversos baculovírus, com número variável, podendo ter de três hrs (em CrleGV) (Lange \& Jehle 2003) a até dezessete hrs (em SpltNPV) (Pang et al. 2001). As hrs estão envolvidas em funções como origens de replicação (oris) (Pearson \& Rohrmann 1995), ativadores (enhancers) de transcrição (Kuzio et al. 1999; Pang et al. 2001), bem como sítios de recombinação homóloga (Hayakawa et al. 1999). As sete hrs encontradas no genoma de LoobMNPV possuem os seguintes tamanhos conforme tabela 8. Essas regiões estão localizadas no genoma conforme representa a figura 11 .

Baseado na montagem do genoma, cada $h r$ teve seus respectivos tamanhos confirmados por meio de amplificação por PCR conforme gel de agarose 0,8\% (figura 14), que apresenta as bandas de cada $h r$ com seus respetivos tamanhos esperados, conforme tabela 8 a seguir. Cada oligonucleotídeo iniciador foi desenhado de modo a anelar-se a aproximadamente 100 pares de base a montante e a jusante de cada terminação das hrs.

Tabela 8. Tamanho das hrs de LoobMNPV e seus respectivos fragmentos de amplificação.

\begin{tabular}{ccc}
\hline $\boldsymbol{H} \boldsymbol{r}$ & Tamanho da $\boldsymbol{h r}$ & Tamanho do amplicon \\
\hline 1 & $684 \mathrm{pb}$ & $884 \mathrm{pb}$ \\
2 & $541 \mathrm{pb}$ & $749 \mathrm{pb}$ \\
3 & $1037 \mathrm{pb}$ & $1237 \mathrm{pb}$ \\
4 & $713 \mathrm{pb}$ & $975 \mathrm{pb}$ \\
5 & $679 \mathrm{pb}$ & $879 \mathrm{pb}$ \\
6 & $361 \mathrm{pb}$ & $561 \mathrm{pb}$ \\
7 & $836 \mathrm{pb}$ & $1036 \mathrm{pb}$ \\
\hline
\end{tabular}



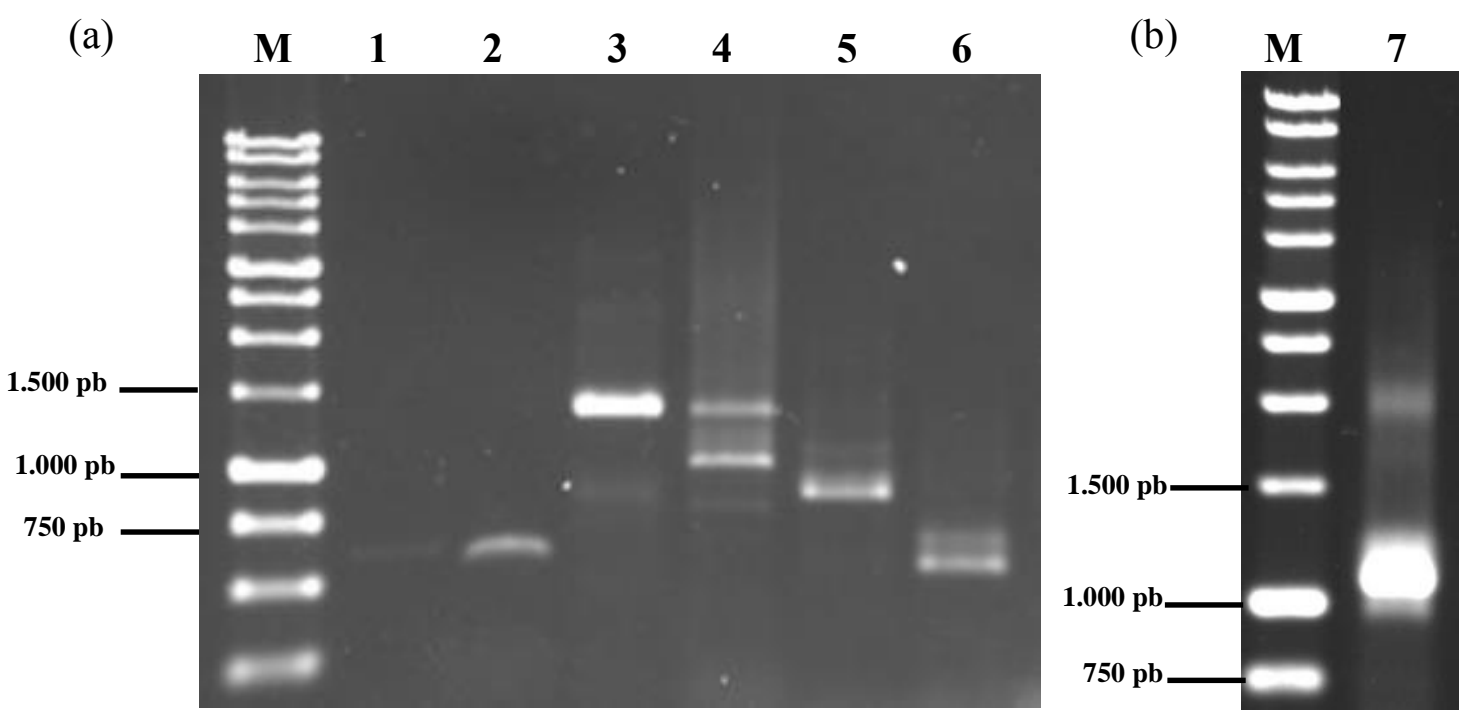

Figura 13. Géis de agarose $0,8 \%$ contendo amplificação por PCR das 7 regiões homólogas encontradas em LoobMNPV, com fragmentos de tamanhos esperados, conforme tabela 8. (a) 1- fragmento esperado da $h r l$ de $884 \mathrm{pb}, 2$ - fragmento da $h r 2$ com $749 \mathrm{pb}, 3$-fragmento da $h r 3$ com $1237 \mathrm{pb}$, 4- fragmento da $h r 4$ com $975 \mathrm{pb}$, 5- fragmento da $h r 5$ com $879 \mathrm{pb}, 6$ - fragmento da $h r 6$ com $561 \mathrm{pb}$ e (b) 7-fragmento da $h r 7$ com $1036 \mathrm{pb}$. M representa o marcador da marca Promega $1 \mathrm{~kb}$ Ladder.

A $h r l$, no entanto, amplificou uma banda de aproximadamente 750 pares de base, divergindo dos esperados $884 \mathrm{pb}$. Para confirmar a $h r 1$ quanto a essa divergência de tamanho, novos oligonucleotídeos serão desenhados, a fim de se amplificar uma região maior do genoma que abrange essa $h r$ (mais 100 pb a jusante e a montante), e posteriormente sequenciar a esperada amplificação, a fim de verificar a montagem nessa região. No entanto, sabe-se que hrs são compostas por regiões repetitivas, e uma dessas regiões pode ter sido anotada a mais, ou a menos. Ademais, deve ser levado em consideração que a amostra isolada possa ter diferentes populações virais, podendo levar também a essa divergência.

Todas as hrs apresentaram cópias de uma repetição de um palíndromo imperfeito em comum ( $h r 1 \mathrm{a}, h r 2 \mathrm{a}, h r 3 \mathrm{a}, h r 3 \mathrm{~b}, h r 4 \mathrm{a}, h r 5 \mathrm{a}, h r 5 \mathrm{~b}, h r 6 \mathrm{a}, h r 6 \mathrm{~b}$ e $h r 7 \mathrm{a})$. A figura 14 apresenta um alinhamento da região mais conservada, de 38 pb, dessa repetição em todas as hrs. O consensus desse alinhamento (figura 14b) é mostrado por um empilhamento de nucleotídeos, no qual quanto maior for o tamanho de fonte do nucleotídeo, maior será seu grau de conservação na sequência, coincidindo com a área sombreada em vermelho do alinhamento, que corresponde a identidade estrita de pares de base. 


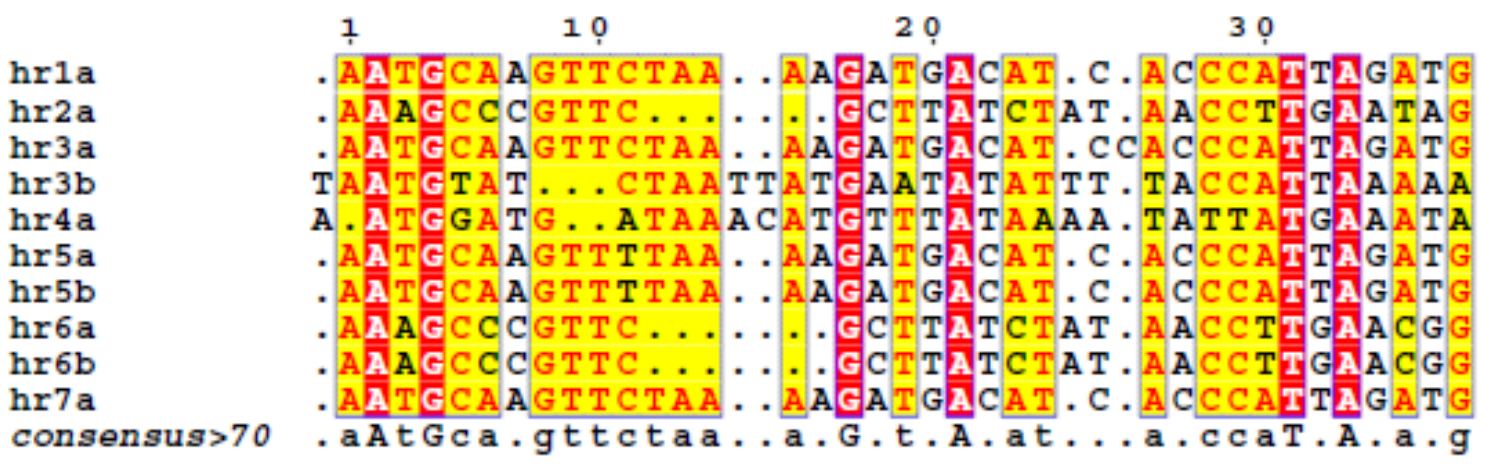

Figura 14. Região repetitiva comum das hrs de LoobMNPV. Alinhamento de DNA da unidade repetitiva de $38 \mathrm{pb}$ comum à todas as hrs LoobMNPV, numeradas sequencialmente, onde as letras indicam a unidade repetitiva dentro da mesma $h r$. Nucleotídeos que não apresentam identidade estrita estão representados nas áreas de sombreamento em vermelho. As áreas sombreadas em amarelo indicam conservação de nucleotídeos com a maioria do grupo alinhado (identidade não estrita). As letras em vermelho indicam nucleotídeos similares no mesmo grupo. A sequência consensus referente ao alinhamento está também representado na figura, com conservação de $>70 \%$.

Buscas no Blast (Altschul et al. 1997) foram realizadas para todas as hrs, no entanto, apenas as hrs 3, 5, 6 e 7 demonstraram correspondência com outras hrs de baculovírus (Orgya lecostigma NPV, Adoxophyes orana GV, Orgya pseudotsugata MNPV e Piearis rapae GV, respectivamente).

As hrs são também são ricas em conteúdo A+T (Guarino \& Summers 1986), que também pode ser observado no gráfico G+C da figura 11. Esse dado corrobora com o dado previamente citado, que as hrs estão envolvidas em funções como origens de replicação (oris) (Pearson \& Rohrmann 1995), uma vez que origens de replicação de diversas espécies possuem em comum uma alto conteúdo $\mathrm{A}+\mathrm{T}$, o que facilita o acesso da maquinaria de replicação ao DNA fita-simples, por essa interação ser mais fraca que as outras (Lodish 2000).

As hrs de Baculovírus podem interagir com outros genes, como é o caso da proteína IE-1, que regula a expressão precoce de genes baculovirais em transcrição, e liga-se a $h r 5$ de AcMNPV, promovendo ativação (enhancement) da transcrição. Esse dado sugere que as hrs possivelmente co-evoluem com as proteínas que a elas se associam (Guarino \& Summers 1986; Rodems \& Friesen 1995). 


\subsection{Análises do contexto filogenético de LoobMNPV na família Baculoviridae}

A filogenia de todos os 72 genomas de baculovírus sequenciados até a presente data (um isolado de cada espécie de baculovírus) (anexo 1) foi inferida conforme a árvore filogenética mostrada na figura 15. Os dados utilizados para fazer essa árvore foram baseados num conjunto de sequencias de aminoácidos concatenados referente aos 37 genes conservados (core genes) presente em todos esses baculovírus. Os core genes (tabela 1) geralmente assumem funções básicas relacionadas à funções biológicas essenciais (Miele et al. 2011), pois podem ser componentes estruturais pertencentes ao processo de infecção, bem como podem participar no processo de transcrição ou replicação viral (Yun-Ru Chen et al. 2008).

Devido ao tamanho desse conjunto de dados gerados, a referida árvore filogenética apresenta uma alta resolução, uma vez que possui um bom suporte de ramo referente a localização no contexto dessa árvore. Além disso, a árvore foi inferida por três algoritmos distintos, o que respalda sua configuração e congruência no resultado. Ressalta-se que a raiz da árvore foi dada no genoma de CuniNPV, o mais basal dos genomas de baculovírus (Afonso et al. 2001). 


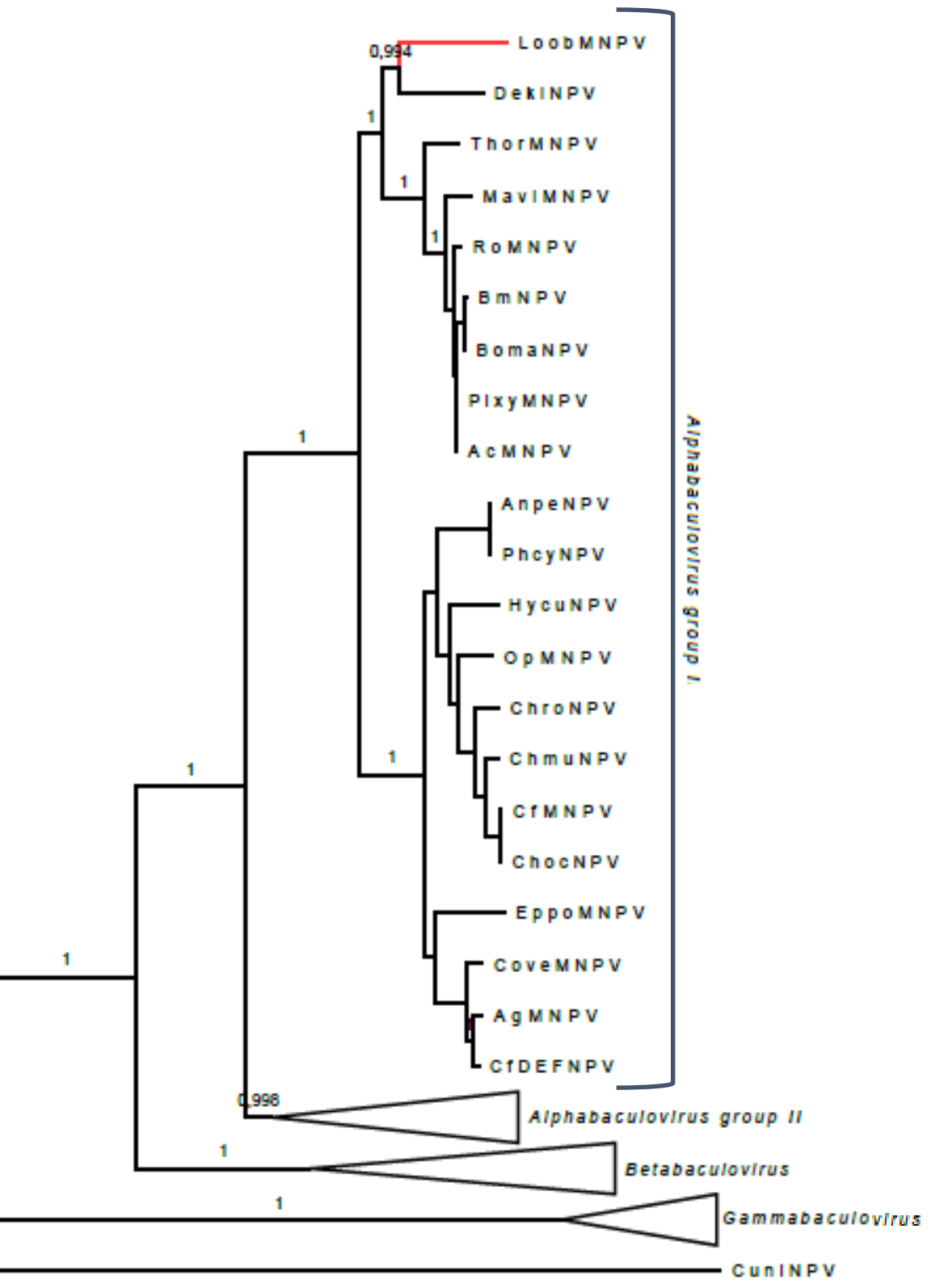

0.8

Figura 15. Filogenia da família Baculoviridae baseada nas 37 proteínas ortólogas (core genes) encontradas em todos os 72 genomas de espécies únicas de baculovirus. O número nos ramos representa o valor de suporte do ramo. O baculovirus CuniNPV (Deltabaculovirus) é o grupo externo. Os gêneros Alphabaculovirus grupo II, Beta e Gammabaculovirus estão colapsados. LoobMNPV (vermelho) é pertencente à Alphabaculovirus grupo I, agrupado junto a DekiNPV e localizado como um clado irmão ao grupo dos vírus similares à AcMNPV.

Conforme referenciado em estudos anteriores (Herniou \& Jehle 2007), a árvore da família Baculoviridae gerada nesse estudo possui quarto grandes gêneros: Alphabaculovirus (dividido em grupo I e II), Betabaculovirus, Deltabaculovirus e Gammabaculovirus.

Herniou e Jehle (2007) descreveram ainda que o gênero Alphabaculovirus (NPV) 
grupo I pode ser dividido em dois clados monofiléticos : clado IA, que conforme análises realizadas, inclui os baculovirus similares a AcMNPV (AcMNPV, RaouMNPV, BmNPV, ThorNPV, BomaNPV e PlxyMNPV), que em geral infectam insetos membros das famílias Noctuidae, Bombycidae e Plutellidae; e o clado IB, que engloba hospedeiros lepidópteros das famílias Noctuidae, Saturniidae, Arctiidae, Lymantriidae e Tortricidae, sendo representado pelos baculovírus AgMNPV, AnpeNPV, PhcyMNPV, HycuNPV, OpMNPV, ChroNPV, ChmuNPV, CfDEFMnPV, ChorcMNPV, CoveMNPV e EppoNPV. Por conseguinte, dado que cada vez mais genomas de baculovirus vem sendo sequenciados e a quantidade de dados informativos está consequentemente aumentando, as relações evolutivas entre baculovirus tendem a ficar cada vez mais claras e respaldadas, permitindo que se faça inferências mais precisas e interpretações mais efetivas acerca da biologia, ecologia e do contexto evolutivo de baculovirus.

A configuração dessa árvore se assemelha àquela descrita pelo primeiro trabalho sobre LoobMNPV (Wolff et al., 2002), onde LoobMNPV também encontrava-se pertencente ao grupo I de Alphabaculovirus, porém, o agrupamento dos vírus pertencentes a esse grupo é divergente, e LoobMNPV agrupou-se com AmalNPV, um vírus que ainda não possui seu genoma completo disponível.

\subsection{Comparações de LoobMNPV a outros Alphabaculovírus}

Com o propósito de analisar a composição gênica, localização e a identidade das ORFs de LoobMNPV em relação aos Alphabaculovírus do grupo I, a tabela encontrada no anexo 3 foi construída, comparando todas as 134 ORFs de LoobMNPV aos genes ortólogos encontrados nos baculovirus mais filogeneticamente relacionados à LoobMNPV: Autographa californica nucleopoliedrovirus (AcMNPV), Antheraea Pernyi nucleopoliedrovirus (AnpeNPV), Maruca vitrata nucleopoliedrovirus (MaviNPV), Dendrolimus kikuchii nucleopoliedrovirus (DekiNPV) e Thysanoplusia orichalcea nucleopoliedrovirus (ThorNPV).

Das ORFs de LoobMNPV, 12 não apresentaram nenhuma similaridade à nenhuma ORF de baculovírus e foram consideradas únicas (LoobNPVOrf-4, LoobNPVOrf-6, LoobNPVOrf-12, LoobNPVOrf-35, LoobNPVOrf-38, LoobNPVOrf-55, LoobNPV Orf-59, 
LoobNPVOrf-60, LoobNPVOrf-61, LoobNPVOrf-71, LoobNPVOrf-84, e LoobNPVOrf97). No entanto, a maior parte, ou seja, 122 ORFs, apresentaram maior identidade a outras previamente descritas em outros baculovírus, e dentre essas, apenas três genes (LoobMNPVOrf-78, LoobMNPVOrf-102 (he65) e LoobMNPVOrf113) apresentaram maior identidade com ortólogos dos granulovírus Pieris rapae granulovirus (PrGV), Agrotis segetum granulovirus (AgseGV) e Xestia c-nigrum granulovirus (XcGV), respectivamente.

Cabe ressaltar que na tabela do anexo 3, essas ORFs supracitadas não apresentam similaridade a nenhum dos genomas comparados, mas no entanto não são ORFs únicas, uma vez que apresentarem maior similaridade aos referidos granulovírus.

Igualmente, um mapa comparativo (figura 16) de LoobMNPV com os mesmos genomas da tabela do anexo 3 foi elaborado, com o intuito de ilustrar graficamente a localização e o grau de similaridade (dado em termos de percentual de identidade, considerando E-values $<10^{-3}$ ) das ORFs de LoobMNPV em relação aos referidos genomas de comparação.

Nesse mapa comparativo, é possível perceber quais ORFs são mais conservadas entre os genomas, ou seja, com alto grau de similaridade, como é o caso dos genes polh (LoobMNPVOrf-1), $\quad$ p74 (LoobMNPVOrf-10), $\quad$ p49 (LoobMNPVOrf-14), pif-1 (LoobMNPVOrf-41), $\quad$ lf-1 (LoobMNPVOrf-67), lef-9 (LoobMNPVOrf-80), lef-8 (LoobMNPVOrf-93), gp64 (LoobMNPVOrf-28), $\quad$ p33 (LoobMNPVOrf-54), $\quad$ p47 (LoobMNPVOrf-105) e pif-2 (LoobMNPVOrf-123). Por outro lado, é possível notar também ORFs mais variáveis, com menor similaridade, como os genes ORF 1629 (LoobMNPVOrf2), ie-2 (LoobMNPVOrf-5), ie-1 (LoobMNPVOrf-19), vp80 (LoobMNPVOrf-43), desmop (LoobMNPVOrf-75), f_protein (LoobMNPVOrf-122), arif-1 (LoobMNPVOrf-124), lef-6 (LoobMNPVOrf-117) e bv/odv-e26 (LoobMNPVOrf-128). Nota-se também as ORFs que não apresentam nenhum grau de similaridade com nenhuma das ORFs comparadas, sendo essas consideradas exclusivas de LoobMNPV, e novas dentre os baculovírus, conforme previamente citadas.

Do mesmo modo que é possível se observar na tabela anexa 3, nessa figura também observa-se que LoobMNPVOrf-78, LoobMNPVOrf-113 e p6.9 (LoobMNPVOrf-47) não 
apresentam similaridade aos genomas comparados, mas no entanto não são ORFs únicas, uma vez que elas são similares a outros baculovírus.

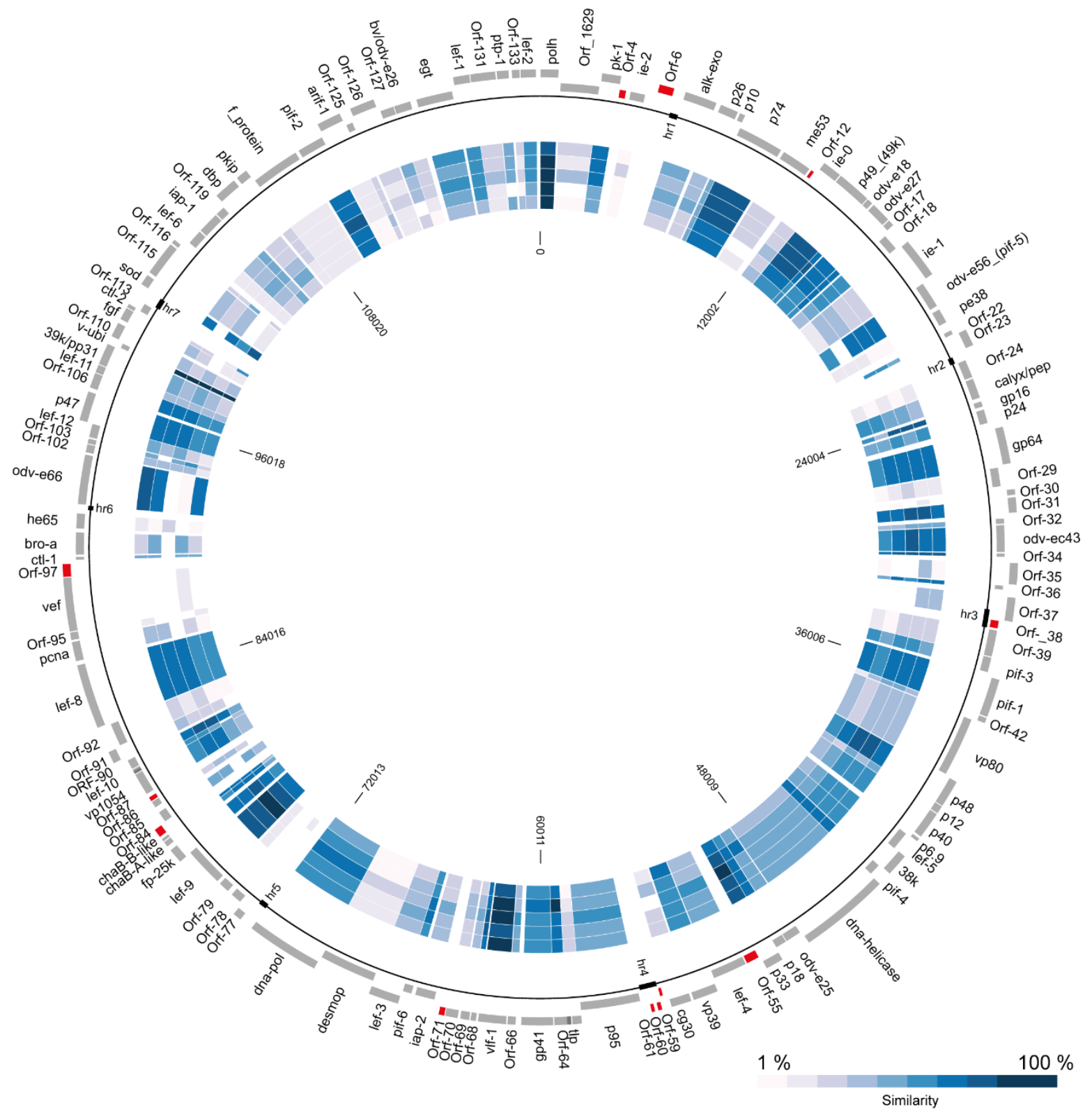

Figura 16. Mapa comparativo do genoma de LoobMNPV (o mais externo em cinza) em relação aos genomas AcMNPV, ThorMNPV, MaviMNPV, DekiNPV e AnpeNPV (respectivamente nessa ordem de dentro para fora). Conforme a legenda no canto inferior, quanto mais escuro o tom de azul, maior é a similaridade, baseada na identidade correspondente a ORF de LoobMNPV. As ORFs únicas de LoobMNPV estão representadas em vermelho no genoma de LoobMNPV, e as hrs em preto, no aro abaixo ao genoma de LoobMNPV. As posições dos nucleotídeos do genoma de LoobMNPV estão destacados na parte mais interna do círculo, em pares de bases. 
Não obstante, foi realizada uma comparação capaz de se analisar a sintenia, bem como inversões e rearranjos genômicos no genoma de LoobMNPV quando comparado aos baculovírus AnpeNPV, MaviMNPV, ThorMNPV, AcMNPV e DekiNPV. A figura 17a ilustra um diagrama circular que apresenta essa relação, onde os referidos genomas de comparação se sobrepõem a LoobMNPV, de maneira que as linhas que saem de cada vírus (denominadas, do inglês ribbons) representam a posição, o tamanho e a orientação das ORFs nos elementos genômicos em relação à LoobMNPV. 


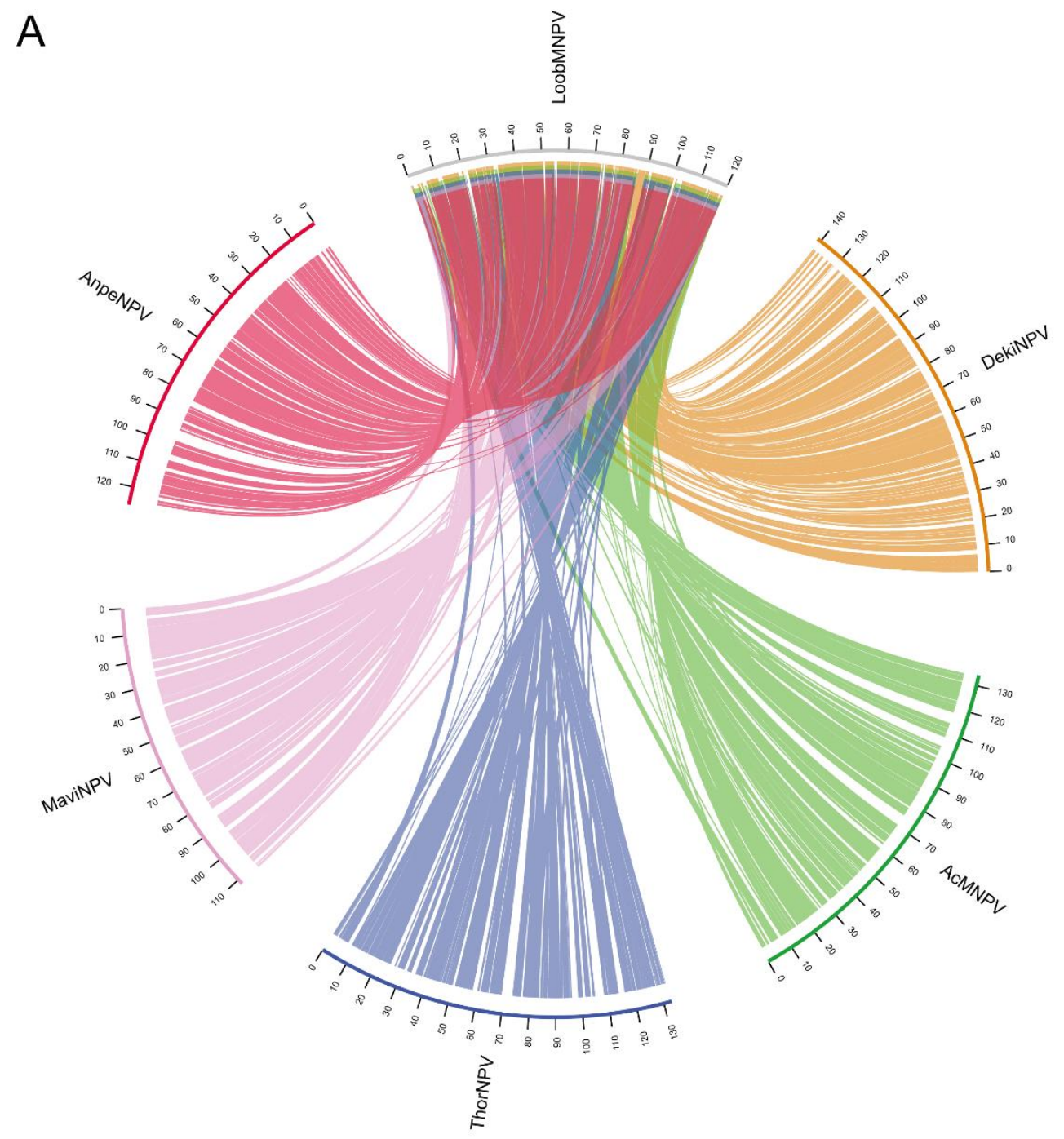

B

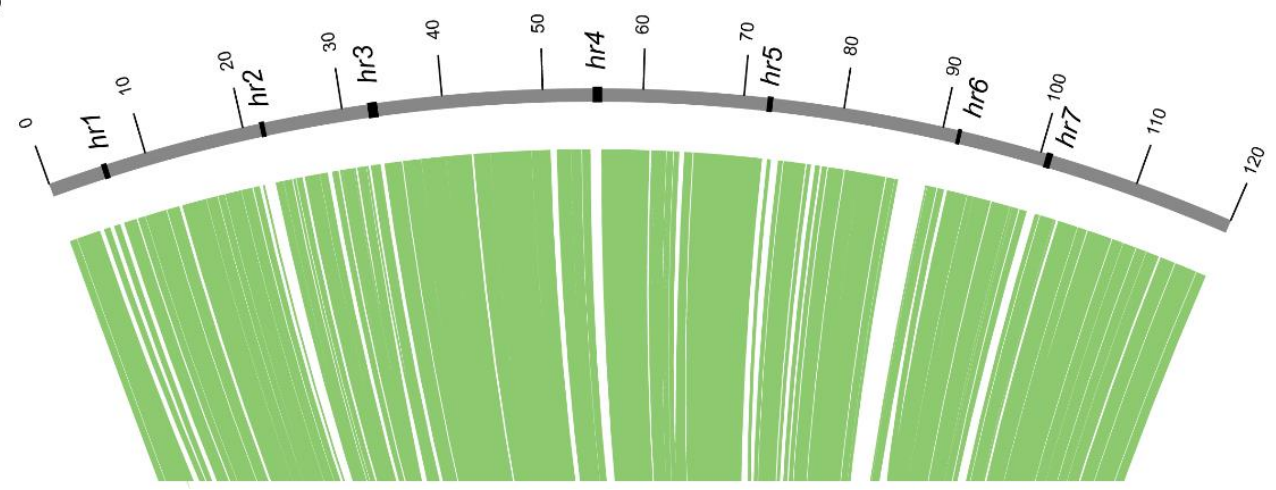

Figura 17. (a) Sintenia genômica de LoobMNPV em relação aos baculovirus AnpeNPV, MaviNPV, ThorMNPV, AcMNPV e DekiNPV), mostrando inversões e rearranjos gênomicos de LoobMNPV em relação aos outros genomas (exceto DekiNPV) na porção central dos genomas, mantendo-se o bloco inicial constante. (b) Ampliação da região em que todos os genomas se sobrepõem, mostrando a localização das 7 hrs de LoobMNPV, que encontram-se próximas as ORFs únicas de LoobMNPV, indicando que $h r s$ são possíveis sítios de inserção gênica. 
Na figura 17a, é interessante observar que, apesar da grande colinearidade entre os genomas, LoobMNPV e DekiNPV possuem inversões genômicas em relação a AnpeNPV, MaviMNPV, ThorMNPV e AcMNPV. Essas inversões são caracterizadas pela manutenção constante das porções inicial dos genomas de LoobMNPV e DekiNPV, enquanto um bloco central apresenta uma grande inversão. Essa configuração corrobora com a filogenia previamente observada na figura 15, uma vez que LoobMNPV e DekiNPV possuem alto grau de sintenia e pertencem ao mesmo clado, sendo desse os únicos genomas. Portanto, é plausível supor que LoobMNPV e a DekiNPV possuem o mesmo ancestral comum e que essa inversão tenha ocorrido em alguma linhagem comum ao ancestral. Assim, essa inversão de DekiNPV e LoobMNPV pode ser considerada uma autapomorfia em relação ao grupo similar a AcMNPV (clado I), uma vez que é uma característica derivada (nova) que está presente exclusivamente nesse único clado terminal.

Estudos prévios relataram que tais rearranjos como esse refletem a história evolutiva em baculovírus, onde vírus com maior grau de ancestralidade possuem consequentemente um maior grau de colinearidade (Hu et al. 1998).

A fim de se observar a região de sobreposição de todos os genomas da figura 17a, uma ampliação desse local foi realizada (figura 17b). Os espaços brancos nessa região representam as ORFs de LoobMNPV que não possuem nenhuma correspondência com os genomas de comparação, ou seja, são exclusivas de LoobMNPV (ORFs únicas).

É interessante notar na figura $17 \mathrm{~b}$ que essas ORFs únicas estão adjacentes ou estão sobrepostas a regiões de $h r$, e conforme relatado em estudos anteriores (Thumbi et al. 2013), rearranjos e aquisições gênicas são de comum ocorrência nas proximidades de hrs em alguns baculovírus. Isso possibilita a transferência e aquisição de novos genes entre vírus por meio de recombinação homóloga (Eveleigh et al. 2007; De Jong et al. 2005), que também é facilitada por fatores como múltiplas infecções no mesmo hospedeiro por diferentes patógenos (Eveleigh et al. 2007), bem como a infecções concomitantes em populações de campo (Kemp 2011). 


\section{5 . Análise das ORFs únicas encontradas em LoobMNPV}

Das ORFs encontradas no genoma de LoobMNPV, 11 foram consideradas únicas, uma vez que, quando realizada as comparações por Blastp (Altschul et al. 1997), não apresentaram similaridade significativa a outras sequências, dentro dos parâmetros estabelecidos citados previamente $\left(\right.$ E-value $\left.<10^{-3}\right)$. Conforme já mencionadas, essas ORFs são: LoobNPVOrf-4, LoobNPVOrf-6, LoobNPVOrf-12, LoobNPVOrf-35, LoobNPVOrf38, LoobMNPVOrf-55, LoobMNPVOrf-59, LoobNPVOrf-61, LoobNPVOrf-71, LoobNPVOrf-84 e LoobMNPVOrf-97.

Essas ORFs podem ter sido adquiridas por três mecanismos distintos de aquisição de genes: grande divergência de sequência, que poderia empurrar genes homólogos para limiares de similaridade inferiores aos comparados; recombinação entre os genes, que produz novas proteínas; e transferência horizontal de genes (do inglês horizontal gene transfer $H G T)$, que é detectada por similaridade de genes a partir de espécies filogeneticamente distintas (Mclysaght, Baldi e Gaut 2003).

Motivos de promotores conhecidos foram também procurados para cada uma dessas ORFs únicas, a partir de 200 pb a montante do códon de iniciação de cada ORF. Promotores precoces, incluindo as sequencias TATA box canônicas (Kogan et al. 1995), seguidas da sequência iniciadora CAGT localizada de 20-40 nucleotídeos a jusante (Blissard et al. 1992; Pullen e Friesen 1995) foram encontradas em LoobNPVOrf-4, 12, 35, 71 e 97. LoobNPVOrf60 possui apenas a sequência iniciadora CAGT. O promotor tardio TAAG, que é necessário para transcrição tardia pela RNA polimerase viral (Garrity et al. 1997), e foi encontrado em LoobNPVOrf-4, 12, 30, 38, 55, e 71. No entanto, mais experimentos são necessários para determinar se essas ORFs são expressas em diferentes fases de expressão viral e se codificam proteínas genuínas.

Além disso, buscas por motivos proteicos conservados foram realizadas, e LoobNPVOrf-4, 6, 12, 38, 55, 61 e 71 não apresentaram similaridade a nenhum domínio previamente predito. 


\subsubsection{ORFs únicas que contêm peptídeos sinal e região transmembrana}

LoobNPVOrf-59 codifica uma proteína que provavelmente é secretada pois contem peptídeo sinal. Em geral, proteínas virais que possuem esses domínios são sintetizadas no retículo endoplasmático (ER), sofrendo diversas modificações pós-traducionais. Essas proteínas estão envolvidas em ligação a receptores do hospedeiro, mediação de fusão de membrana e penetração na célula, direcionamento da morfogênese viral até o sítio de brotamento (no caso de vírus envelopados como os baculovirus), atuação como antígenos que neutralizam anticorpos, e até mesmo com atividade de transporte, agindo como canal iônico (Doms et al. 1993).

LoobNPVOrf-84 apresenta regiões transmembrana, e pode estar envolvida na interação do vírus com a superfície da membrana plasmática do hospedeiro, mediando o acoplamento do vírus ao receptor do hospedeiro, ou até mesmo permitindo uma fusão celular pH-dependente mediada por glicoproteínas de fusão celular e endocitose (Romanowski \& Matsuura, 1985)

\subsubsection{ORF única relacionada ao sistema imune}

LoobNPVOrf-60 possui um domínio que corresponde a um similar de imunoglobulina (do inglês Ig-like ou Immunoglobulin-like molecules). Outras proteínas de inseto com esse domínio já foram relatadas na literatura, como a hemolina, um componente da hemolinfa que participa de processos como ligação à superfície de bactérias e formação de complexos proteicos que iniciam respostas imunes do hospedeiro (Zingemagel et al. 1990). A hemolina também foi encontrada em transcritos obtidos a partir das cerdas de $L$. obliqua (Carrijo-Carvalho \& Chudzinski-Tavassi 2007).

Diversos imuno-moduladores codificados por vírus já foram descritos (Spriggs 1996), e podem estar envolvidos na regulação do sistema imune, protegendo células

infectadas pelo vírus contra o ataque de outras células do sistema imune (Barnes e Grundy 1992; Beersma et al. 1993).

Para vírus, a expressão de proteínas relacionadas ao sistema imune pode indicar uma susceptibilidade direcionada em infecções por múltiplos patógenos, como uma maneira de 
proteger o hospedeiro contra patógenos oportunistas, reduzindo a competição e consequentemente beneficiando a propagação viral (Ardisson-Araujo et al. 2015).

\subsubsection{ORF única relacionada a fator de terminação de transcrição}

LoobNPVOrf-35 apresentou uma interessante e alta similaridade com um fator de transcrição de eucarioto (do inglês transcription terminator factor 2 - TTF2) da lepidóptera Danaus plexippus (GenBank: EHJ68439.1), revelando 44\% de identidade e um E-value de

$3 \mathrm{e} 10^{-11}$. No entanto, após filtrar esse resultado focando apenas na família Baculoviridae, o referido gene apresentou alta similaridade ao gene trans-ativador global (do inglês Global Transactivator-GTA) do baculovírus AnpeNPV, com de 66\% identidade e um E-value de $1 \mathrm{e} 10^{-6}$.

Primeiramente, é interessante que se compreenda o significado dos valores gerados pelo Blastp, conforme o próprio NCBI (Geer et al. 2010). O E-value, (do inglês Expectation value) representa o valor estatístico baseado na probabilidade calculada a partir da qualidade do alinhamento (score) e o tamanho do banco de dados. Vale lembrar que score é a nota atribuída pelo algoritmo do alinhamento, com base nas nos pareamentos perfeitos (matches) e nos imperfeitos (mismatches) entre a sequência de entrada e a sequência do banco de dados. Ou seja, quanto menor for o valor de E-value, mais significativo é o score e o alinhamento. Por outro lado, quanto ao valor de identidade também observado nos resultados gerados acima, esse refere-se ao percentual em que as sequencias comparadas possuem os mesmos resíduos de amino ácidos (ou nucleotídeos) na mesma posição do alinhamento.

Nesse sentido, observou-se que o E-value do alinhamento de LoobNPVOrf-35 e do TTF2 de Danaus plexippus possui um valor menor, ou seja, mais significativo que o E-value do alinhamento de LoobNPVOrf-35 e o GTA de AnpeNPV, enquanto o valor de identidade foi o oposto, melhor para o alinhamento de LoobMNPVOrf-36 com GTA de AnpeNPV, do que com TTF2 de Danaus plexippus.

Dessa forma, decidiu-se aprofundar a busca, no sentido de se discutir qual seria a origem de LoobNPVOrf-35, se oriunda do hospedeiro lepidóptero, a partir de HGT, ou se é uma variação do gene já existente em baculovírus.

Para contextualizar, fatores de transcrição (do inglês transcription factos -Tfs) em geral são fundamentais em um amplo conjunto de processos de desenvolvimento, devido a 
sua habilidade de causar diversas mudanças no padrão de expressão de genes a jusante (Weatherbee et al. 1999). Mais especificamente, o Fator de Terminação de Transcrição 2 (do inglês Transcription Terminator Factor 2), está envolvido em liberar os transcritos de RNA do complexo de elongação da RNA polimerase II (Liu, Xie, \& Price 1998), consequentemente funcionando como um regulador negativo de transcrição, uma vez que ele faz com que os complexos de elongação sejam terminados mais cedo (Xie \& Price 1997).

Os genes GTA estão presentes em membros do grupo I de Alphabaculovirus, e conforme estudos prévios (Hughes \& Friedman 2003), o GTA possui um papel importante na ativação transcricional de genes virais e provavelmente foi originado do hospedeiro, por HGT, a partir do ancestral comum ao clado que inclui os baculovirus AcMNPV, BmMNPV, OpMNPV, e EpMNPV. Katsuma et al. (2008) propuseram que um homólogo a GTA de BmMNPV age como um fator de virulência em larvas de inseto, e pode ser requerido para a ativação de genes do hospedeiro e/ou e genes virais, acelerando assim, o tempo de morte das lagartas hospedeiras.

Baseado em análises do domínio, foi analisado nesse trabalho que LoobNPVOrf-35 os genes TTF2 e os genes GTA são todos membros da família SNF2. Essa família contem proteínas com sequencias similar àquelas encontradas em muitas famílias de proteínas de DNA e RNA helicase, e também em diversas proteínas envolvidas em processos celulares como regulação da transcrição, recombinação de DNA, desenovelamento de cromatina e vários outros tipos de reparo de DNA (Eisen, Sweder \& Hanawalt 1995).

Nesse sentido, é possível que a aquisição de LoobNPVOrf-35 no contexto genômico do vírus possa estar relacionada com a interferência causada por esse gene na maquinaria transcricional do hospedeiro, levando a um consequente benefício da própria transcrição viral, por mecanismos de indução da transcrição viral, ou até mesmo inibição da transcrição do hospedeiro.

Entretanto, sabe-se que baculovírus possuem longos transcritos de mRNA ( Chen et al. 2013), e outra hipótese seria a de que a possível aquisição dessa ORF poderia estar relacionada a inibição desses longos transcritos, através da terminação precoce dos complexos de elongação de mRNA, com o propósito de acelerar a infecção e também atuar em outros genes do hospedeiro no início da infecção viral 


\subsubsection{Análise Filogenética de LoobMNPVOrf-35, e genes TTF2 e GTA}

Para verificar se a LoobNPVOrf-35 foi independentemente adquirida pelo vírus a partir do hospedeiro, por meio de HGT, ou se essa ORF é uma variação divergente do gene GTA presente em Alphabaculovirus do grupo I, com o mesmo ancestral comum, análises filogenéticas foram realizada (figura 18). Uma árvore filogenética foi construída a partir de um conjunto de dados composto por todos os genes TTF2 que atingiram os melhores valores de identidade e E-value de organismos eucariotos (incluindo Insecta, que demonstrou ter os melhores valores), bem como todos os genes de GTA presentes em vírus do Alphabaculovírus grupo I (anexo 2).

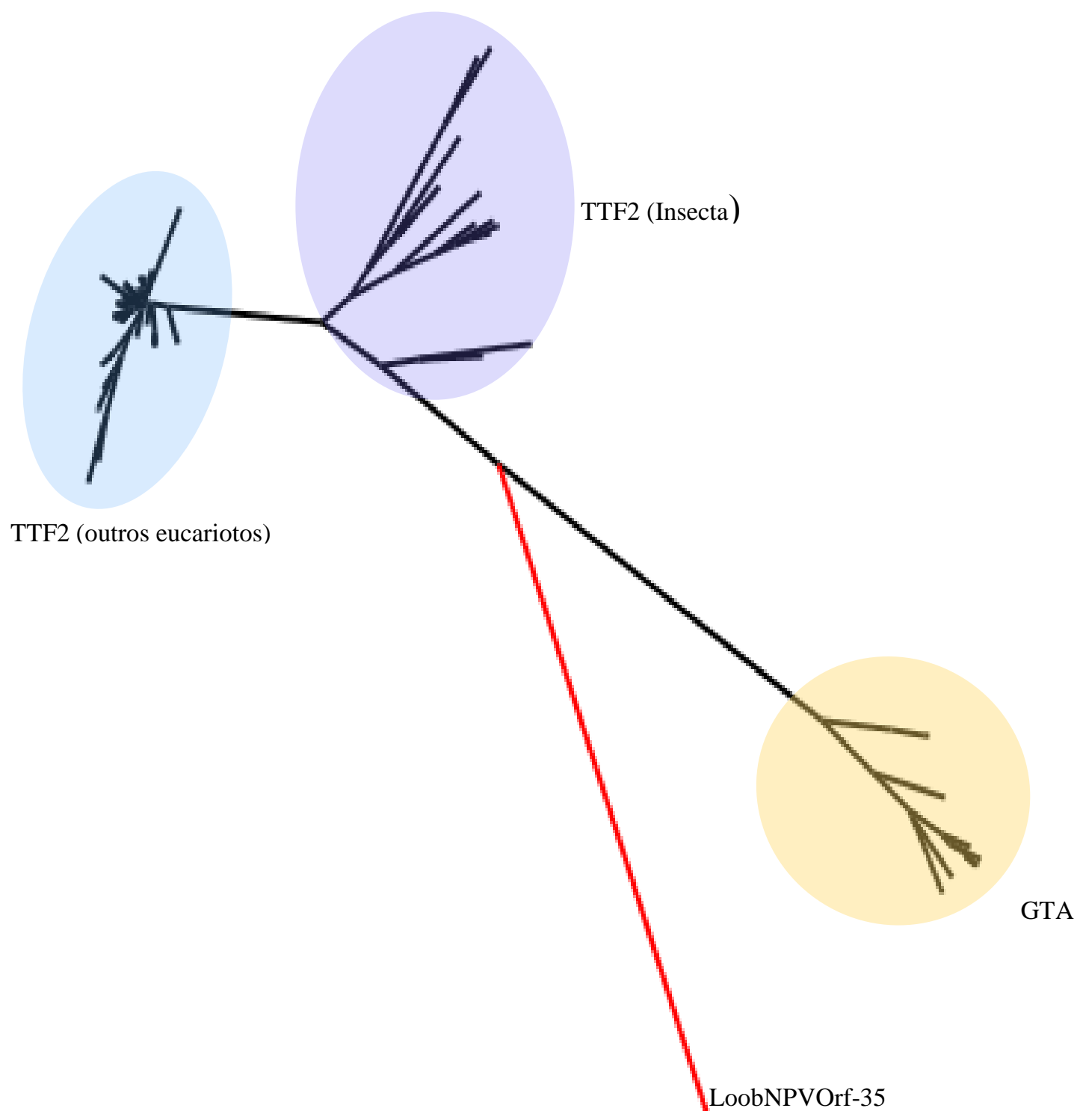

Figura 18. Filogenia por máxima verossimilhança de LoobNPVOrf-35 com os genes TTF2 e GTA, conforme banco de dados do anexo 2. Os genes TTF2 da classe Insecta estão sombreados em azul escuro, os genes TTF2 
de outros eucariotos estão sombreados em azul claro e os genes GTA estão sombreados em bege. LoobNPVOrf35 está destacado com o ramo vermelho.

Conforme a árvore acima apresentada, LoobMNPVOrf-35 possui um longo tamanho de ramo, que indica que essa sequência é divergente das outras sequências a ele comparadas. Isso pode significar que esse gene tenha acumulado diversas mutações únicas ao longo de sua sequência, por influência de deriva genética ou por seleção divergente atuante nesse gene.

Essa característica de longo ramo descrita acima pode estar relacionada a natureza da sequência, que teve que evoluir rapidamente para que continuasse mantida no contexto evolutivo do vírus, sendo resultado de seleção positiva. Seleção positiva, é por sua vez, um evento evolutivo influenciado por novos mutantes produzidos, que possuem maior valor adaptativo (fitness) que a média da população, com tendências a se ter elevação das frequências nas futuras gerações (Suzuki \& Gojobori 1999).

Não obstante, Nickel et al. (2008) observaram que, em geral, TFs estão bem representados dentre os genes que são preditos a se submeterem a seleção positiva, evidência que corrobora com esse cenário.

Por outro lado, uma segunda hipótese à essa filogenia apresentada seria um problema filogenético denominado "atração de ramificações longa" (do inglês Long Branch Attraction) (Gribaldo \& Philippe 2002), que é um artefato que ocorre devido à alta e rápida frequência de mudanças independentes naquele ramo, afetando o verdadeiro sinal filogenético e fazendo com que a relação filogenética pareça ser mais próxima do que ela realmente.

No entanto, cabe ressaltar que a árvore foi realizada pelo método de Máxima Verossimilhança, que é um dos melhores para se desenhar filogenias corretas e com suporte estatístico mais robusto, quando comparado aos métodos de parcimônia, que geralmente são os mais afetados pelo efeito de atração de ramificações longa (Zvelebi \& Baum 2008).

\subsubsection{Teste de hipótese para a origem de LoobMNPVOrf-35}

Em vista às distintas possibilidades da origem do gene LoobNPVOrf-35 analisadas na árvore filogenética observada na figura 18, buscou-se embasamento estatístico que pudesse levar a uma hipótese mais conclusiva sobre o fato observado. Assim, utilizou-se um método estatístico alternativo ao teste de hipóteses clássico, que utiliza a estatística Bayesiana 
por meio do Fator de Bayes (Goodman \& Bayes, 1999; Kass et al. 2007), que é baseado na seguinte fórmula:

Probabilidade a priori da hipótese nula X Fator de Bayes $=$ Probabilidade posterior da hipótese nula

$$
\text { Onde Fator de Bayes }=\frac{\text { Probabilidade }(\text { dado da hipótese nula })}{\text { Probabilidade }(\text { dado da hipótese alternativa })}
$$

Sabe-se que se o fator de Bayes entre 1-3, significa que a força da evidência contra a hipótese nula é fraca, enquanto que quando é entre 3-20 a força da evidência contra a hipótese nula é moderada, e entre 20-150 a força da evidência contra hipótese nula é forte, e quando é maior que 150, a força da evidência contra a hipótese nula é muito forte (Goodman e Bayes 1999).

Desse modo, para se analisar a quais restrições (constraints) de melhor significância LoobNPVOrf-35 ficaria submetido, se junto aos genes GTA ou aos genes TTF2, considerouse o constraint de GTA como hipótese alternativa 1 (H1), o constraint de TTF2 hipótese alternativa $2(\mathrm{H} 2)$ e a hipótese nula (H0) sem nenhum constraint.

Obteve-se um resultado dado em valores de probabilidade marginal, onde para o constraint com GTA o valor foi de -14940.61 , enquanto que com TTF2 foi de $\operatorname{lnL}=-1455.06$, e a hipótese nula foi de $\ln L=-14953.00$. Com esses valores, calculou-se o Fator de Bayes de acordo com a fórmula acima para H1(GTA), que foi de 12,39, ou seja, moderado contra a hipótese nula; e para H2 (TTF2), que foi de 2,06 (fraco contra a hipótese nula). Com base nesses resultados, observou-se que é mais provável que LoobNPVOrf-35 esteja mais próximo ao grupo oriundo de TTF2, e que portanto, essa ORF foi adquirida por HGT.

\subsubsection{Análise da estrutura secundária do alinhamento de LoobMNPVOrf-35, TTF2 e GTA.}

A visualização de sequências por meio de alinhamentos permite uma análise mais pontual quanto aos detalhes relacionados às regiões conservadas, regiões não-conservadas, mutações, inserções, dentre outras peculiaridades.

Dessa forma, um alinhamento múltiplo apresentando estruturas secundárias foi realizado conforme a figura 19, contendo LoobNPVORF-35 e genes GTA e TTF2. A 
predição das estruturas secundárias foi realizada com base em cristais previamente descritos que possuíam a maior similaridade com LoobNPVOrf-35, que também fizeram parte do alinhamento. Esses cristais Chd1 (código do Protein Data Bank : 3mwy (Hauk et al.2010)) e SWI2/SNF2 (código do Protein Data Bank: 1z63(Durr et al. 2005)) estão envolvidos no remodelamento da cromatina, regulando esse processo que é dependente da atividade da

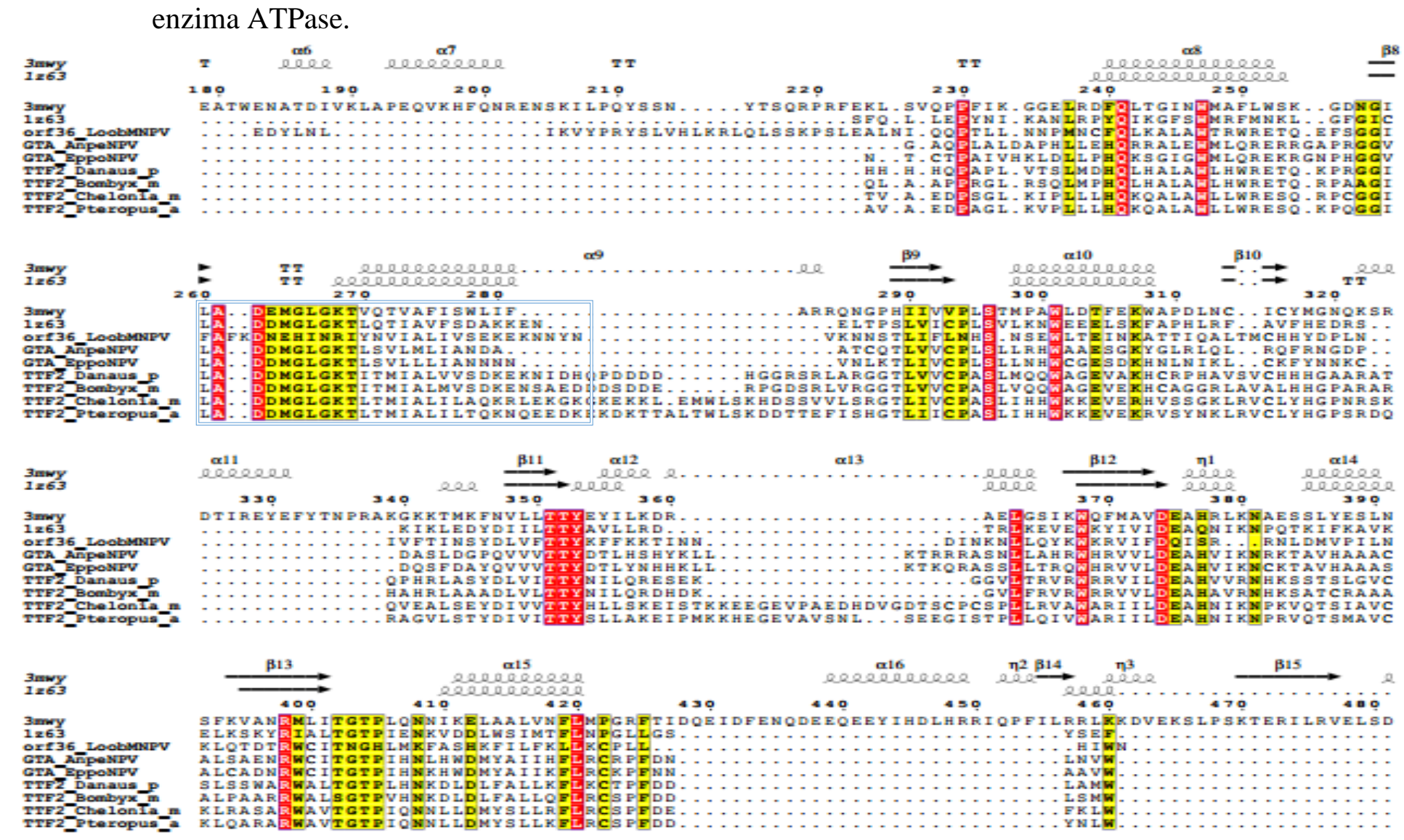

Figura 19. Alinhamento múltiplo feito com sequencias de aminoácidos, apresentando estrutura secundária de LoobNPVOrf-35 com base nos dois cristais mais semelhantes a essa ORF ( 3mwy (Hauk et al.2010) e 1z63(Durr et al.r 2005)), alinhados a genes de GTA de AnpeNPV e EppoMPV e os genes TTF2 de Danaus plexippus, Bombyx mori, Chelonia mydas e Pterotopus alecto. O destaque do retângulo azul indica região de alinhamento conservada dentre todas as sequencias, mas que demonstra que LoobNPVOrf-35, apesar de possuir o mesmo domínio SNF2 que GTA e TTF2, ainda assim é bem divergente. As cores representam regiões de maior nível de similaridade proteica, sendo vermelho identidade estrita, e amarelo similaridade. Diversas estruturas secundárias em alfa hélice $(\alpha)$ e folha beta $(\beta)$ demonstram-se conservadas no alinhamento.

Assim, com base nas análises do alinhamento acima apresentado, é interessante notar que existem diversas estruturas secundárias de folha beta e alfa hélice conservadas e em comum à todas as sequencias, indicando similaridade dessas sequencias devido a presença do mesmo domínio conservado SNF2 comum a todas elas. No entanto, em relação a região 
destacada no retângulo azul, uma região de alta conservação entre as sequencias, é notável que LoobNPVOrf-35 muito diverge das outras sequencias alinhadas, o que torna provável que essa ORF de LoobMNPV esteja associado a outra origem.

Além disso, com base em um reconstrução da relação de evolução entre genes que foram potencialmente adquiridos por HGT, comparados a uma filogenia da família Baculoviridae, Hughes \& Friedman (2003) relataram que baculovírus que possuem genes da família SNF2, possuem também ortólogos em organismos celulares e agrupam-se próximo a insetos (Drosophila), corroborando com a possível hipótese que LoobNPVOrf-35 foi originado por HGT, a partir de um gene que codifica uma proteína oriunda do inseto hospedeiro desse vírus.

\subsubsection{Análise do contexto gênico de LoobMNPVOrf-35 em relação à Alphabaculovirus grupo I}

Em relação ao contexto gênico ao qual está inserido o gene GTA (figura 20), que por sua vez é encontrado em membros pertencentes ao grupo I de Alphabaculovirus (exceto em MaviNPV, LoobMNPV e DekiNPV), foi analisado que sua localização é bem conservada dentro desse grupo, estando sempre localizada entre os genes lef-12 e odv-e66. Cabe ressaltar que todos esses que não contêm o GTA estão filogeneticamente próximos, conforme observase na árvore filogenética (figura 20).

Em LoobMNPV, o gene localizado entre esses dois genes é LoobNPVOrf-105, que corresponde a Ac-like Orf-44. Por outro lado, LoobNPVOrf-35 está inserido em um contexto gênico completamente diferente, localizado entre LoobNPVOrf-34 (Ac-like Orf-110) e LoobNPVOrf-36 (Ac-like Orf-111). Essa análise nos permite inferir que LoobNPVOrf-35 possui uma origem diferente, não relacionada ao gene GTA, ou que houve algum rearranjo que alterou a sintenia desse bloco gênico.

Foi observado também que o gene da $p 47$ é bem conservado em sua posição, e está presente em todos os genomas de Alphabaculovírus grupo I, uma vez que é um core gene. No entanto, as ORFs similares a Ac-like Orf 43, Ac-like Orf 44 (em LoobMNPV, ORFs 103 e 102, respectivamente) e Ac-like Orf 45 são bem variáveis quanto a sua posição nos genomas, estando presente em alguns e ausente em outros. Ainda, a orientação de GTA 
acompanha a orientação de lef-12 e Ac-like Orf 43, Ac-like Orf 44 e odv-e56 (se presente).

A

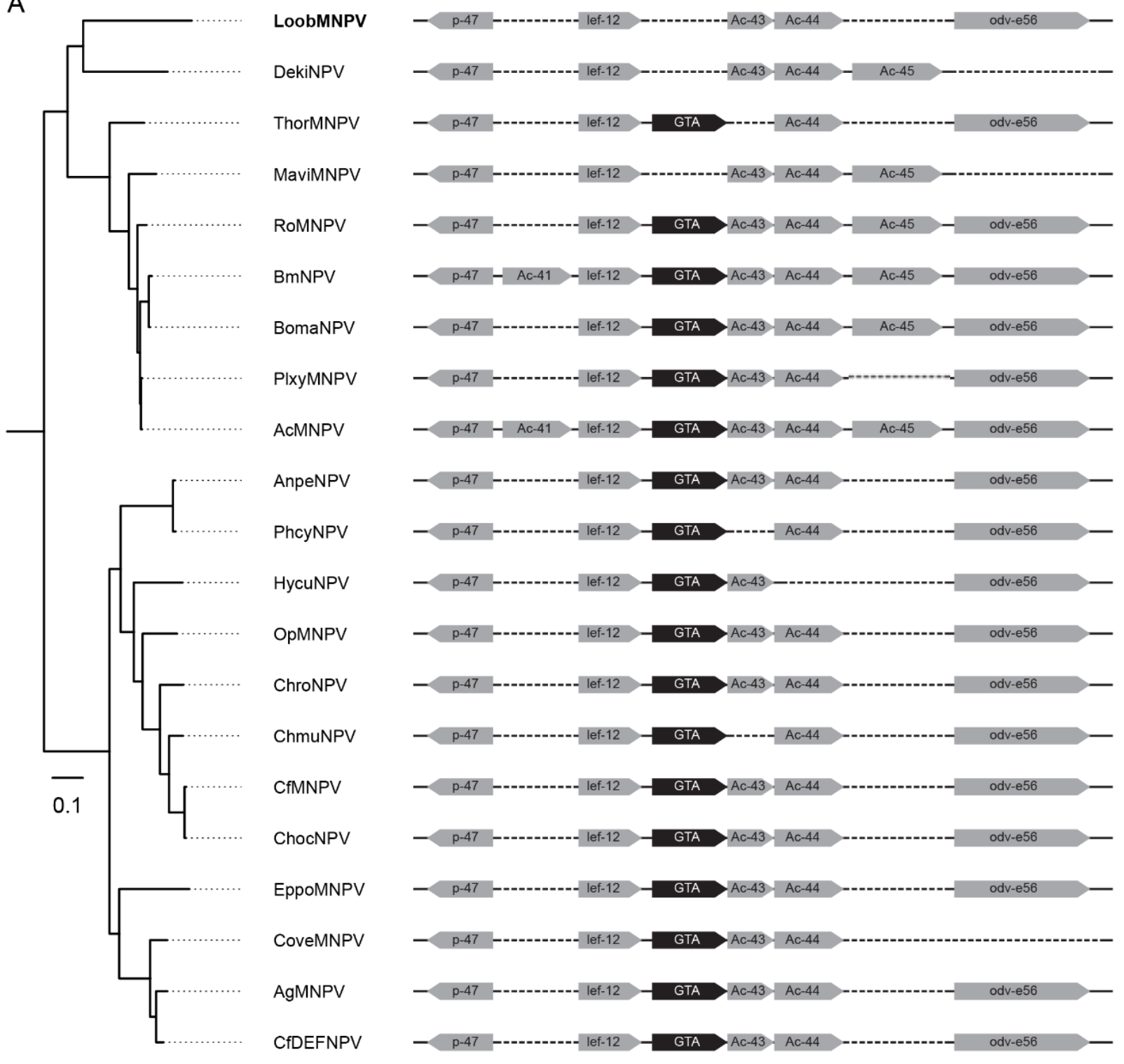

B

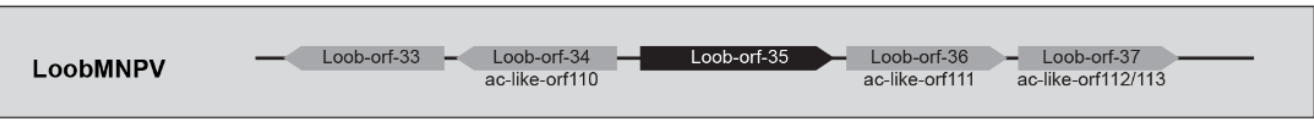

Figura 20. Contexto gênico do gene GTA presente nos membros de Alphabaculovirus grupo I, alinhado à filogenia previamente apresentada na figura 15, comparado ao contexto gênico de LoobNPVOrf-35. (a) Os contextos gênicos de AcMNPV, AgMNPV, AnpeNPV, BmNPV, BomaNPV, CfMNPV, ChoocMNPV, ChmuNPV, ChroNPV, DekiNPV, EppoNPV, HycuNPV, LoobMNPV, MaviMNPV, OpMNPV, PhycyMNPV, PlxyMNPV, RoMNPV e ThorMNPV possuem o gene GTA sempre entre $p-47$, lef-12 e odv-e56, com a presença ou ausência de algumas ORFs como Ac-like Orf 41, Ac-like Orf 43, Ac-like Orf 44 e Ac-like Orf 45. LoobMNPV, DekiNPV e MaviNPV são os únicos que não possuem o gene GTA. As linhas tracejadas indicam 
a ausência de ORF. (b) Posição de LoobNPVOrf-35 no contexto do genoma de LoobMNPV, localizada entre LoobNPVOrf-34 (Ac-like Orf-110) e LoobNPVOrf-36 (Ac-like Orf-111).

\subsubsection{Conclusões sobre LoobMNPVOrf-35}

Diante o exposto, sugere-se duas hipóteses para a origem de LoobMNPVOrf-35: a primeira que ele tenha sofrido pressões seletivas que levaram a uma variação do gene GTA; ou pode-se se tratar de uma aquisição independente a partir do hospedeiro, mecanismo já conhecido, como é o caso de genes como a interleucina-10, que foi capturada do hospedeiro de forma independente por diferentes vírus de DNA, em pelo menos três eventos evolutivos diferentes (Hughes \& Friedman 2003).

Pelas análises realizadas nesse trabalho, LoobMNPVOrf-35 mostrou-se provavelmente ter sido adquirido a partir da segunda hipótese, ou seja, por transferência horizontal de genes do hospedeiro para o vírus. No entanto, em ambos os casos, para que se possa investigar mais precisamente a origem desse gene, seria necessário a realização de sequenciamentos de novos genomas de baculovirus pertencentes ao grupo I de Alphabaculovirus, buscando uma maior amostragem nesse grupo, com uma posterior reconstrução dessa filogenia, com intuito de entender quantos e quais eventos evolutivos originam esses novos genes.

Adicionalmente, visado analisar a função e o envolvimento dessa ORF no contexto viral, experimentos in vitro e in vivo são também necessários. Entretanto, um fator restringente quanto a realização dessas análises está relacionada à ausência de uma cultura de células de inseto capaz de propagar esse vírus in vitro, assim como seu cultivo in vivo é também limitante, uma vez que essas lagartas são sensíveis às condições laboratoriais. Portanto, sistemas alternativos ainda devem ser explorados, para que nova linhagem viral possa ser analisada. 


\subsection{Peculiaridades do Genoma LoobMNPV}

\subsubsection{Ausência dos genes da catepsina e quitinase no genoma de LoobMNPV}

Curiosamente, LoobMNPV não codifica dois genes comumente encontrados em baculovírus, que são responsáveis pela melanização e liquefação do hospedeiro nas fases tardias da infecção: os genes codificadores das enzimas catepsina e quitinase (Hawtin et al. 1997). Além do envolvimento desses genes no espalhamento horizontal de vírus no campo (Cory et al. 2013), foi também observado que a catepsina e a quitinase interagem diretamente uma com a outra, apresentando uma interdependência na promoção da liquefação do hospedeiro em ambos os níveis temporal e espacial, e, portanto, em geral os seus genes são adquiridos e perdidos juntos (Hodgson, Arif, \& Krell 2011).

É provável que os baculovírus que possuem esses genes o tenham obtido a partir do hospedeiro, como é o caso da quitinase, que participa na degradação de um componente do exoesqueleto de insetos, a quitina, uma estrutura rígida que é periodicamente reconstruída para possibilitar o crescimento de larvas de inseto (Hawtin et al. 1997). Os genes da quitinase estão presentes nos baculovírus pertencentes aos NPVs dos Grupos I e II, bem como em vários genomas de GV. Em análises filogenéticas, a quitinase de vírus como AcMNPV (Ac Orf 126) e BmNPV (Bm Orf 103), são filogeneticamente agrupadas a várias quitinases oriundas de lepidópteros, como por exemplo, apresentando mais de $60 \%$ de identidade com a quitinase de B. mori (Fukamizo et al. 2011). Entretanto, dentre os Alphabaculovirus do grupo I, apenas LoobMNPV, Anticarsia gemmatalis nucleopoliedrovírus (AgMNPV) (Oliveira et al., 2006) e Philosamia Cynthia nucleopoliedrovírus (PhcyNPV) (Qian et al., 2013) não possuem os genes da catepsina e quitinase. Para AgMNPV, entretanto, estudos demonstraram que a introdução recombinante do gene da catepsina (v-cath) e quitinase (chiA) em seu genoma resulta em uma melhora de sua atividade inseticida no combate à larvas de $A$. gemmatalis, resgatando a liquefação com consequente aumento da dispersão viral (Lima et al. 2013).

Por conseguinte, conforme Lemaire (2002), é geralmente observado o hábito gregário, caracterizado pela aglomeração de centenas de indivíduos, formando manchas escuras em troncos ou galhos de árvores frutíferas, em lagartas da família Saturniidae, como L. obliqua e P.cynthia, bem como em lagartas da família Noctuidae, como A. gemmatalis, 
que no entanto, são consideradas um estágio transitório da evolução de polifenismo de fase, uma vez que suas agregações variam de acordo com a densidade de suas populações (Silva et al. 2013).

Portanto, supõe-se que a ausência desses genes pode estar relacionada gregários, caracterizado por apresentarem alterações de características fenotípicas, incluindo cor, morfologia, ontogenia, comportamento e até resistência a patógenos (Lee, Simpson, \& Raubenheimer 2004; Reeson 2001). Desse modo, uma vez que lagartas gregárias

permanecem em aglomerados, o vírus pode ser facilmente espalhado entre elas, sem a necessidade de nenhum mecanismo para alavancar seu espalhamento, o que poderia gerar a consequente perda desses genes no contexto desse vírus.

Essas observações nos permitem concluir que ambos os genes são provavelmente não essenciais para a persistência dos baculovírus no ambiente, uma vez que outros mecanismos de persistência baseados nos hábitos do hospedeiro também já foram previamente observados (Ardisson-Araújo et al. 2014).

\section{CONCLUSÕES E PERSPECTIVAS}

Esse é o primeiro trabalho que descreve o genoma completo de um baculovírus, isolado a partir de uma lagarta de interesse médico. Baseado na análise genômica e filogenética realizada, o vírus LoobMNPV, objeto de estudo dessa pesquisa, encontra-se localizado em Alphabaculovirus grupo I. Esse dado encontra-se em concordância a estudos prévios de caracterização desse vírus (Wolff et al. 2002) em relação ao grupo, mas não é condizente quanto a sua localização no clado, uma vez que LoobMNPV é um clado irmão ao clado dos genomas similares a AcMNPV. Nesse contexto, esse genoma apresentou-se muito divergente, com diversas inversões e rearranjos genômicos quando comparado aos outros genomas desse grupo, provavelmente devido à grande escala de fluxo gênico que ele foi submetido.

Ademais, algumas ORFs de LoobMNPV foram possivelmente adquiridas por meio de transferência horizontal de genes (HGT), como LoobMNPVOrf-35, que revelou ser um fator terminador de transcrição possivelmente envolvido na interferência da maquinaria transcricional do hospedeiro, ou envolvido em interferir no DNA do próprio vírus, 
promovendo a transcrição a fim de beneficiar tradução viral e consequentemente, a sua propagação no interior da célula.

LoobMNPV apresentou ausência dos genes da catepsina e quitinase, que por usa vez estão presentes em quase todos os genomas de Alphabaculovirus do grupo I. Essa perda é provavelmente devido a aspectos relacionados ao comportamento gregário observado em lagartas de L. obliqua, que faz com que o vírus não necessite de estratégias e mecanismos para se espalhar no ambiente, uma vez que as lagartas já estão agrupadas.

Dessa forma, a elucidação do genoma completo de LoobMNPV poderá beneficiar estudos relacionados ao controle biológico das crescentes populações da larva L. obliqua, consequentemente evitando acidentes em humanos, bem como proporcionará mais dados a serem utilizados nos estudos sobre a evolução e a biologia de baculovirus como um todo.

\section{REFERÊNCIAS BIBLIOGRÁFICAS}

(“Baculovirus". In: WIKIMEDIA COMMONS, WIKIPÉDIA, a Enciclopédia Livre. Flórida: Wikimedia Foundation, 2015. Disponível Em: <http://commons.wikimedia.org/wiki/Baculovirus\#mediaviewer/File:NpvLebenszyklus.jpg>. Acesso Em: 28 Fev. 2015). (n.d.).

(Lonomia obliqua. In: WIKIMEDIA COMMONS, WIKIPÉDIA, a enciclopédia livre. Flórida: Wikimedia Foundation, 2015. Disponível em: <http://commons.wikimedia.org/wiki/File:Lonomia-obliqua-citsc-2.jpg?uselang=ptbr>. Acesso em: 28 fev. 2015. (n.d.).

Abella, H.B, M.G.B. Marques, K.R.L.M. Silva, M.G. Rossoni, J. B. T. (2006). Acidentes com lagartas do gênero Lonomia registrados no Centro de Informação Texicológica do Rio Grande do Sul no período de 1997 a 2005. In A. Nicolella (Ed.), Toxicovigilância - toxicologia clínica: dados e indicadores selecionados. (pp. 29-34). Porto Alegre.

Abellla, H.B., Ramos, C.J, Marques, M.G., Boff, G.J., Torres, J.B., Nicolella, A. D. R. (1999). Acidentes por larvas de lepidópteros do gênero Lonomia no Rio Grande do Sul. Rev. Bras. Toxicol., 2, 81-173.

Adams, J. R., and McClintock, J. T. (1991). Baculoviridae, nuclear polyhedrosis viruses Part 1. Nuclear polyhedrosis viruses of insects. In J. R. A. and J. R. Bonami (Ed.), Atlas of Invertebrate Viruses (pp. Chapter 6, 87-180). CRC Press, Boca Raton. 
Afonso, C. L., Tulman, E. R., Lu, Z., Balinsky, C. a, Moser, B. a, Becnel, J. J., ... Kutish, G. F. (2001). Genome sequence of a baculovirus pathogenic for Culex nigripalpus. Journal of Virology, 75(22), 11157-11165. http://doi.org/10.1128/JVI.75.22.11157

Akermann, H.-W. and W. A. S. (1983). A morphological investigation of 23 baculoviruses. J. Invertebr. Pathol., (41), 269-280.61-88.

Alexander, J. O. (1984). Arthropods and Human Skin (pp. 177-97). Berlin: Springer Verlag-Heidelberg.

Altschul, S. F., Gish, W., Pennsylvania, T., \& Park, U. (1990). Basic Local Alignment Search Tool. J. Mol. Biol., (215), 403-410.

Altschul, S. F., Madden, T. L., Schäffer, a a, Zhang, J., Zhang, Z., Miller, W., \& Lipman, D. J. (1997). Gapped BLAST and PSI-BLAST: a new generation of protein database search programs. Nucleic Acids Research, 25(17), 3389-402. Retrieved from http://www.pubmedcentral.nih.gov/articlerender.fcgi?artid=146917\&tool=pmcentrez \&rendertype $=$ abstract

Alvarez-Flores, M.P., Fritzen, M., Reis, C.V., Chudzinski-Tavassi, A. M. (2006). Losac, a factor X activator from Lonomia obliqua bristle extract: its role in the pathophysiological mechanisms and cell survival. Biochem. Biophys. Res. Commun, (343), 1216-1223.

Ana, S., Miele, B., Garavaglia, J., Nicol, M., \& Ghiringhelli, P. D. (2011). Baculovirus : Molecular Insights on Their Diversity and Conservation, 2011. http://doi.org/10.4061/2011/379424

Aran, R. H. B., \& Hanseok, K. O. (2008). Detecting Horizontally Transferred and Essential Genes Based on Dinucleotide Relative Abundance. DNA Research, (15), 267-276.

Ardisson-Araújo, D. M. P., de Melo, F. L., Andrade, M. D. S., Sihler, W., Báo, S. N., Ribeiro, B. M., \& de Souza, M. L. (2014). Genome sequence of Erinnyis ello granulovirus (ErelGV), a natural cassava hornworm pesticide and the first sequenced sphingid-infecting betabaculovirus. BMC Genomics, 15, 856.

http://doi.org/10.1186/1471-2164-15-856

Ardisson-Araujo, D. M. P., Rohrmann, G. F., Ribeiro, B. M., \& Clem, R. (2015). Functional characterization of hesp018, a baculovirus-encoded serpin gene. The Journal of General Virology. http://doi.org/10.1099/vir.0.000041

AROCHA-PIÑANGO, C. (1967). Fibrinolisis producida por contacto con orugas comunicacion preliminar. Acta Cient. Venezolana, (18), 136-139. 
Ayres, M. D., Howard, S. C., Kuzio, J., Lopez-Ferber, M., \& Possee, R. D. (1994). The complete DNA sequence of Autographa californica nuclear polyhedrosis virus. Virology, 202(2), 586-605. http://doi.org/10.1006/viro.1994.1380

Baculovirus. In: WIKIMEDIA COMMONS, WIKIPÉDIA, a Enciclopédia Livre. Flórida: Wikimedia Foundation, 2015. Disponível Em:

<http://commons.wikimedia.org/wiki/Baculovirus\#mediaviewer/File:Nucleopolyhedro virus_german.png>. Acesso Em: 28 Fev. 2015). (n.d.).

Baele, G., Lemey, P., \& Vansteelandt, S. (2013). Make the most of your samples : Bayes factor estimators for high-dimensional models of sequence evolution. BMC Genomics, 14(85), 1-18.

Barnes, P. D., \& Grundy, J. E. (1992). Down-regulation of the class I HLA heterodimer and f12-microglobulin on the surface of cells infected with cytomegalovirus, 2395-2403.

Beersma, M.F., Bijlmakers, M.J., and Ploegh, H. L. (1993). Human cytomegalovirus downregulates HLA class I expression by reducing the stability of class I H chains. $J$. Immunol., (151), 4455-4464.

Benson, G. (1999). Tandem repeats finder: a program to analyze DNA sequences. Nucleic Acids Research, 27(2), 573-580.

Bergold, G. H. (1947). Die isolierung des polyeder-virus and die natur der polyeder. Naturforsch, 122- 143.

Biomatters. (n.d.). Geneious version (7.1.6). Retrieved from http://www.geneious.com/??

Blissard, G. W., \& Rohrmann, G. F. (1990). Baculovirus diversity and molecular biology. Annual Review of Entomology, 35(67), 127-55. http://doi.org/10.1146/annurev.en.35.010190.001015

Blissard, Gary W, Kogan, P. H., \& Rohrmannt, F. (1992). A Synthetic Early Promoter from a Baculovirus : Roles of the TATA Box and Conserved Start Site CAGT Sequence in Basal Levels of Transcription, 793, 783-793.

Braunagel, S. C. and M. D. S. (2007). Molecular Biology of the Baculovirus OcclusionDerived Virus Envelope. Curr Drug Targets, , 8, 1084-1095.

Caovilla, J.J., Barros, E. J. (2004). Efficacy of two different doses of antilonomic serum in the resolution of hemorrhagic syndrome resulting from envenoming by Lonomia obliqua caterpillars: a randomized controlled trial. Toxicon, (43), 811-818.

Cardoso, A. E. C., Haddad-Junior, V. (2005). Acidentes por Lepidópteros ( larvas e adultos de mariposas ): estudo dos aspectos epidemiológicos , clínicos e terapêuticos *, 80(6), 571-578. 
Carrijo-Carvalho, L. C., \& Chudzinski-Tavassi, A. M. (2007). The venom of the Lonomia caterpillar: an overview. Toxicon : Official Journal of the International Society on Toxinology, 49(6), 741-57. http://doi.org/10.1016/j.toxicon.2006.11.033

Catarina, C. C. de I. T. de S. (2008). Base de dados Estatística-Plataforma Epi-info. 2008. Florianópolis.

Chen, Y.-R., Wu, C.-Y., Lee, S.-T., Wu, Y.-J., Lo, C.-F., Tsai, M.-F., \& Wang, C.-H. (2008). Genomic and host range studies of Maruca vitrata nucleopolyhedrovirus. The Journal of General Virology, 89(Pt 9), 2315-30.

http://doi.org/10.1099/vir.0.2008/001412-0

Chen, Y.-R., Zhong, S., Fei, Z., Hashimoto, Y., Xiang, J. Z., Zhang, S., \& Blissard, G. W. (2013). The Transcriptome of the Baculovirus Autographa californica Multiple Nucleopolyhedrovirus in Trichoplusia ni Cells. Journal of Virology, 87(11), 63916405. http://doi.org/10.1128/JVI.00194-13

Cheng, X. W., \& Carner, G. R. (2000). Characterization of a single-nucleocapsid nucleopolyhedrovirus of Thysanoplusia orichalcea L. (Lepidoptera: Noctuidae) from Indonesia. Journal of Invertebrate Pathology, 75(4), 279-87. http://doi.org/10.1006/jipa.2000.4933

Chor, B., \& Tuller, T. (2005). Maximum likelihood of evolutionary trees: hardness and approximation. Bioinformatics (Oxford, England), 21 Suppl 1, i97-106. http://doi.org/10.1093/bioinformatics/bti1027

Cory, J. S., Myers, J. H., Myers, H., \& Coryl, S. (2013). THE ECOLOGY AND EVOLUTION OF INSECT BACULOVIRUSES. Annual Review of Ecology, 34(2003), 239-272. http://doi.org/10.1146/132402

Costa, R. (1994). Acidentes por Lagartas Venenosas. In Venenos animais: uma visão integrada (pp. 327-338). Rio de Janeiro: Ed. de Publicações Científicas.

CRUZ, I. (2002). Manejo de lepidópteras-praga integrado de pragas. In Controle biológico no Brasil: parasitóides e predadores (pp. 320-328). São Paulo: Manole.

Derksen, A. C. G., and Granados, R. R. (1988). Alteration of a lepidopteran peritrophic membrane by baculoviruses and enhancement of viral infectivity. Virology, (167), $242-250$.

DIDHAM, R.K., GHAZOUL, J., STORK, N.E. \& DAVIS, A. J. (1996). Insects in fragmented forests: a functional approach. Trends Ecol. Evol., 11(6), 255- 260. http://doi.org/http://dx.doi.org/10.1016/0169-5347(96)20047-3

Donato, J.L., Moreno, R.A., Hyslop, S., Duarte, A., Antunes, E., Le Bonniec, B., \& F., Rendu, F., de Nucci, G. (1998). Lonomia obliqua caterpillar spicules trigger human 
blood coagulation via activation of factor $\mathrm{X}$ and prothrombin. Thromb. Haemost., (79), 539-542.

Duarte, AC, Caovilla, J, Lorini, I, Lorini, D, Mantovani, G, S., \& J, Manfre, PC, Ssilveira, RC, Moura, S. (1990). Insuficiência renal aguda por acidentes com lagartas. Jornal Brasileiro de Nefrologia, (12), 184-186.

Durr, H., Korner, C., Muller, M., Hickmann, V., Hopfner, K. P. (2005). X-ray structures of the Sulfolobus solfataricus SWI2/SNF20052 ATPase core and its complex with DNA. Cell(Cambridge, Mass.), 121, 363-373.

Eisen, J. a, Sweder, K. S., \& Hanawalt, P. C. (1995). Evolution of the SNF2 family of proteins: subfamilies with distinct sequences and functions. Nucleic Acids Research, 23(14), 2715-23. Retrieved from http://www.pubmedcentral.nih.gov/articlerender.fcgi?artid=307096\&tool=pmcentrez \&rendertype $=$ abstract

Entwistle, P.F., P.H. Adams, and H. F. E. (1978). Epizootiology of a nuclear polyhedrosis virus in European spruce sawfly (Gilpinia hercyniae): the rate of passage of infective virus through the gut of birds during cage tests. J Invertebr Pathol, 31(3), 307-12.

Falcon, L. A. and R. T. H. (1985). Electron microscope observations of multiple occluded virions in the granulosis virus of the codling moth, Cydia pomonella. J. Invertebr. Pathol., 45, 356-359.

Fang, M., et al. (2009). Autographa californica multiple nucleopolyhedrovirus core gene ac96 encodes a per Os infectivity factor (PIF-4). J Virol, 83(23), 12569- 78.

Federici, B. A. (1986). Ultrastructure of baculoviruses. In R. R. G. and B. A. Federici (Ed.), The biology of baculoviruses (pp. 61-88). CRC Press: Boca Raton.

Felsenstein J. (1985). Confidence limits on phylogenies: an approach using the bootstrap. Evolution, (39), 783-791.

Freitas, A.V.L., Francini, R.B. \& Brown, K. . (2003). Insetos como indicadores ambientais. (L. Cullen, R. Rudran \& C. Valladares-Padua, orgs.). In Métodos de estudo em Biologia da conservação e manejo da vida silvestre (L. Cullen, R. Rudran \& $C$. Valladares-Padua, orgs.) (pp. p.125-151.). UFPR.

Friesen, P. D. (1997). Regulation of Baculovirus Early Gene Expression. In The Baculoviruses (pp. 41-170). New York and London: Press, Plenum.

Friesen, P. D., \& Millert, L. K. (1987). Divergent Transcription of Early 35- and 94Kilodalton Protein Genes Encoded by the HindlIl K Genome Fragment of the Baculovirus Autographa californica Nuclear Polyhedrosis Virust. J Virol, (July), 2264-2272. 
Fukamizo, T., Sato, H., Mizuhara, M., Ohnuma, T., Gotoh, T., Hiwatashi, K., \& Takahashi, S. (2011). Chitinase from Autographa californica multiple nucleopolyhedrovirus: rapid purification from Sf-9 medium and mode of action. Bioscience, Biotechnology, and Biochemistry, 75(9), 1763-9. http://doi.org/10.1271/bbb.110300

Gamborgi, G.P., Metcalf, E.B., Barros, E. J. G. (2006). Acute renal failure provoked by toxin from caterpillars of the species Lonomia obliqua. Toxicon, (47), 68-74.

Garavaglia, M. J., Miele, S. A. B., Iserte, J. A., Belaich, M. N., \& Ghiringhelli, P. D. (2012). The ac53, ac78, ac101, and ac103 genes are newly discovered core genes in the family Baculoviridae. Journal of Virology, 86(22), 12069-79. http://doi.org/10.1128/JVI.01873-12

Garrity, D. B., Chang, M., \& Blissard, G. W. (1997). Late Promoter Selection in the Baculovirus gp64 Envelope Fusion Protein Gene, 181(231), 167-181.

Geer, L. Y., Marchler-Bauer, A., Geer, R. C., Han, L., He, J., He, S., ... Bryant, S. H. (2010). The NCBI BioSystems database. Nucleic Acids Research, 38(Database issue), D492-6. http://doi.org/10.1093/nar/gkp858

Goley, E.D., et al. (2006). Dynamic nuclear actin assembly by Arp2/3 complex and a baculovirus WASP-like protein. Science, 314(5798), 464-7.

Goodman, S. N., \& Bayes, I. (1999). Toward Evidence-Based Medical Statistics. 2: The Bayes Factor. Ann Intern Med, 12(130), 1019-1021.

Grant, J. R., \& Stothard, P. (2008). The CGView Server: a comparative genomics tool for circular genomes. Nucleic Acids Research, 36(Web Server issue), W181-4. http://doi.org/10.1093/nar/gkn179

Gribaldo, S., \& Philippe, H. (2002). Ancient Phylogenetic Relationships. Theoretical Population Biology, 61(4), 391-408. http://doi.org/10.1006/tpbi.2002.1593

Guarino, L. A., Dong, W. E. N., Xu, B. I. N., Broussard, D. R., Davis, R. W., \& Jarvis, D. L. (1992). Baculovirus Phosphoprotein pp31 Is Associated with Virogenic Stroma. $J$ Virol, 66(12), 7113-7120.

Guarino, L. A., \& Summers, M. D. (1986). Interspersed Homologous DNA of Autographa californica Nuclear Polyhedrosis Virus Interspersed Homologous DNA of Autographa californica Nuclear Polyhedrosis Virus Enhances Delayed-Early Gene Expression. $J$ Virol, 60(1), 215.

Guindon S., G. O. (2003). PhyML: “A simple, fast, and accurate algorithm to estimate large phylogenies by maximum likelihood." Systematic Biology, 52(5), 696-704. 
Haddad Jr V, C. J., \& Cardoso JLC, Wen FH, França FOS, M. C. (2003). Erucismo e Lepidopterismo. In Animais peçonhentos no Brasil (pp. 220-3). São Paulo: Sarvier.

Hauk, G., McKnight, J.N., Nodelman, I.M., Bowman, G. D. (2010). The chromodomains of the Chd1 chromatin remodeler regulate DNA access to the ATPase motor. Mol.Cell, $39,711-723$.

Hawtin, R. E., Zarkowska, T., Arnold, K., Thomas, C. J., Gooday, G. W., King, L. a, ... Possee, R. D. (1997). Liquefaction of Autographa californica nucleopolyhedrovirusinfected insects is dependent on the integrity of virus-encoded chitinase and cathepsin genes. Virology, 238(2), 243-53. http://doi.org/10.1006/viro.1997.8816

Hayakawa, T., Ko, R., Okano, K., Seong, S. I., Goto, C., \& Maeda, S. (1999). Sequence analysis of the Xestia c-nigrum granulovirus genome. Virology, 262(2), 277-297.

Hegedus, D., et al. (2009). New insights into peritrophic matrix synthesis, architecture, and function. Annu Rev Entomol, (54), 285-302.

Henrique, R., \& Moraes, P. (2002). Identificação dos inimigos naturais de Lonomia obliqua Walker, 1855 (Lepidoptera, Saturniidae) e possiveis fatores deerminantes do aumento da sua população. Escola Superiror de Agricultura Luiz de QueirozESALQ-USP.

HEPPNER, J. B. (1991). Faunal regions and the diversity of Lepidoptera. Trop. Lepid., $2(1), 1-85$.

Herniou, E. a, \& Jehle, J. a. (2007). Baculovirus phylogeny and evolution. Current Drug Targets, 8(10), 1043-50. Retrieved from http://www.ncbi.nlm.nih.gov/pubmed/17979664

Herniou, E. a, Luque, T., Chen, X., Vlak, J. M., Winstanley, D., Cory, J. S., \& O'Reilly, D. R. (2001). Use of whole genome sequence data to infer baculovirus phylogeny. Journal of Virology, 75(17), 8117-8126. http://doi.org/10.1128/JVI.75.17.8117

Herniou, E. A., Olszewski, J. A., Reilly, D. R. O., \& Cory, J. S. (2004). Ancient Coevolution of Baculoviruses and Their Insect Hosts Ancient Coevolution of Baculoviruses and Their Insect Hosts, 78(7). http://doi.org/10.1128/JVI.78.7.3244

Hodgson, J. J., Arif, B. M., \& Krell, P. J. (2011). Interaction of Autographa californica multiple nucleopolyhedrovirus cathepsin protease progenitor (proV-CATH) with insect baculovirus chitinase as a mechanism for proV-CATH cellular retention. Journal of Virology, 85(8), 3918-29. http://doi.org/10.1128/JVI.02165-10

Hughes, A. L., \& Friedman, R. (2003). Genome-wide survey for genes horizontally transferred from cellular organisms to baculoviruses. Molecular Biology and Evolution, 20(6), 979-87. http://doi.org/10.1093/molbev/msg107 
Jehle, J. a, Blissard, G. W., Bonning, B. C., Cory, J. S., Herniou, E. a, Rohrmann, G. F., ... Vlak, J. M. (2006). On the classification and nomenclature of baculoviruses: a proposal for revision. Archives of Virology, 151(7), 1257-66. http://doi.org/10.1007/s00705-006-0763-6

Jiang, Y., et al. (2009). Evidence of a major role of GP64 in group I alphabaculovirus evolution. Virus Res, 1-2(142), 85-91.

Jones, D. T., Taylor, W. R., \& Thornton, J. M. (1992). The rapid generation of mutation data matrices from protein sequences. Bioinformatics, 8(3), 275-282.

Jorg ME. (1933). Nota prévia sobre el principio ativo urticante de Hylesia Nigricans (Lepidoptera, Hemileueidae) y Ias dermitis provocadas por el miemo. Reun Soc Argent Patol, (8), 482-95.

K Katoh, K Misawa, K Kuma, T. M. (2002). MAFFT: a novel method for rapid multiple sequence alignment based on fast Fourier transform. Nucleic Acids Research, 30 (14), 3059-3066.

Kass, R. E., \& Raftery, A. E. (2007). Bayes Factors. Journal of the American Statistical Association, , 90(430), 773-795.

Katsuma, S., Fujii, T., Kawaoka, S., \& Shimada, T. (2008). Bombyx mori nucleopolyhedrovirus SNF2 global transactivator homologue ( Bm33) enhances viral pathogenicity in B . mori larvae. J Gen Virol, 89, 3039-3046. http://doi.org/10.1099/vir.0.2008/004887-0

Keddie, B. A., G. W. Aponte, and L. E. Volkman. 1989. The pathway of infection of Autographa californica nuclear polyhedrosis virus in an insect host. Science 243: (n.d.), (243).

Kelen EMA, Picarelli ZP, D. A. (1995). Hemorrhagic syndrome induced by contact with caterpillars of the genus Lonomia (Saturniidae, Hemileucinae). J. Toxic - Toxin Rev., (14), 283-308.

Kerfeld, C. a, \& Scott, K. M. (2011). Using BLAST to teach "E-value-tionary" concepts. PLoS Biology, 9(2), e1001014. http://doi.org/10.1371/journal.pbio.1001014

Kikhno, I., et al. (2002). Characterization of pif, a gene required for the per os infectivity of Spodoptera littoralis nucleopolyhedrovirus. J. Gen Virol., (83), 3013-3022.

King, L. A. \& Possee, R. D. (1992). The Baculovirus Expression Vector System: a Laboratory Guide. (C. \& Hall., Ed.). London. 
Kogan, P. H., Chen, X., \& Blissard, G. W. (1995). Overlapping TATA-Dependent and TATA-Independent Early Promoter Activities in the Baculovirus gp64 envelope fusion protein Gene. J Virol, 69(3), 1452-1461.

Kost, T. A., Condreay, J. P. , Jarvis, D. L. (2005). Baculovirus as versatile vectors for protein expression in insect and mammalian cells. Nat Biotechnol, 23, 567-575.

Kowacs, P.A., Cardoso, J., Entres, M., Novak, E.M., Werneck, L. C. (2006). Fatal intracerebral hemorrhage secondary to Lonomia obliqua caterpillar envenoming, a case report. Arq. Neuropsiquiatr, , (. 64), 1030-1032.

Krzywinski, M., Schein, J., Birol, I., Connors, J., Gascoyne, R., Horsman, D., ... Marra, M. A. (2009). Circos : An information aesthetic for comparative genomics Circos : An information aesthetic for comparative genomics. Genome Res., 19, 1639-1645. http://doi.org/10.1101/gr.092759.109

Kuzio, J., Pearson, M. N., Harwood, S. H., Funk, C. J., Evans, J. T., Slavicek, J. M., \& Rohrmann, G. F. (1999). Sequence and analysis of the genome of a baculovirus pathogenic for Lymantria dispar. Virology, 253(1), 17-34.

Lange, M., \& Jehle, J. a. (2003). The genome of the Cryptophlebia leucotreta granulovirus. Virology, 317(2), 220-236. http://doi.org/10.1016/S0042-6822(03)00515-4

Lee, K. P., Simpson, S. J., \& Raubenheimer, D. (2004). A comparison of nutrient regulation between solitarious and gregarious phases of the specialist caterpillar, Spodoptera exempta (Walker). Journal of Insect Physiology, 50(12), 1171-80. http://doi.org/10.1016/j.jinsphys.2004.10.009

Lemaire, C. (1972). Révision du genre Lonomia Walker (Lep. Attacidae). Annaes de La Societe Entomologique Du France (N.S.), 8(4), 767-861.

LEMAIRE, C. (2002). The Saturniidae of America - Hemileucinae. (p. 1388p). Keltern, Goecke \& Evers.

Lima, A. A., Aragão, C. W. S., de Castro, M. E. B., Oliveira, J. V. D. C., Sosa Gómez, D. R., \& Ribeiro, B. M. (2013). A recombinant Anticarsia gemmatalis MNPV harboring chiA and v-cath genes from Choristoneura fumiferana defective NPV induce host liquefaction and increased insecticidal activity. PloS One, 8(9), e74592. http://doi.org/10.1371/journal.pone.0074592

Liu, M., Xie, Z., \& Price, D. H. (1998). A Human RNA Polymerase II Transcription Termination Factor Is a SWI2/SNF2 Family Member. Journal of Biological Chemistry, 273(40), 25541-25544. http://doi.org/10.1074/jbc.273.40.25541

Lodish HF. (2000). Molecular cell biology (4th ed.). New York: W.H. Freeman. 
Lorini, L. (1999). A taturana - Aspectos Biológicos e Morfológicos da Lonomia obliqua. EDIUPF - Passo Fundo- RS.

LORINI, L. M. (2005). Criação, Comportamento Sexual e Inimigos Naturais de Lonomia obliqua Walker, 1855 (Lepidoptera: Saturnidae). Universidade Federal do Paraná.

Lorini, L. M., Zarbin, P. H. G., \& Tedesco, C. D. (2007). Biology of Laboratory-Reared Lonomia Obliqua (Lepidoptera: Saturniidae). Florida Entomologist, 90(4), 770-771. http://doi.org/10.1653/0015-4040(2007)90[770:BOLLOL]2.0.CO;2

Lu, A., Miller, L. K. (1997). Regulation of baculovirus late and very late gene expression. In L. K. Miller (Ed.), In The Baculoviruses (pp. 193-216). New York: Plenum.

Luque, T., Finch, R., Crook, N., O’Reilly, D. R., \& Winstanley, D. (2001). The complete sequence of the Cydia pomonella granulovirus genome. The Journal of General Virology, 82(Pt 10), 2531-2547.

Mäkelä, A. R., Matilainen, H., White, D. J., Ruoslahti, E., \& Oker-Blom, C. (2006). Enhanced baculovirus-mediated transduction of human cancer cells by tumor-homing peptides. Journal of Virology, 80(13), 6603-11. http://doi.org/10.1128/JVI.00528-06

Mclysaght, A., Baldi, P. F., \& Gaut, B. S. (2003). Extensive gene gain associated with adaptive evolution of poxviruses. PNAS, 100(26).

Miller, L.K., Lingg, A.J., Bulla, L. A. J. (1983). Bacterial viral and fungal insecticides. Science, (219), $715-721$.

Mitchell, D. (2007). GC content and genome length in Chargaff compliant genomes. Biochemical and Biophysical Research Communications, 353(1), 207-10. http://doi.org/10.1016/j.bbrc.2006.12.008

Moraes, R. (2003). Lepidópteros de Importância Médica. In Animais Peçonhentos (pp. 211-219). São Paulo: Savier/FAPESP.

Moraes, R. H. P. (2002). Identificação dos Inimigos Naturais de Lonomia obliqua Walker, 1855 (Lepidóptera: Saturniidae) e possíveis fatos determinantes do aumento de sua população. Escola Superior “Luiz Queiroz Filho"- ESALQ.

Moreira, C., \& Moresco, I. (2007). Ocorrência de acidentes provocados por Lonomia obliqua Walker, no Estado do Paraná , no período de 1989 a 2001 Occurrence of accidents caused by Lonomia obliqua Walker, in the State of Paraná between 1989 and 2001. Sociedade Brasileira de Medicina Tropical, 40(2), 242-246.

Moscardi, F. (1999a). Assessment of the application of baculoviruses for control of lepidoptera. Апnи Rev Entomo, (44), 257-289. 
Moscardi, F. (1999b). Assessment of the application of baculoviruses for control of lepidoptera. Annu Rev Entomol, 44, 257-289.

Nickel, G. C., Tefft, D. L., Goglin, K., \& Adams, M. D. (2008). An empirical test for branch-specific positive selection. Genetics, 179(4), 2183-93.

http://doi.org/10.1534/genetics.108.090548

Nie, Z.-M., Zhang, Z.-F., Wang, D., He, P.-A., Jiang, C.-Y., Song, L., ... Zhang, Y.-Z. (2007). Complete sequence and organization of Antheraea pernyi nucleopolyhedrovirus, a dr-rich baculovirus. BMC Genomics, 8, 248. http://doi.org/10.1186/1471-2164-8-248

Notredame, C., Higgins, D. G., \& Heringa, J. (2000). T-Coffee: A novel method for fast and accurate multiple sequence alignment. Journal of Molecular Biology, 302(1), 205-17. http://doi.org/10.1006/jmbi.2000.4042

O’Reilly D, Miller LK, L. V. (1992). Baculovirus Expression Vectors: a laboratory manual. (F. and Company., Ed.) (p. 347 p.). New York.

Oliveira, J. V. D. C., Wolff, J. L. C., Garcia-Maruniak, A., Ribeiro, B. M., de Castro, M. E. B., de Souza, M. L., ... Zanotto, P. M. D. A. (2006). Genome of the most widely used viral biopesticide: Anticarsia gemmatalis multiple nucleopolyhedrovirus. The Journal of General Virology, 87(Pt 11), 3233-50. http://doi.org/10.1099/vir.0.82161-0

Oliver, J. L., \& Marín, A. (1996). A Relationship Between GC Content and CodingSequence Length. Journal of Molecular Evolution, 216-223.

Paillot, A. (1926). Sur une nouvelle maladie du noyau au grasserie des chenilles de P. brassicae et un nouveau groupe de microoganismes parasites. Compt. Rend, (182), $180-2$.

Pang, Y., Yu, J., Wang, L., Hu, X., Bao, W., Li, G., ... Yang, H. (2001). Sequence analysis of the Spodoptera litura multicapsid nucleopolyhedrovirus genome. Virology, 287(2), 391-404. http://doi.org/10.1006/viro.2001.1056

Pearson, M. N. and G. F. R. (2002). Transfer, incorporation, and substitution of envelope fusion proteins among members of the Baculoviridae, Orthomyxoviridae, and Metaviridae (insect retrovirus) families. J. Virol., (76), 5301-5304.

Pearson, M. N., \& Rohrmann, G. F. (1995). Lymantria dispar nuclear polyhedrosis virus homologous regions : characterization of their ability to function as replication origins . Lymantria dispar Nuclear Polyhedrosis Virus Homologous Regions : Characterization of Their Ability To Function as Repli. J Virol, 69(1).

PESCE, H, DELGADO, A. (1971). Poisoning from adult moths and caterpillars. In Venomous Animals and their Venoms. (p. 3: 120-156). New York: Academic Press. 
Pinto, A.F.M., Berger, M., Reck- Jr., J., Terra, R.M., Guimarães, J. A. (2010). Lonomia obliqua venom: In vivo effects and molecular aspects associated with the hemorrhagic syndrom. Toxicon, 56(7), 1103-1112.

Pinto, A.F.M., Dobrovolski, R., Veiga, A.B.G., Guimara es, J. A. (2004). Lono-fibrase, a novel a-fibrinogenase from Lonomia obliqua caterpillars. Thromb. Res., (113,), 147154.

Podgwaite, J. D. (1981). Natural disease within dense gypsy moth populations, in The Gypsy Moth: Research Towards Integrated Pest Management D.C. (C. C. D. and M. L. McManus, Ed.). Washington: U.S. Dept. of Agriculture.

Posada, D. (2003). jModelTest : Phylogenetic Model Averaging. Mol. Biol. Evol., 20012004. http://doi.org/10.1093/molbev/msn083

Price, M. N., Dehal, P. S., \& Arkin, A. P. (2009). FastTree: computing large minimum evolution trees with profiles instead of a distance matrix. Molecular Biology and Evolution, 26(7), 1641-50. http://doi.org/10.1093/molbev/msp077

Pullen, S. S., \& Friesen, P. D. (1995). The CAGT Motif Functions as an Initiator Element during Early Transcription of the Baculovirus Transregulator ie-1, 69(6), 3575-3583.

Qian, H., Zhang, Y., Wu, Y., Sun, P., Zhu, S., Guo, X., ... Wang, W. (2013). Analysis of the genomic sequence of Philosamia cynthia nucleopolyhedrin virus and comparison with Antheraea pernyi nucleopolyhedrin virus. BMC Genomics, 14(1), 115. http://doi.org/10.1186/1471-2164-14-115

Rambaut, A. (n.d.). FigTree. Retrieved from http://tree.bio.ed.ac.uk/software/figtree/

Reeson, A. F. (2001). Melanism and disease resistance in insects, 637-649.

Rice, C., \& Miller, L. K. (1986). Baculovirus transcription in the presence of inhibitors and in nonpermissive Drosophila cells *. Virus Res., 6, 155-172.

Robert, X., \& Gouet, P. (2014). Deciphering key features in protein structures with the new ENDscript server. Nucleic Acids Research, 42(Web Server issue), W320-4. http://doi.org/10.1093/nar/gku316

Rodems, S. M., \& Friesen, P. D. (1995). Transcriptional Enhancer Activity of hr 5 Requires Dual- Palindrome Half Sites That Mediate Binding of a Dimeric Form of the Baculovirus Transregulator IE1, 69(9), 5368-5375.

Rohrmann, G. F. (2014). Baculovirus nucleocapsid aggregation (MNPV vs SNPV): an evolutionary strategy, or a product of replication conditions? Virus Genes, 49(3), 3517. http://doi.org/10.1007/s11262-014-1113-5 
Rohrmann GF. (2013). Baculovirus Molecular Biology (Third Edit). Bethesda (MD): National Library of Medicine (US), National Center for Biotechnology Information. Retrieved from http://www.ncbi.nlm.nih.gov/books/NBK49500

Romanowski V., Matsuura Y., B. D. H. L. (1985). Complete sequence of the S RNA of lymphocytic choriomeningitis virus (WE strain) compared to that of Pichinde arenavirus. Virus Res., 1, 101-114.

Ronquist, F., Teslenko, M., van der Mark, P., Ayres, D. L., Darling, A., Höhna, S., ... Huelsenbeck, J. P. (2012). MrBayes 3.2: efficient Bayesian phylogenetic inference and model choice across a large model space. Systematic Biology, 61(3), 539-42. http://doi.org/10.1093/sysbio/sys029

Rubio, G. B. G. (2001). Vigilância epidemiológica da distribuição da lagarta Lonomia obliqua Walker, 1855, no Estado do Paraná, Brasil. Cad Saúde Pública., 17(4), 1036.

Sambrook J, F. E. and M. T. (1989). Molecular cloning: a laboratory manual. New York: Cold Spring Harbor Laboratory Press.

Saúde, O. P.-A. da, \& Brasil, R. no. (1996). MANUAL DE VIGILÂNCIA DA SAÚDE DE POPULAÇÕES EXPOSTAS A AGROTOXICOS.

Seibert, C.S., Tanaka-Azevedo, A.M., Santoro, M.L., Mackessy, S. P., \& Torquato, R.J.S., Lebrun, I., Tanaka, A.S., Sano-Martins, I. S. (2006). Purification of a phospholipase A2 from Lonomia obliqua caterpillar bristle extract. Biochem. Biophys. Res. Commun, (342), 1027-1033.

Shimodaira, H., \& Hasegawa, M. (1989). Multiple Comparisons of Log-Likelihoods with Applications to Phylogenetic Inference. Molecular Biology and Evolution, 1114-1116.

Silva, D. D. A., Claudia, A. N. A., Goncalves, L. R. C., Sousa-e-silva, M. C. C., \& Higashi, H. G. (1996). DEVELOPMENT OF AN ANTIVENOM AGAINST TOXINS OF LONOMIA OBLIQUA CATERPILLARS, 34(9), 1045-1049.

Silva, F. W. S., Viol, D. L., Faria, S. V, Lima, E., Valicente, F. H., \& Elliot, S. L. (2013). Two's a crowd: phenotypic adjustments and prophylaxis in Anticarsia gemmatalis larvae are triggered by the presence of conspecifics. PloS One, 8(4), e61582. http://doi.org/10.1371/journal.pone.0061582

Spriggs, M. . (1996). One step ahead of the game: viral immuno-modulatory molecules. Annu. Reg. Immunol., (14), 101-130.

Stacy, E. W. . (1962). A generalization of the Gamma Distribution. The Annals of Mathematical Statistics, 33(3), 1187-1192. Retrieved from http://scholar.google.com/scholar?hl=en\&btnG=Search\&q=intitle:No+Title\#0 
Stamatakis, A. (2006). RAxML-VI-HPC: maximum likelihood-based phylogenetic analyses with thousands of taxa and mixed models. Bioinformatics (Oxford, England), 22(21), 2688-90. http://doi.org/10.1093/bioinformatics/btl446

STEHR, F. (1987). Order Lepidoptera. In Immature Insects (pp. 288 - 596). Dubuque, Yowa: Kendal/Hunt.

Suzuki, Y., \& Gojobori, T. (1999). A method for detecting positive selection at single amino acid sites. Molecular Biology and Evolution, 16(10), 1315-28. Retrieved from http://www.ncbi.nlm.nih.gov/pubmed/10563013

Tavare' S. (1986). Some probabilistic and statistical problems in the analysis of DNA sequences. In M. RM (Ed.), Some mathematical questions in biology —DNA sequence analysis. (pp. 57-86). Providence (RI): American Mathematical Society.

Terra, W. R., and Ferreira, C. (1994). Insect digestive enzymes: Properties, compartmentalization and function. Com. Biochem. Physiol, (109), 1-62.

Thézé, J., Bézier, A., Periquet, G., Drezen, J.-M., \& Herniou, E. a. (2011). Paleozoic origin of insect large dsDNA viruses. Proceedings of the National Academy of Sciences of the United States of America, 108(38), 15931-5. http://doi.org/10.1073/pnas.1105580108

Toxicológicas, C. de I. (1999). Manual de diagnóstico e tratamento de acidentes por Lonomia .ed.rev.Centro de Informação Toxicológica. Manual de Diagnóstico e Tratamento de Acidentes por .ed.rev.(org.HudsonBarretoAbella,etall)PortoAlegre, 1999,20p. 1. Lagarta urticante.2. .3.Animais Peç. ( et all HudsonBarretoAbella, Ed.) (ed.rev.). PortoAlegre.

Vago, C., et al. (1974). Present status of the nomenclature and classification of invertebrate viruses. J Invertebr Pathol, 23(2), 133-4.

Van Oers, M.M., Flipsen, J.T.M., Reusken, C.B.E.M., V., \& J.M. (1994). Specificity of baculovirus p10 functions. Virology, (200), $513-23$.

Veiga, A. B. G., Pinto, A. F. ., \& Guimarães, J. a. (2003). Fibrinogenolytic and procoagulant activities in the hemorrhagic syndrome caused by Lonomia obliqua caterpillars. Thrombosis Research, 111(1-2), 95-101. http://doi.org/10.1016/j.thromres.2003.08.020

Veiga, A.B.G., Blochtein, B., Guimara es, J. A. (2001). Structures involved production, secretion and injection of the venom produced by the caterpillar Lonomia obliqua (Lepidoptera, saturniidae). Toxicon, 39, 1343-1351. 
Vulinec, K. (1990). Collective security: aggregation by insects as a defense. In J. . Evans, D.L., Schmidt (Ed.), Insect Defenses - Adaptive Mechanisms and Strategies of Prey and Predators. (pp. 251-288). New York: State University of New York.

Wang, P., and Granados, R. R. (1997). An intestinal mucin is the target substrate for a baculovirus enhancin. Proc. Natl. Acad. Sci. USA, 94(13), 6977-6982.

WIKIMEDIA COMMONS. In: WIKIPÉDIA, a enciclopédia livre. Flórida: Wikimedia Foundation, 2015. Disponível em: <http://commons.wikimedia.org/wiki/File:Lonomia-obliqua-citsc-1.jpg>. Acesso em: 28 fev. 2015. (n.d.).

Wilson, E. O. (2003). Biodiversity. Washington: National Academy Press.

Wolff, J. L. C., Moraes, R. H. P., Kitajima, E., de Souza Leal, E., \& de A Zanotto, P. M. (2002). Identification and characterization of a baculovirus from Lonomia obliqua (Lepidoptera: Saturniidae). Journal of Invertebrate Pathology, 79(3), 137-45. Retrieved from http://www.ncbi.nlm.nih.gov/pubmed/12133702

Xeros, N. (1952). Cytoplasmic polyhedral virus diseases. Nature, (170), 1073.

Xie, Z., \& Price, D. (1997). Drosophila Factor 2, an RNA Polymerase II Transcript Release Factor, Has DNA-dependent ATPase Activity. Journal of Biological Chemistry, 272(50), 31902-31907. http://doi.org/10.1074/jbc.272.50.31902

Yang, C. L., Stetler, D. A., \& Weaver, R. F. (1991). Structural comparison of the Autographa californica nuclear polyhedrosis virus-induced RNA polymerase and the three nuclear RNA polymerases from the host, Spodoptera fiugiperda. Virus Research, , 20, 251-264.

Yuan, M., et al. (2011). Identification of Autographa californica nucleopolyhedrovirus ac93 as a core gene and its requirement for intranuclear microvesicle formation and nuclear egress of nucleocapsids. J Virol, 85(22), 11664-74.

Zannin, M., Lourenço, D.M., Motta, G., Costa, L.R.D., Grando, M., Gamborgi, G., \& P., Noguti, M.A., Chudzinski-Tavassi, A. M. (2003). Blood coagulation and fibrinolytic factors in 105 patients with hemorrhagic syndrome caused by accidental contact with Lonomia obliqua caterpillar in Santa Catarina, Southern Brazil. Thromb. Haemost., $89,355-364$.

Zingemagel, R. M., White, J., Roberts, J. L., Sharrow, S., Med, J. E., Murphy, K. M., ... Schmidt, O. (1990). Hemolin : An Insect-Immune Protein Belonging to the Immunoglobulin Superfamily, 174(1988).

Zvelebil, M., Baum, J. O. (2008). Understanding bioinformatics. (D. Holdsworth, Ed.). Garland Science, Taylor \& Francis Group, LLC. 


\section{ANEXOS}

Anexo 1. Baculovírus utilizados na construção da árvore filogenética referente a família Baculoviridae.

\begin{tabular}{|c|c|c|c|}
\hline Nome do vírus & Nome da sequencia & $\begin{array}{c}\text { Tamanho } \\
\text { do } \\
\text { genoma } \\
\text { (pb) }\end{array}$ & $\begin{array}{l}\text { Número } \\
\text { de acesso }\end{array}$ \\
\hline Adoxophyes honmai nucleopolyhedrovirus & AdhoNPV & 113220 & AP006270 \\
\hline Adoxophyes orana granulovirus & AdorGV & 99657 & AF547984 \\
\hline Adoxophyes orana nucleopolyhedrovirus & AdorNPV & 111724 & EU591746 \\
\hline Agrotis ipsilon multiple nucleopolyhedrovirus & AgipMNPV_Strain_Illinois & 155122 & EU839994 \\
\hline Agrotis segetum granulovirus & AgseGV & 131680 & AY522332 \\
\hline Agrotis segetum nucleopolyhedrovirus & AsNPV & 147544 & DQ123841 \\
\hline Antheraea pernyi nucleopolyhedrovirus & AnpeMNPV & 126629 & DQ486030 \\
\hline Anticarsia gemmatalis nucleopolyhedrovirus & AgMNPV & 132239 & DQ813662 \\
\hline Apocheima cinerarium nucleopolyhedrovirus & ApciNPV & 123876 & FJ914221 \\
\hline Autographa californica nucleopolyhedrovirus & AcMNPV & 133894 & L22858 \\
\hline Bombyx mandarina nucleopolyhedrovirus & BomaNPV-S1 & 126770 & FJ882854 \\
\hline Bombyx mori nucleopolyhedrovirus & BmNPV-C1 & 127901 & KF306215 \\
\hline Buzura suppressaria nucleopolyhedrovirus & BusuNPV & 120420 & KF611977 \\
\hline Choristoneura fumiferana multiple nucleopolyhedrovirus & CfDEFNPV & 131160 & AY327402 \\
\hline Choristoneura fumiferana multiple nucleopolyhedrovirus & CfMNPV & 129593 & AF512031 \\
\hline Choristoneura murinana $M N P V$ & ChmuMNPV & 124688 & KF894742 \\
\hline Choristoneura occidentalis granulovirus & ChocGV & 104710 & DQ333351 \\
\hline Choristoneura occidentalis nucleopolyhedrovirus & ChocNPV & 128446 & КC961303 \\
\hline Choristoneura rosaceana alphabaculovirus & ChroNPV & 129052 & KC961304 \\
\hline Chrysodeixis chalcites nucleopolyhedrovirus & ChchNPV & 149622 & AY864330 \\
\hline Clanis bilineata nucleopolyhedrovirus & ClbiNPV_IDZ1 & 135454 & DQ504428 \\
\hline Clostera anachoreta granulovirus & ClanGV-HBHN & 101487 & HQ116624 \\
\hline
\end{tabular}




\begin{tabular}{|c|c|c|c|}
\hline Nome do vírus & Nome da sequencia & $\begin{array}{l}\text { Tamanho } \\
\text { do } \\
\text { genoma } \\
\text { (pb) }\end{array}$ & $\begin{array}{c}\text { Número } \\
\text { de acesso }\end{array}$ \\
\hline Condylorrhiza vestigialis multiplenucleopolyhedrovirus & CoveMNPV & 125767 & EU919397 \\
\hline Cryptophlebia leucotreta granulovirus & CrleGV_CV3 & 110907 & AY229987 \\
\hline Culex nigripalpus nucleopolyhedrovirus & CuniNPV & 108252 & AF403738 \\
\hline Cydia pomonella granulovirus & $\mathrm{CpGV}$ & 123500 & U53466 \\
\hline Dendrolimus kikuchii nucleopolyhedrovirus & DekiNPV_YN & 141454 & JX193905 \\
\hline Diatraea saccharalis granulovirus & DisaGV & & \\
\hline Ectropis obliqua nucleopolyhedrovirus & EcobNPV_Strain_A1 & 131204 & DQ837165 \\
\hline Epinotia aporema granulovirus & EpapGV & 119082 & JN408834 \\
\hline Epiphyas postvittana nucleopolyhedrovirus & EppoMNPV & 118584 & AY043265 \\
\hline Erinnyis ello granulovirus & EeGV & 119082 & KJ406702 \\
\hline Euproctis pseudoconspersa nucleopolyhedrovirus & EupsNPV_Strain_Hangzhou & 141291 & FJ227128 \\
\hline Helicoverpa armigera granulovirus & $\mathrm{HaGV}$ & 169794 & EU255577 \\
\hline Helicoverpa armigeranucleopolyhedrovirus & HaNPV_G4 & 130759 & AF271059 \\
\hline Helicoverpa armigera multiple nucleopolyhedrovirus & HaMNPV & 154196 & EU730893 \\
\hline Helicoverpa zea single nucleopolyhedrovirus & HzSNPV & 130869 & AF334030 \\
\hline Hemileuca sp. Nucleopolyhedrovirus & HespNPV & 140633 & KF158713 \\
\hline Hyphantria cunea nucleopolyhedrovirus & HycuNPV & 132959 & AP009046 \\
\hline Leucania separata nucleopolyhedrovirus & LeseNPV_Strain_AH1 & 168041 & AY394490 \\
\hline Lonomia obliqua multiple nucleopolyhedrovirus & LoobMNPV & 120023 & KP763670 \\
\hline Lymantria dispar multiple nucleopolyhedrovirus & LdMNPV & 161046 & AF081810 \\
\hline Lymantria xylina multiple nucleopolyhedrovirus & LyxyMNPV-5 & 156344 & GQ202541 \\
\hline Mamestra brassicae multiple nucleopolyhedrovirus & MabrMNPV_K1 & 152710 & JQ798165 \\
\hline Mamestra configurata nucleopolyhedrovirus & MacoNPV-A_90/2 & 155060 & U59461 \\
\hline
\end{tabular}




\begin{tabular}{|c|c|c|c|}
\hline Nome do vírus & Nome da sequencia & $\begin{array}{c}\text { Tamanho } \\
\text { do } \\
\text { genoma } \\
\text { (pb) }\end{array}$ & $\begin{array}{c}\text { Número } \\
\text { de acesso }\end{array}$ \\
\hline Neodiprion abietis nucleoplyhedrovirus & NeabNPV & 84264 & DQ317692 \\
\hline Neodiprion lecontei nucleopolyhedrovirus & NeleNPV & 81755 & AY349019 \\
\hline Neodiprion sertifer nucleopolyhedrovirus & NeseNPV & 86462 & AY430810 \\
\hline Orgyia leucostigma nucleopolyhedrovirus & OrleNPV_I_CFS-77 & 156179 & EU309041 \\
\hline Orgyia pseudotsugata multiple nucleopolyhedrovirus & OpMNPV & 131995 & U75930 \\
\hline Philosamia cynthia ricini nucleopolyhedrovirus virus & PhcyNPV & 125376 & JX404026 \\
\hline Phthorimaea operculella granulovirus & PoGV & 119217 & AF499596 \\
\hline Pieris rapae granulovirus & PrGV & 108592 & GQ884143 \\
\hline Plutella xylostella granulovirus & PlxyGV & 100999 & AF270937 \\
\hline Plutella xylostella multiple nucleopolyhedrovirus & PlxyMNPV_CL3 & 134417 & DQ457003 \\
\hline Pseudaletia unipuncta granulovirus & PsunGV_Stain_Hawaiin & 176677 & EU678671 \\
\hline Pseudoplusia includens single nucleopolyhedrovirus & PsinSNPV-IE & 139132 & KC136318 \\
\hline Rachiplusia oи multiple nucleopolyhedrovirus & RoMNPV & 131526 & AY145471 \\
\hline Spodoptera exigua multiple nucleopolyhedrovirus & SeMNPV & 135611 & AF169823 \\
\hline Spodoptera frugiperda multiple nucleopolyhedrovirus & SfMNPV_I_3AP2 & 131331 & EF035042 \\
\hline Spodoptera littoralis nucleopolyhedrovirus & SIMNPV_AN1956 & 137998 & JX454574 \\
\hline Spodoptera litura granulovirus & SpliGV_SLGV-K1 & 124121 & DQ288858 \\
\hline Spodoptera litura nucleopolyhedrovirus & SINPV_II & 148634 & EU780426 \\
\hline Spodoptera litura nucleopolyhedrovirus & SpliNPV_G2 & 139342 & AF325155 \\
\hline Sucra jujuba nucleopolyhedrovirus & SujuNPV & 135952 & KJ676450 \\
\hline Thysanoplusia orichalcea nucleopolyhedrovirus & ThorMNPV & 132978 & JX467702 \\
\hline Trichoplusia ni single nucleopolyhedrovirus & TnNPV & 134394 & DQ017380 \\
\hline Xestia c-nigrum granulovirus & $\mathrm{XcGV}$ & 178733 & AF162221 \\
\hline
\end{tabular}


Anexo 2. Conjunto de sequências utilizado para a geração da árvore filogenética contendo os genes GTA, TTF2 e LoobNPVOrf-35.

\begin{tabular}{|c|c|c|c|}
\hline Nome da sequencia & Gene & Organismo & $\begin{array}{l}\text { Tamanho } \\
\text { (aa) }\end{array}$ \\
\hline TTF2 Odobenus r. & $\begin{array}{l}\text { Fator de terminação de } \\
\text { transcriçąão } 2\end{array}$ & Odobenus rosmarus divergens & 280 \\
\hline & $\begin{array}{l}\text { Fator de terminação de } \\
\text { transcrição } 2\end{array}$ & & \\
\hline TTF2_Condylura c. & Fator de terminação de & Condylura cristata & $2 / 7$ \\
\hline TTF2_Chinchilla 1. & & Chinchilla lanigera & 277 \\
\hline TTF2_Ailuropoda m. & $\begin{array}{l}\text { Fator de terminação de } \\
\text { transcrição } 2\end{array}$ & Ailuropoda melanoleuca & 280 \\
\hline TTF2 Vicugna $p$. & $\begin{array}{l}\text { Fator de terminação de } \\
\text { transcrição } 2\end{array}$ & Vicugna pacos & 259 \\
\hline TTF2 Tursiops t. & $\begin{array}{l}\text { Fator de terminação de } \\
\text { transcrição } 2\end{array}$ & Tursiops truncatus & 278 \\
\hline TTF2 Trichechus m. & $\begin{array}{l}\text { Fator de terminação de } \\
\text { transcrição } 2\end{array}$ & Trichechus manatus latirostris & 275 \\
\hline TTF2 Takifuour $r$ & $\begin{array}{l}\text { Fator de terminação de } \\
\text { transcrição } 2\end{array}$ & Takifuou rubrines & 269 \\
\hline TTF2 Sus s & $\begin{array}{l}\text { Fator de terminação de } \\
\text { transcrição } 2\end{array}$ & 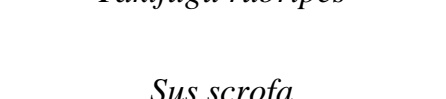 & 278 \\
\hline 1112 _ous s. & $\begin{array}{l}\text { Fator de terminação de } \\
\text { transcrição } 2\end{array}$ & & \\
\hline TTF2 Sarconbilus $h$ & $\begin{array}{l}\text { Fator de terminação de } \\
\text { transcrição } 2\end{array}$ & Sorex araneus & 278 \\
\hline TTF2_Sarcophilus h. & $\begin{array}{l}\text { Fator de terminação de } \\
\text { transcrição } 2\end{array}$ & Sarcophilus harrisii & 277 \\
\hline TTF2_Saimiri b. & $\begin{array}{l}\text { Fator de terminação de } \\
\text { transcrição } 2\end{array}$ & Saimiri boliviensis & 278 \\
\hline TTF2_Rattus n. & $\begin{array}{c}\operatorname{transcrição~} 2 \\
\text { Fator de terminação de } \\
\text { transcricão } 2\end{array}$ & Rattus norvegicus & 278 \\
\hline TTF2_Pteropus a. & $\begin{array}{l}\operatorname{transcrição~} 2 \\
\text { Fator de terminação de }\end{array}$ & Pteropus alecto & 278 \\
\hline TTF2_Pongo a. & $\begin{array}{c}\text { transcrição } 2 \\
\text { Fator de terminação de }\end{array}$ & Pongo abelii & 278 \\
\hline TTF2_Papio a. & $\begin{array}{l}\text { transcrição } 2 \\
\text { Fator de terminação de }\end{array}$ & Papio anubis & 278 \\
\hline TTF2_Pantholops h. & $\begin{array}{l}\text { transcrição } 2 \\
\text { Fator de terminação de }\end{array}$ & Pantholops hodgsonii & 275 \\
\hline TTF2_Pan t. & $\begin{array}{l}\text { transcrição } 2 \\
\text { Fator de terminação de }\end{array}$ & Pan troglodytes & 278 \\
\hline TTF2_Pan p. & $\begin{array}{c}\text { transcrição } 2 \\
\text { Fator de terminação de }\end{array}$ & Pan paniscus & 278 \\
\hline TTF2_Otolemur g. & transcrição 2 & Otolemur garnettii & 278 \\
\hline
\end{tabular}




\begin{tabular}{|c|c|c|c|}
\hline Nome da sequencia & Gene & Organismo & $\begin{array}{l}\text { Tamanho } \\
\text { (aa) }\end{array}$ \\
\hline & $\begin{array}{l}\text { Fator de terminação de } \\
\text { transcrição } 2\end{array}$ & & \\
\hline TTF2_Orcinus o. & & Orcinus orca & 278 \\
\hline TTF2_Octodon d. & $\begin{array}{l}\text { Fator de terminação de } \\
\text { transcrição } 2\end{array}$ & Octodon degus & 277 \\
\hline TTF2 Ochotona $\mathrm{p}$. & $\begin{array}{l}\text { Fator de terminação de } \\
\text { transcrição } 2\end{array}$ & Ochotona princeps & 278 \\
\hline TTF2 Nomascus 1. & $\begin{array}{l}\text { Fator de terminação de } \\
\text { transcrição } 2\end{array}$ & Nomascus leucogenys & 278 \\
\hline TTF2 Nasonia v. & $\begin{array}{l}\text { Fator de terminação de } \\
\text { transcrição } 2\end{array}$ & Nasonia vitripennis & 264 \\
\hline TTF2_Myotis 1. & $\begin{array}{l}\text { Fator de terminação de } \\
\text { transcrição } 2\end{array}$ & Myotis lucifugus & 278 \\
\hline TTF2_Myotis d. & $\begin{array}{l}\text { Fator de terminação de } \\
\text { transcrição } 2\end{array}$ & Myotis davidii & 278 \\
\hline TTF2 Myotis b. & $\begin{array}{l}\text { Fator de terminação de } \\
\text { transcrição } 2\end{array}$ & Myotis brandtii & 278 \\
\hline TTF2 Mustela p. & $\begin{array}{l}\text { Fator de terminação de } \\
\text { transcrição } 2\end{array}$ & Mustela putorius furo & 280 \\
\hline TTF2_Musca d. & $\begin{array}{l}\text { Fator de terminação de } \\
\text { transcrição } 2\end{array}$ & Musca domestica & 270 \\
\hline TTF2_Monodelphis d. & $\begin{array}{l}\text { Fator de terminação de } \\
\text { transcrição } 2\end{array}$ & Monodelphis domestica & 277 \\
\hline TTF2 Microtus o. & $\begin{array}{l}\text { Fator de terminação de } \\
\text { transcrição } 2\end{array}$ & Microtus ochrogaster & 278 \\
\hline 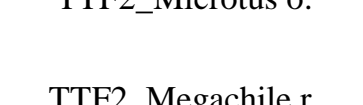 & $\begin{array}{l}\text { Fator de terminação de } \\
\text { transcrição } 2\end{array}$ & Matrotus ochogaster & 258 \\
\hline 1TF2_Megachile r. & $\begin{array}{l}\text { Fator de terminação de } \\
\text { transcrição } 2\end{array}$ & Megachile rotundata & 258 \\
\hline 11F__Macaca m. & $\begin{array}{l}\text { Fator de terminação de } \\
\text { transcrição } 2\end{array}$ & Macaca mulatta & $2 / 8$ \\
\hline TTF2_Macaca f. & $\begin{array}{l}\text { Fator de terminação de } \\
\text { transcrição } 2\end{array}$ & Macaca fascicularis & 278 \\
\hline TTF2_Jaculus j. & $\begin{array}{l}\text { Fator de terminação de } \\
\text { transcricão } 2\end{array}$ & Jaculus & 279 \\
\hline TTF2_Homo s. & Fator de terminação de & Homo sapiens & 278 \\
\hline TTF2_Heterocephalus g. & $\begin{array}{c}\text { transcrição } 2 \\
\text { Fator de terminação de }\end{array}$ & PHeterocephalus glaber & 277 \\
\hline TTF2_Gorilla g. & $\begin{array}{l}\text { transcrição } 2 \\
\text { Fator de terminação de }\end{array}$ & Gorilla & 278 \\
\hline TTF2_Echinops t. & & Echinops telfairi & 277 \\
\hline
\end{tabular}


Fator de terminação de

TTF2_Dasypus n. transcrição 2

Dasypus novemcinctus

277

\begin{tabular}{|c|c|c|c|}
\hline Nome da sequencia & Gene & Organismo & $\begin{array}{c}\text { Tamanho } \\
\text { (aa) }\end{array}$ \\
\hline TTF2_Danio r. & $\begin{array}{l}\text { Fator de terminação de } \\
\text { transcriçãa } 2\end{array}$ & Danio rerio & 272 \\
\hline TTF2 Danaus n & $\begin{array}{l}\text { Fator de terminação de } \\
\text { transcrição } 2\end{array}$ & Danaus nlexinnus & 255 \\
\hline 1112__Lantaus p. & $\begin{array}{l}\text { Fator de terminação de } \\
\text { transcrição } 2\end{array}$ & Culex auinauefasciatus & 269 \\
\hline TTF2 Chrvsemys n & $\begin{array}{l}\text { Fator de terminação de } \\
\text { transcrição } 2\end{array}$ & culex quinquefasciatus & 269 \\
\hline 11F2_Chrysemys p. & $\begin{array}{l}\text { Fator de terminação de } \\
\text { transcrição } 2\end{array}$ & Chrysemys picta bellul & 280 \\
\hline TTF2_Chelonia m. & Fator de terminação de & Chelonia mydas & 280 \\
\hline TTF2_Ceratotherium s. & $\begin{array}{l}\text { transcrição } 2 \\
\text { Fator de terminação de }\end{array}$ & Ceratotherium simum & 238 \\
\hline TTF2_Ceratitis c. & $\begin{array}{l}\text { transcrição } 2 \\
\text { Fator de terminação de }\end{array}$ & Ceratitis capitata & 266 \\
\hline TTF2_Cavia p. & $\begin{array}{l}\text { transcrição } 2 \\
\text { Fator de terminação de }\end{array}$ & Cavia porcellus & 277 \\
\hline TTF2_Capra h. & Fator de terminação de & Capra hircus & 275 \\
\hline TTF2_Canis 1. & $\begin{array}{l}\text { transcrição } 2 \\
\text { Fator de terminação de }\end{array}$ & Canis lupus familiaris & 278 \\
\hline TTF2_Camelus f. & $\begin{array}{c}\text { transcriçãao } 2 \\
\text { Fator de terminação de }\end{array}$ & Camelus ferus & 278 \\
\hline TTF2_Callithrix j. & $\begin{array}{l}\text { transcrição } 2 \\
\text { Fator de terminação de }\end{array}$ & Callithrix jacchus & 278 \\
\hline TTF2_Bos t. & $\begin{array}{l}\text { transcrição } 2 \\
\text { Fator de terminação de }\end{array}$ & Bos taurus & 275 \\
\hline TTF2_Bombyx m. & $\begin{array}{l}\text { transcrição } 2 \\
\text { Fator de terminação de }\end{array}$ & Bombyx mori & 254 \\
\hline TTF2_Bombus t. & $\begin{array}{l}\text { transcrição } 2 \\
\text { Fator de terminação de }\end{array}$ & Bombus terrestris & 259 \\
\hline TTF2_Bombus i. & $\begin{array}{l}\operatorname{transcriçao~} 2 \\
\text { Fator de terminação de }\end{array}$ & Bombus impatiens & 259 \\
\hline TTF2_Apis m. & $\begin{array}{l}\text { transcrição } 2 \\
\text { Fator de terminação de }\end{array}$ & Apis mellifera & 261 \\
\hline TTF2_Apis d. & $\begin{array}{l}\text { transcrição } 2 \\
\text { Fator de terminação de }\end{array}$ & Apis dorsata & 260 \\
\hline TTF2_Alligator s. & $\begin{array}{l}\text { transcrição } 2 \\
\text { Fator de terminação de }\end{array}$ & Alligator sinensis & 280 \\
\hline TTF2_Aliigator m. & & Alligator mississippiensis & 280 \\
\hline
\end{tabular}


Fator de terminação de transcrição 2

Acyrthosiphon pisum

262

TTF2_Acyrthosiphon p. 2

Gene Organismo

Tamanho

(aa)

Fator de terminação de transcrição 2

TTF2_Acromyrmex e.

Transativador Global

GTA_RaouMNPV

GTA_PlxyMNPV

GTA_PhcyNPV

Transativador Global

GTA_OrpsMNPV

Transativador Global

GTA_HycuNPV

GTA_EppoNPV

GTA_ChroNPV

GTA_ChocNPV

GTA_ChMU

GTA_ChfuMNPV 2

GTA_ChfuMNPV 1

GTA_AnpeNPV 2

GTA_AnpeNPV 1

GTA_AgMNPV

Transativador Global

Transativador Global

Transativador Global

Transativador Global

Transativador Global

Transativador Global

Transativador Global

Transativador Global

Transativador Global

Transativador Global

GTA_AcMNPV

Acromyrmex echinatior

Rachiplusia ou MNPV

Plutella xylostella multiple

nucleopolyhedrovirus

Philosamia cynthia ricini

nucleopolyhedrovirus virus

Orgyia pseudotsugata multiple

nucleopolyhedrovirus

236

236

235

Hyphantria cunea nucleopolyhedrovirus

232

Epiphyas postvittana nucleopolyhedrovirus

Choristoneura rosaceana alphabaculovirus

Choristoneura occidentalis alphabaculovirus

234

Choristoneura murinana alphabaculovirus

Choristoneura fumiferana DEF multiple nucleopolyhedrovirus

Choristoneura fumiferana multiple nucleopolyhedrovirus

Antheraea pernyi nucleopolyhedrovirus

234

Antheraea pernyi nucleopolyhedrovirus

Anticarsia gemmatalis nucleopolyhedrovirus

Autographa californica nucleopolyhedrovirus 


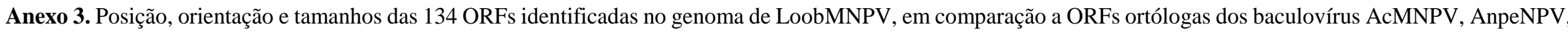

MaviMNPV e DekiNPV, apresentando percentual de identidade de amino ácidos.

\begin{tabular}{|c|c|c|c|c|c|c|c|c|c|c|c|c|c|}
\hline \multirow[b]{2}{*}{$\begin{array}{c}\text { LoobMPV } \\
\text { ORFs }\end{array}$} & \multirow[b]{2}{*}{ Nome } & \multirow[b]{2}{*}{ Posição(pb) } & \multirow[b]{2}{*}{$\begin{array}{c}\text { Tamanho } \\
\text { (aa) }\end{array}$} & \multicolumn{2}{|c|}{$\underline{\text { AcMNPV }}$} & \multicolumn{2}{|c|}{ AnpeNPV } & \multicolumn{2}{|c|}{ MaviMNPV } & \multicolumn{2}{|c|}{ DekiNPV } & \multicolumn{2}{|c|}{ ThorNPV } \\
\hline & & & & ORF & $\begin{array}{c}\text { Ident } \\
\%\end{array}$ & ORF & $\begin{array}{c}\text { Ident } \\
\%\end{array}$ & ORF & $\begin{array}{c}\text { Ident } \\
\%\end{array}$ & ORF & $\begin{array}{c}\text { Ident } \\
\%\end{array}$ & ORF & $\begin{array}{c}\text { Ident } \\
\%\end{array}$ \\
\hline 1 & Polh & $1 \rightarrow 750$ & 250 & Ac-PH & 84,02 & polyhedrin & 91,8 & polh & 90,57 & polh & 91,36 & $\mathrm{ph}$ & 90,57 \\
\hline 2 & ORF 1629 & $823 \longleftarrow 2454$ & 544 & $\begin{array}{c}\text { Ac- } \\
\text { ORF1629 }\end{array}$ & 45,3 & 1629-capsid & 26,55 & orf1629 & 45,3 & & & pp78/83 & 36,71 \\
\hline 3 & pk-1 & $2465 \rightarrow 3274$ & 269 & $\mathrm{pk}-1$ & 71,43 & pk-1 & 58,96 & pk-1 & 71,64 & pk-1 & 62,69 & pk-1 & 70,57 \\
\hline 4 & LoobNPVOrf-4 & $3271 \leftarrow 3573$ & 101 & & & & & & & & & & \\
\hline 6 & LoobNPVOrf-6 & $4812 \rightarrow 5456$ & 214 & & & & & & & & & & \\
\hline 7 & alk-exo & $5893 \rightarrow 7239$ & 449 & alk-exo & 55,79 & alk-exo & 45,21 & alk-exo & 53,77 & alk-exo & 52,55 & alk-exo & 53,88 \\
\hline 8 & p26 & $7392 \rightarrow 8168$ & 258 & Ac-p26 & 54,1 & p26 & 45,7 & $\mathrm{p} 26$ & 54,1 & p26 & 46,22 & $\mathrm{p} 26$ & 48,94 \\
\hline 9 & p10 & $8227 \rightarrow 8487$ & 87 & Ac-p10 & 58,57 & p10 & 60,81 & p10 & 59,15 & p10 & 61,43 & p10 & 57,75 \\
\hline 10 & p74 & $8488 \leftarrow 10437$ & 650 & p74 & 82,69 & p74 & 75,27 & p74 & 78,05 & p74 & 76,31 & p74 & 81,76 \\
\hline 11 & me 53 & $10540 \longleftarrow 11835$ & 432 & me53 & 44,98 & me 53 & 36,27 & me53 & 44,06 & & & me53 & 41,15 \\
\hline 12 & LoobNPVOrf-12 & $11893 \leftarrow 12063$ & 57 & & & & & & & & & & \\
\hline 14 & $\mathrm{p} 49(49 \mathrm{k})$ & $12980 \rightarrow 14422$ & 480 & p49(49k) & 82,77 & $\mathrm{p} 49(49 \mathrm{k})$ & 68,41 & $\mathrm{p} 49(49 \mathrm{k})$ & 81,7 & me53 & 70,37 & $\mathrm{p} 49(49 \mathrm{k})$ & 82,77 \\
\hline 15 & odv-e18 & $14419 \rightarrow 14691$ & 91 & odv-e18 & 75,86 & odv-e18 & 62,5 & odv-e18 & 72,53 & odv-e18 & 63,04 & odv-e18 & 79,37 \\
\hline 16 & odv-e27 & $14738 \rightarrow 15599$ & 286 & odv-e27 & 72,6 & odv-e27 & 62,02 & odv-e27 & 72,76 & odv-ec27 & 65,17 & odv-ec27 & 72,82 \\
\hline 17 & LoobNPVOrf-17 & $15613 \rightarrow 15897$ & 95 & $\begin{array}{l}\text { AcOrf- } \\
145\end{array}$ & 74,03 & $\begin{array}{l}\text { Anpe- } \\
\text { ORF136 }\end{array}$ & 65 & $\begin{array}{c}\text { Mv- } \\
\text { ORF115 }\end{array}$ & 73,81 & Deki-ORF10 & 75 & $\begin{array}{l}\text { Thor- } \\
\text { ORF136 }\end{array}$ & 71,43 \\
\hline 18 & LoobNPVOrf-18 & $15969 \longleftarrow 16682$ & 237 & $\begin{array}{l}\text { AcOrf- } \\
146\end{array}$ & 67,96 & $\begin{array}{l}\text { Anpe- } \\
\text { ORF137 }\end{array}$ & 47,57 & $\begin{array}{c}\text { Mv- } \\
\text { ORF114 }\end{array}$ & 65,05 & Deki-ORF9 & 58,45 & $\begin{array}{l}\text { Thor- } \\
\text { ORF137 }\end{array}$ & 63,9 \\
\hline 19 & ie- 1 & $16738 \rightarrow 18405$ & 556 & ie-1 & 46,26 & ie-1 & 35,74 & ie-1 & 47,12 & ie-1 & 50,21 & ie-1 & 45,56 \\
\hline 20 & odve-56 & $18463 \longleftarrow 19590$ & 376 & odve-56 & 72,7 & odve-56 & 67,29 & odv-e56 & 68,65 & & & odv-e56 & 73,56 \\
\hline 21 & pe38 & $19719 \longleftarrow 20363$ & 214 & pe38 & 28,42 & pe38 & 33,64 & pe38 & 29,73 & pe38 & 34,81 & pe38 & 28,49 \\
\hline 22 & LoobNPVOrf-22 & $20706 \longleftarrow 20921$ & 71 & $\begin{array}{c}\text { AcOrf- } \\
152\end{array}$ & 60,47 & & & $\begin{array}{c}\text { Mv- } \\
\text { ORF120 }\end{array}$ & 65,12 & & & $\begin{array}{l}\text { Thor- } \\
\text { ORF143 }\end{array}$ & 64,29 \\
\hline 23 & LoobNPVOrf-23* & $20958 \rightarrow 21680$ & 240 & & & & & & & & & & \\
\hline 24 & LoobNPVOrf-24 & $22071 \longleftarrow 22862$ & 263 & $\begin{array}{c}\text { AcOrf- } \\
132\end{array}$ & 35,62 & $\begin{array}{c}\text { Anpe- } \\
\text { ORF123 }\end{array}$ & 33,79 & $\begin{array}{c}\text { Mv- } \\
\text { ORF101 }\end{array}$ & 33,94 & Deki-ORF20 & 28,68 & $\begin{array}{l}\text { Thor- } \\
\text { ORF125 }\end{array}$ & 29,75 \\
\hline 25 & calyx/pep & $22895 \longleftarrow 23765$ & 289 & calyx/pep & 52,57 & calyx/pep & 67,47 & calyx/pep & 52,01 & calyx/pep & 67,46 & calyx/pep & 56,35 \\
\hline
\end{tabular}




\begin{tabular}{|c|c|c|c|c|c|c|c|c|c|c|c|c|c|}
\hline \multirow[b]{2}{*}{$\begin{array}{c}\text { LoobMPV } \\
\text { ORFs }\end{array}$} & \multirow[b]{2}{*}{ Nome } & \multirow[b]{2}{*}{ Posição(pb) } & \multirow[b]{2}{*}{$\begin{array}{c}\text { Tamanho } \\
\text { (aa) }\end{array}$} & \multicolumn{2}{|c|}{ AcMNPV } & \multicolumn{2}{|c|}{ AnpeNPV } & \multicolumn{2}{|c|}{ MaviMNPV } & \multicolumn{2}{|c|}{ DekiNPV } & \multicolumn{2}{|c|}{ ThorNPV } \\
\hline & & & & ORF & $\begin{array}{c}\text { Ident } \\
\%\end{array}$ & ORF & $\begin{array}{c}\text { Ident } \\
\% \\
\end{array}$ & ORF & $\begin{array}{c}\text { Ident } \\
\%\end{array}$ & ORF & $\begin{array}{c}\text { Ident } \\
\% \\
\end{array}$ & ORF & $\begin{array}{c}\text { Ident } \\
\% \\
\end{array}$ \\
\hline 27 & p24 & $24240 \longleftarrow 24854$ & 204 & p24 & 67,54 & $\mathrm{p} 24$ & 55,73 & p24 & 60,94 & p24 & 62,24 & p24 & 59,39 \\
\hline 28 & gp64 & $25121 \rightarrow 26653$ & 510 & gp64 & 72,92 & gp64 & 67,85 & gp64 & 73,82 & gp64 & 73,32 & gp64 & 73,76 \\
\hline 29 & LoobNPVOrf-29 & $26702 \longleftarrow 27514$ & 270 & $\begin{array}{l}\text { AcOrf- } \\
124\end{array}$ & 36,4 & $\begin{array}{l}\text { Anpe- } \\
\text { ORF114 }\end{array}$ & 25 & Mv-ORF93 & 37,39 & Deki-ORF35 & 35,71 & $\begin{array}{l}\text { Thor- } \\
\text { ORF117 } \\
\text { Thor- }\end{array}$ & 36,84 \\
\hline 30 & LoobNPVOrf-30 & $27660 \rightarrow 27926$ & 88 & & & & & & & Deki-ORF33 & 33,82 & ORF117 & 36,76 \\
\hline 31 & LoobNPVOrf-31 & $27986 \rightarrow 28634$ & 215 & $\begin{array}{l}\text { AcOrf- } \\
106\end{array}$ & 78,57 & Anpe-ORF99 & 71,71 & Mv-ORF83 & 79,23 & Deki-ORF47 & 75 & $\begin{array}{l}\text { Thor- } \\
\text { ORF101 }\end{array}$ & 79,72 \\
\hline 32 & LoobNPVOrf-32 & $28810 \longleftarrow 29062$ & 84 & $\begin{array}{l}\text { AcOrf- } \\
108\end{array}$ & 55,56 & $\begin{array}{l}\text { Anpe- } \\
\text { ORF100 }\end{array}$ & 46,15 & Mv-ORF84 & 57,41 & Deki-ORF46 & 52,73 & $\begin{array}{l}\text { Thor- } \\
\text { ORF102 }\end{array}$ & 61,11 \\
\hline 33 & odv-ec43 & $29084 \longleftarrow 30229$ & 381 & $\begin{array}{l}\text { AcOrf- } \\
109\end{array}$ & 75,7 & $\begin{array}{l}\text { Anpe- } \\
\text { ORF101 }\end{array}$ & 63,17 & Mv-ORF85 & 76,55 & Deki-ORF45 & 71,68 & $\begin{array}{l}\text { Thor- } \\
\text { ORF103 }\end{array}$ & 74,94 \\
\hline 34 & LoobNPVOrf-34 & $30258 \longleftarrow 30425$ & 55 & $\begin{array}{l}\text { AcOrf- } \\
110\end{array}$ & 81,48 & $\begin{array}{l}\text { Anpe- } \\
\text { ORF103 }\end{array}$ & 74,07 & Mv-ORF86 & 79,63 & Deki-ORF49 & 83,64 & $\begin{array}{l}\text { Thor- } \\
\text { ORF104 }\end{array}$ & 79,63 \\
\hline 35 & LoobNPVOrf-35 & $30630 \rightarrow 31538$ & 302 & Ac-GTA & 28,11 & $\begin{array}{l}\text { giodal } \\
\text { transactivator }\end{array}$ & 24,65 & & & $\begin{array}{l}\text { DEK1- } \\
\text { ORF138 }\end{array}$ & 46,88 & ORF117 & 50 \\
\hline 36 & LoobNPVOrf-36 & $31581 \longleftarrow 31784$ & 67 & $\begin{array}{c}\text { AcOrf- } \\
111 \\
\text { AcOrf- }\end{array}$ & 73,13 & $\begin{array}{l}\text { Anpe- } \\
\text { ORF104 }\end{array}$ & 56,92 & Mv-ORF87 & 65,62 & Deki-ORF42 & 74,63 & $\begin{array}{l}\text { Thor- } \\
\text { ORF105 } \\
\text { Thor- }\end{array}$ & 74,63 \\
\hline 37 & LoobNPVOrf-37 & $32024 \longrightarrow 33028$ & 334 & $\begin{array}{l}\text { AcOrf- } \\
113\end{array}$ & 47,93 & & & & & & & $\begin{array}{l}\text { Thor- } \\
\text { ORF106 }\end{array}$ & 53,23 \\
\hline 38 & LoobNPVOrf-38 & $33038 \leftarrow 33391$ & 117 & & & & & & & & & & \\
\hline 39 & LoobNPVOrf-39 & $33445 \leftarrow 34579$ & 378 & $\begin{array}{l}\text { AcOrf- } \\
114\end{array}$ & 40,48 & $\begin{array}{c}\text { Anpe- } \\
\text { ORF106 }\end{array}$ & 33,97 & Mv-ORF88 & 38,13 & Deki-ORF40 & 30,95 & $\begin{array}{l}\text { Thor- } \\
\text { ORF109 }\end{array}$ & 40,94 \\
\hline 40 & pif-3 & $34585 \longleftarrow 35238$ & 218 & $\begin{array}{l}\text { AcOrf- } \\
115\end{array}$ & 62,63 & $\begin{array}{c}\text { Anpe- } \\
\text { ORF107 }\end{array}$ & 63,19 & pif-3 & 63,16 & pif-3 & 58,03 & pif-3 & 63,16 \\
\hline 41 & pif-1 & $35367 \rightarrow 36968$ & 533 & $\begin{array}{l}\text { AcOrf- } \\
119\end{array}$ & 74,67 & pif-1 & 70,16 & pif-1 & 73,5 & pif-1 & 67,89 & pif-1 & 73,92 \\
\hline 42 & LoobNPVOrf-42 & $36984 \longrightarrow 37235$ & 83 & $\begin{array}{l}\text { AcOrf- } \\
120\end{array}$ & 53,75 & $\begin{array}{c}\text { Anpe- } \\
\text { ORF112 }\end{array}$ & 32,5 & Mv-ORF92 & 53,09 & Deki-ORF32 & 50 & $\begin{array}{l}\text { Thor- } \\
\text { ORF114 }\end{array}$ & 55 \\
\hline 43 & vp80 & $37262 \longleftarrow 39775$ & 837 & vp80 & 50,99 & p87 & 52,47 & vp80 & 47,23 & $\mathrm{p} 87$ & 47,22 & vp80 & 49,02 \\
\hline 44 & p48 & $39802 \rightarrow 40974$ & 391 & $\mathrm{p} 48$ & 78,72 & p48 & 66,92 & $\mathrm{p} 45$ & 76,92 & $\mathrm{p} 45$ & 74,68 & p48 & 78,52 \\
\hline 46 & $\mathrm{p} 40$ & $41317 \rightarrow 42456$ & 380 & $\mathrm{p} 40$ & 67,02 & $\mathrm{p} 40$ & 52,53 & $\mathrm{p} 40$ & 65,96 & $\mathrm{p} 40$ & 61,92 & bv/odv-c42 & 66,14 \\
\hline 47 & p6.9* & $42521 \rightarrow 42694$ & 57 & & & & & & & & & & \\
\hline
\end{tabular}




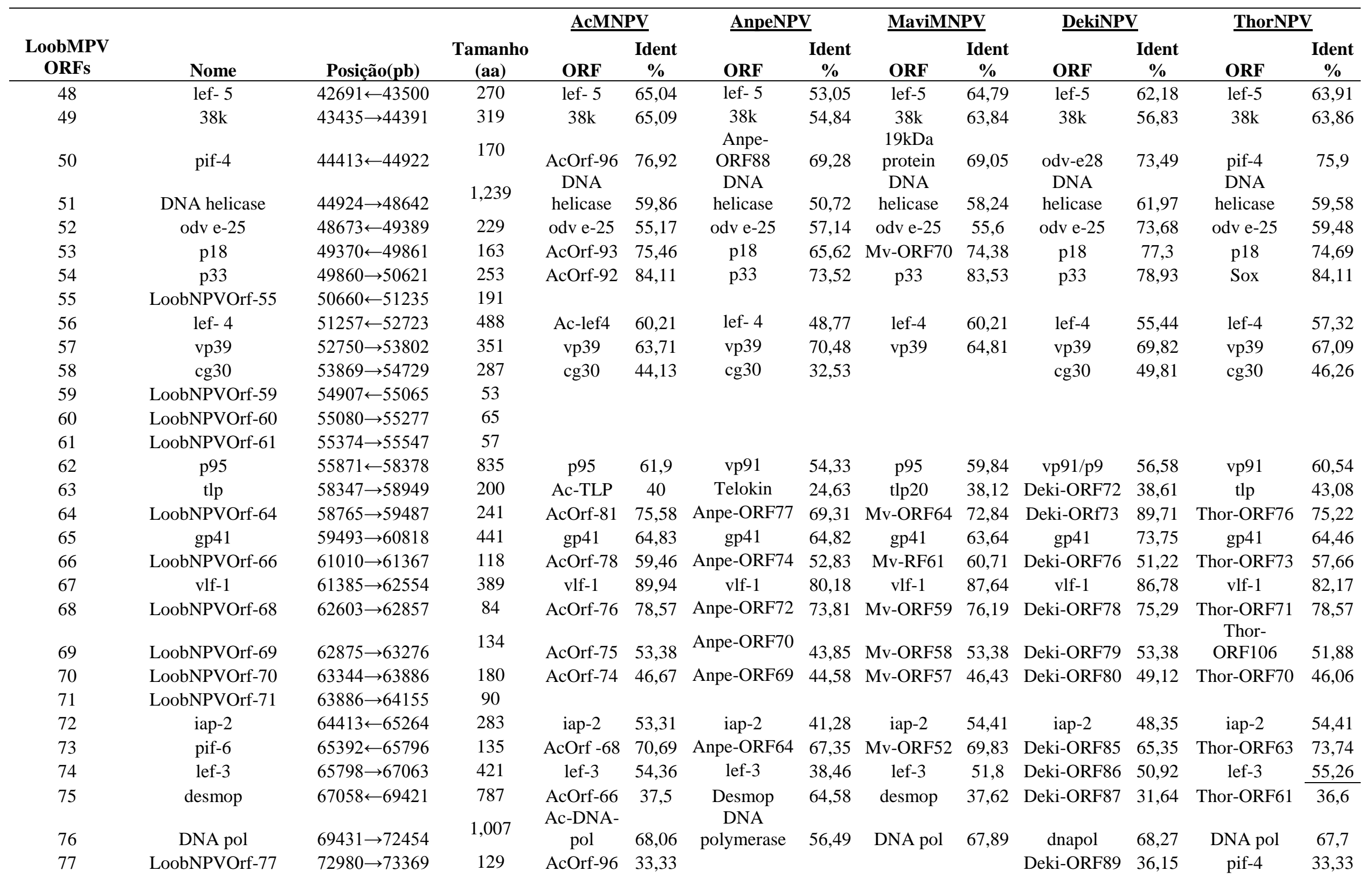




\begin{tabular}{|c|c|c|c|c|c|c|c|c|c|c|c|c|c|}
\hline \multirow[b]{2}{*}{$\begin{array}{c}\text { LoobMPV } \\
\text { ORFs }\end{array}$} & \multirow[b]{2}{*}{ Nome } & \multirow[b]{2}{*}{ Posição(pb) } & \multirow[b]{2}{*}{$\begin{array}{c}\text { Tamanho } \\
\text { (aa) }\end{array}$} & \multicolumn{2}{|c|}{$\underline{\text { AcMNPV }}$} & \multicolumn{2}{|c|}{ AnpeNPV } & \multicolumn{2}{|c|}{$\underline{\text { MaviMNPV }}$} & \multicolumn{2}{|c|}{$\underline{\text { DekiNPV }}$} & \multicolumn{2}{|c|}{ ThorNPV } \\
\hline & & & & ORF & $\begin{array}{c}\text { Ident } \\
\%\end{array}$ & ORF & $\begin{array}{c}\text { Ident } \\
\% \\
\end{array}$ & ORF & $\begin{array}{c}\text { Ident } \\
\%\end{array}$ & ORF & $\begin{array}{c}\text { Ident } \\
\% \\
\end{array}$ & ORF & $\begin{array}{c}\text { Ident } \\
\% \\
\end{array}$ \\
\hline 78 & LoobNPVOrf-78* & $73445 \leftarrow 73942$ & 165 & & & & & & & & & & \\
\hline 79 & LoobNPVOrf-79 & $74119 \longleftarrow 74604$ & 162 & AcOrf-63 & 37,01 & & & Mv-ORF47 & 33,77 & Deki-ORF91 & 34,19 & Thor-ORF58 & 36,18 \\
\hline 80 & lef-9 & $74707 \longleftarrow 76365$ & 493 & lef-9 & 82,52 & lef-9 & 71,98 & lef-9 & 83,13 & lef-9 & 82,93 & lef-9 & 83,13 \\
\hline 81 & $\mathrm{fp}-25 \mathrm{k}$ & $76319 \rightarrow 76954$ & 211 & $\mathrm{fp}-25 \mathrm{k}$ & 75,12 & $\mathrm{fp}-25 \mathrm{k}$ & 68,68 & $\mathrm{fp}-25 \mathrm{k}$ & 80,22 & $\mathrm{fp}-25 \mathrm{k}$ & 76,22 & $\mathrm{fp}-25 \mathrm{k}$ & 73,17 \\
\hline 82 & ChaB-like & $77113 \rightarrow 77367$ & 85 & AcOrf-60 & 70 & $\mathrm{fp}$ & 60 & Mv-ORF44 & 70 & Deki-ORF94 & 70,49 & ChaB-like & 71,67 \\
\hline 83 & ChaB-like & $77370 \rightarrow 77522$ & 50 & AcOrf-59 & 78 & ChaB-like & 52 & Mv-ORF43 & 70 & Deki-ORF95 & 76 & ChaB-like & 76 \\
\hline 84 & LoobNPVOrf-84 & $77598 \rightarrow 77987$ & 129 & & & & & & & & & & \\
\hline 85 & LoobNPVOrf-85 & $77973 \leftarrow 78464$ & 163 & AcOrf-57 & 60,49 & Anpe-ORF55 & 46,63 & & & Deki-ORF96 & 62,96 & Thor-ORF53 & 59,88 \\
\hline 86 & LoobNPVOrf-86 & $78676 \leftarrow 78981$ & 102 & AcOrf-56 & 46,53 & & & Mv-ORF42 & 45,54 & Deki-ORF97 & 45,76 & Thor-ORF52 & 47,52 \\
\hline 87 & LoobNPVOrf-87 & $78984 \longleftarrow 79202$ & 72 & AcOrf-55 & 52,63 & Anpe-ORF54 & 52,63 & Mv-ORF41 & 50 & Deki-ORF98 & 52,63 & Thor-ORF51 & 55 \\
\hline 88 & vp1054 & $79334 \longleftarrow 80437$ & 367 & AcOrf-54 & 70,33 & vp1054 & 53,26 & vp1054 & 69,23 & vp1054 & 59,02 & Thor-ORF50 & 71,15 \\
\hline 89 & lef-10 & $80295 \leftarrow 80534$ & 79 & lef-10 & 62,82 & lef-10 & 52,54 & lef-10 & 58,97 & & & lef-10 & 63,89 \\
\hline 90 & LoobNPVOrf-90 & $80531 \leftarrow 80962$ & 143 & AcOrf-53 & 78,68 & Anpe-ORF51 & 58,09 & Mv-ORF38 & 76,47 & $\begin{array}{l}\text { Deki- } \\
\text { ORF100 } \\
\text { Deki- }\end{array}$ & 73,57 & Thor-ORF48 & 77,94 \\
\hline 91 & LoobNPVOrf-91 & $81076 \rightarrow 81606$ & 177 & AcOrf-52 & 47,78 & & & Mv-ORF37 & 41,24 & $\begin{array}{l}\text { ORF101 } \\
\text { Deki- }\end{array}$ & 44,69 & Thor-ORF47 & 40,91 \\
\hline 92 & LoobNPVOrf-92 & $81619 \longleftarrow 82611$ & 331 & AcOrf-51 & 38,94 & Anpe-ORF50 & 28,48 & Mv-ORF36 & 37,93 & ORF102 & 32,17 & Thor-ORF46 & 38,94 \\
\hline 93 & lef-8 & $82635 \rightarrow 85298$ & 887 & lef-8 & 72,67 & lef-8 & 64,61 & lef-8 & 72,67 & lef-8 & 69,45 & lef-8 & 71,96 \\
\hline 94 & pena & $85435 \rightarrow 86253$ & 273 & pena & 50,2 & Pcna & 26,82 & & & $\begin{array}{c}\text { Deki- } \\
\text { ORF104 }\end{array}$ & 47,43 & pena & 48,44 \\
\hline 95 & LoobNPVOrf-95 & $86299 \rightarrow 86643$ & 115 & AcOrf-48 & 38,39 & Etm & 32,94 & & & & & & \\
\hline 96 & vef & $86646 \rightarrow 88940$ & 764 & & & & & & & vef-2 & 36,72 & & \\
\hline 97 & LoobNPVOrf-97 & $88846 \rightarrow 89403$ & 186 & & & & & & & & & & \\
\hline 98 & ctl-1 & $89519 \longleftarrow 89680$ & 53 & ctl-1 & 60,38 & ctl-1 & 60,38 & & & ctl-1 & 58,49 & ctl-1 & 60,38 \\
\hline 99 & bro-a & $89729 \longleftarrow 90688$ & 319 & Ac-bro & 42,47 & bro-b & 44,86 & & & dk-bro-2 & 72,36 & bro-b & 61,18 \\
\hline 100 & he $65^{* *}$ & $90814 \leftarrow 91473$ & 220 & he65 & 36,77 & he65 & 29,18 & he65 & 37,58 & & & he65 & 28,95 \\
\hline 101 & odv-e66 & $91820 \longleftarrow 93916$ & 698 & $\begin{array}{l}\text { Ac-odv- } \\
\text { e66 }\end{array}$ & 79,02 & odv-e66 & 69,57 & & & $\begin{array}{c}\text { odv-e66 } \\
\text { Deki- }\end{array}$ & 33,05 & odv-e66 & 76,49 \\
\hline 102 & LoobNPVOrf-102 & $93976 \longleftarrow 94365$ & 130 & AcOrf-44 & 52,89 & Anpe-ORF44 & 36,04 & Mv-ORF32 & 49,61 & $\begin{array}{l}\text { ORF107 } \\
\text { Deki- }\end{array}$ & 52,63 & Thor-ORF41 & 54,46 \\
\hline 103 & LoobNPVOrf-103 & $94352 \longleftarrow 94588$ & 78 & AcOrf-43 & 60,78 & Anpe-ORF43 & 43,14 & Mv-ORF31 & 59,57 & ORF108 & 63,46 & & \\
\hline 104 & lef-12 & $94616 \longleftarrow 95215$ & 199 & AcOrf-41 & 55 & lef-12 & 36,9 & lef-12 & 52,75 & lef-12 & 43,85 & lef-12 & 51,65 \\
\hline 105 & $\mathrm{p} 47$ & $95187 \rightarrow 96422$ & 402 & Ac-p47 & 72,89 & $\mathrm{p} 47$ & 64,27 & $\mathrm{p} 47$ & 72,14 & $\mathrm{p} 47$ & 69,31 & $\mathrm{p} 47$ & 72,46 \\
\hline
\end{tabular}




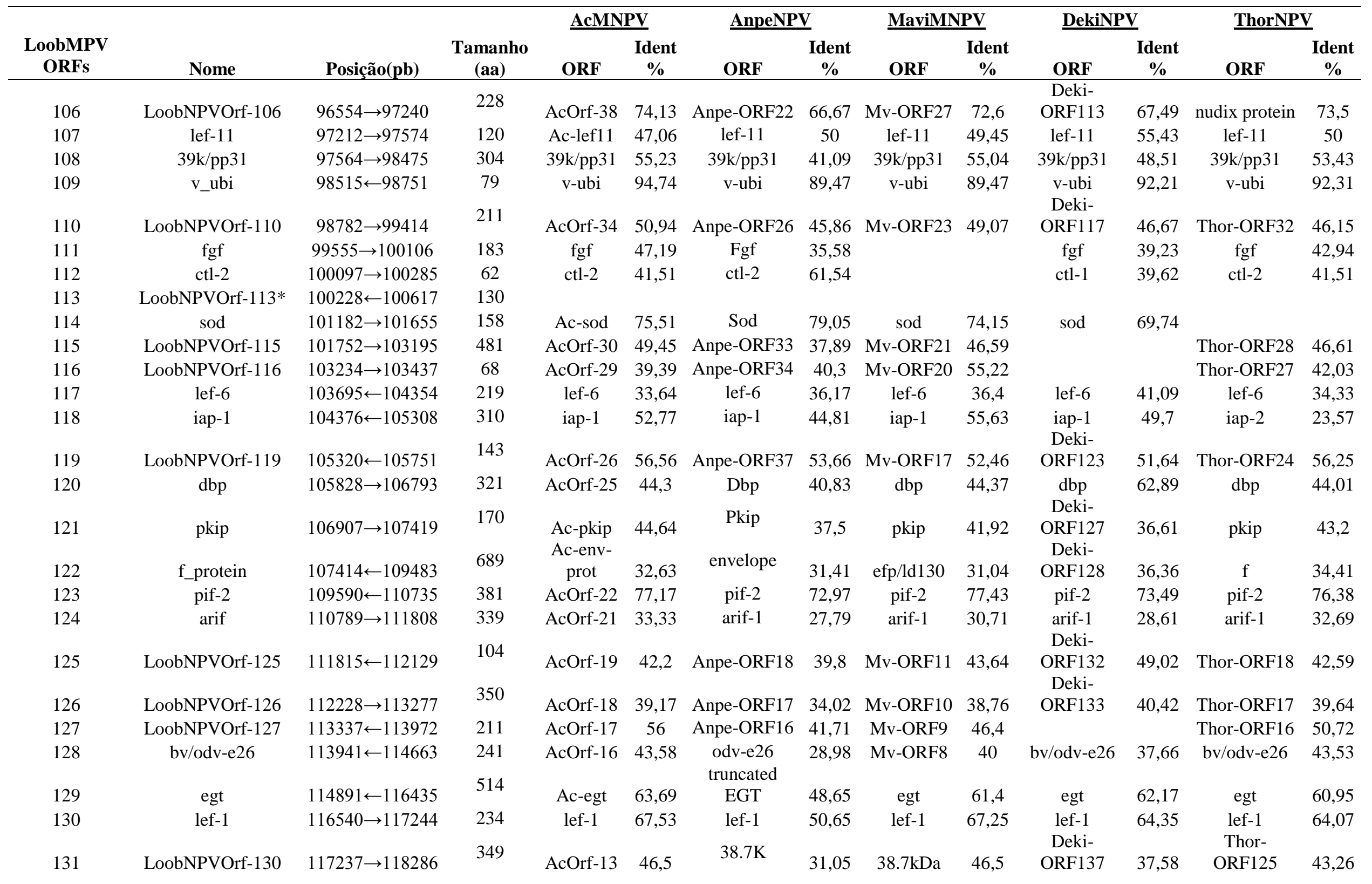




\begin{tabular}{|c|c|c|c|c|c|c|c|c|c|c|c|c|c|}
\hline \multirow[b]{2}{*}{$\begin{array}{c}\text { LoobMPV } \\
\text { ORFs }\end{array}$} & \multirow[b]{2}{*}{ Nome } & \multirow[b]{2}{*}{ Posição(pb) } & \multirow[b]{2}{*}{$\begin{array}{c}\text { Tamanho } \\
\text { (aa) }\end{array}$} & \multicolumn{2}{|c|}{ AcMNPV } & \multicolumn{2}{|c|}{ AnpeNPV } & \multicolumn{2}{|c|}{ MaviMNPV } & \multicolumn{2}{|c|}{$\underline{\text { DekiNPV }}$} & \multicolumn{2}{|c|}{ ThorNPV } \\
\hline & & & & ORF & $\begin{array}{c}\text { Ident } \\
\%\end{array}$ & ORF & $\begin{array}{c}\text { Ident } \\
\%\end{array}$ & ORF & $\begin{array}{c}\text { Ident } \\
\%\end{array}$ & ORF & $\begin{array}{c}\text { Ident } \\
\%\end{array}$ & ORF & $\begin{array}{c}\text { Ident } \\
\%\end{array}$ \\
\hline 132 & ptp-1 & $118304 \rightarrow 118819$ & 171 & ptp-1 & 62,72 & ptp-1 & 54,12 & ptp-1 & 56,55 & & & ptp-1 & 60,95 \\
\hline 133 & LoobNPVOrf-132 & $118906 \rightarrow 119277$ & 124 & AcOrf-5 & 40,16 & Anpe-ORF5 & 48,08 & $\begin{array}{c}\text { Mv- } \\
\text { ORF125 }\end{array}$ & 39,68 & $\begin{array}{c}\text { Deki- } \\
\text { ORF144 }\end{array}$ & 29,91 & Thor-ORF5 & 35,77 \\
\hline 134 & lef- 2 & $119258 \rightarrow 119920$ & 220 & lef-2 & 65,24 & lef-2 & 45,93 & lef-2 & 62,86 & lef-2 & 57,35 & lef-2 & 62,38 \\
\hline
\end{tabular}

* ORFs que não únicas, mas que possuem correspondência com outros baculovírus (LoobNPVOrf-23 possui maior similaridade com AgMNPV (gp147), p6.9 possui maior similaridade com PespNPV (ac57-like), LoobNPVOrf-78 possui maior similaridade com PrGV (orf 101) e LoobNPVOrf-113 possui maior similaridade com XcGV (orf 127)

**LoobNPVOrf-100 (he65) possui maior identidade primeiramente com AgseGV (orf132). 